Policy Research Working Paper 4301

\title{
India's Journey Toward an Effective Patent System
}

\author{
Bruce Abramson
}

The World Bank

South Asia Region

Finance and Private Sector Development Unit August 2007 
Policy Research Working Paper 4301

\section{Abstract}

The decade following India's accession to the World Trade Organization's Trade-Related Aspects of Intellectual Property ushered in numerous changes to the country's patent system, culminating in a series of amendments in 2005. But a functioning patent system is more than a statute. This paper discusses the steps that India must still take to develop an effective, functioning patent system capable of attracting foreign direct investment, motivating domestic innovation and education, and filtering its benefits to all elements of Indian society, including the poor and the possessors of traditional knowledge. The analysis combines data studies of historical and recent patenting activity in India and by Indians, interviews with Indian government officials, intellectual property attorneys, industrialists, and researchers, and lessons gleaned from patent systems abroad. It identifies critical needs and concrete steps to meet them. Improving public awareness of the revenuegenerating potential of patents will enhance incentives for the participation of individuals and small and medium enterprises in the patent system. Formalizing guidelines for patents derived through government research funds - coupled with needed changes in institutional governance-will enhance prospects for technology transfer from laboratories to commercial markets. Compensation schemes for traditional knowledge will extend the benefits of intellectual property rights to the poorest members of society. This paper's recommendations would help India achieve both a fully functioning patent system and a mechanism for ensuring that poor people living traditional lifestyles receive their share of the social gains that a working innovation system can confer..

This paper — a product of the Finance and PSD Division, South Asia PREM Finance and PSD Department—is part of a larger effort in the department to better understand and help support innovation and competitiveness in India. Copies of the paper are available free from the World Bank, 1818 H Street NW, Washington, DC 20433. Please contact Mark Dutz, room MC 10-145, telephone 202-473 4291, fax 202-522 1145, email address mdutz@worldbank.org. Policy Research Working Papers are also posted on the Web at http://econ.worldbank.org. The author may be contacted at bdabramson@ gmail.com. August 2007. (104 pages)

The Policy Research Working Paper Series disseminates the findings of work in progress to encourage the exchange of ideas about development issues. An objective of the series is to get the findings out quickly, even if the presentations are less than fully polished. The papers carry the names of the authors and should be cited accordingly. The findings, interpretations, and conclusions expressed in this paper are entirely those of the authors. They do not necessarily represent the views of the International Bank for Reconstruction and Development/World Bank and its affiliated organizations, or those of the Executive Directors of the World Bank or the governments they represent. 


\title{
India's Journey toward An Effective Patent System
}

\author{
Bruce Abramson $^{1}$ \\ Finance and Private Sector Development Unit \\ South Asia Region \\ The World Bank
}

\footnotetext{
${ }^{1}$ President, Informationism, Inc.; bdabramson@gmail.com; +1-415-839-73311 or +1-202-299-4171; www.theinformationist.com. The author would like to thank Carl Dahlman, Mark Dutz and Vinod K. Goel for helpful comments. The paper was funded by the World Bank and DFID Trust Fund TF055833 as a background paper for the 2007 World Bank publication Unleashing India's Innovation: Toward Sustainable and Inclusive Growth (Mark Dutz, ed.). The views expressed here are the author's and do not necessarily reflect those of the World Bank, its Executive Directors, or the countries they represent.
} 



\section{Contents}

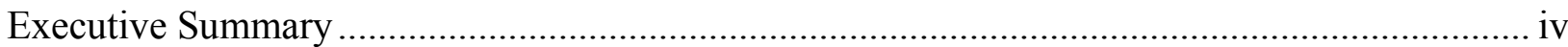

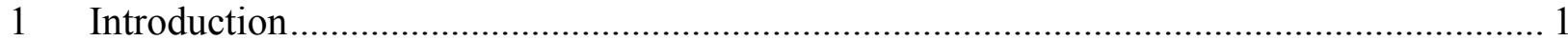

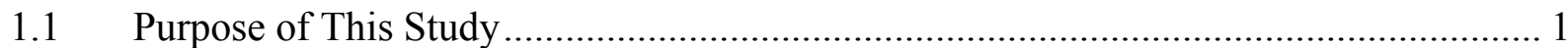

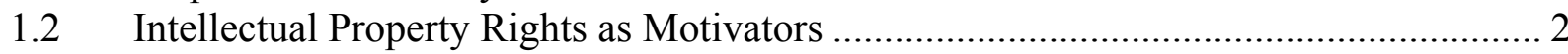

1.3 Types of Intellectual Property Rights …………...................................................... 3

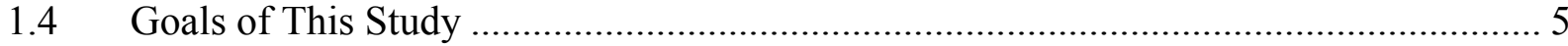

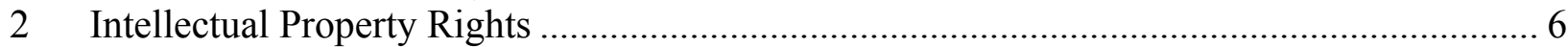

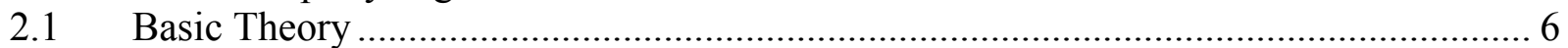

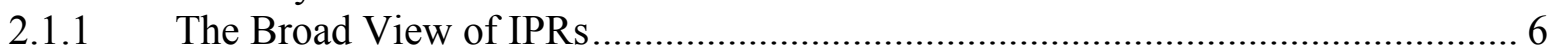

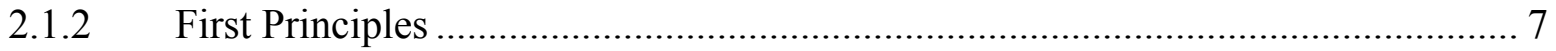

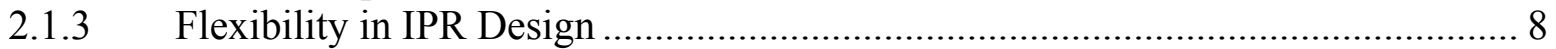

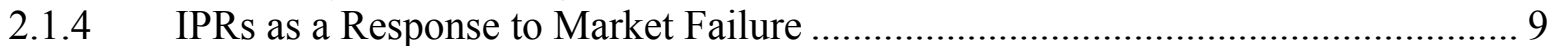

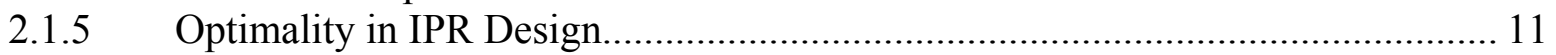

2.1.6 The IPR Enforcement Conundrum ………....................................................... 14

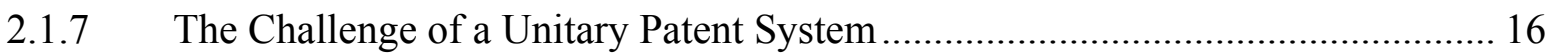

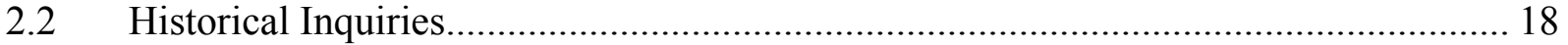

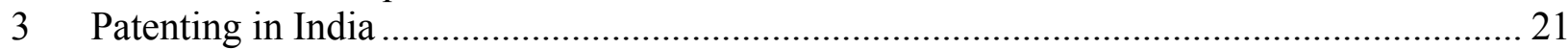

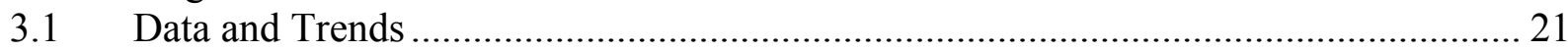

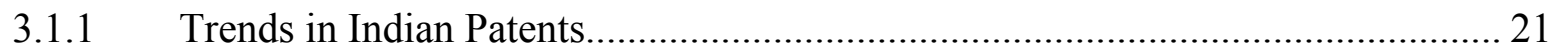

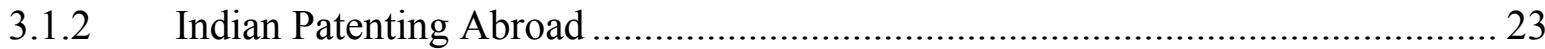

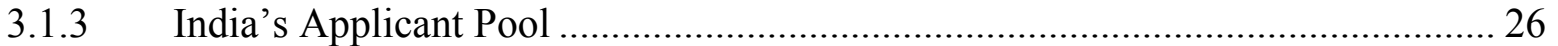

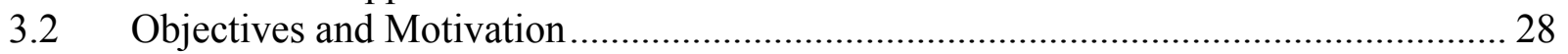

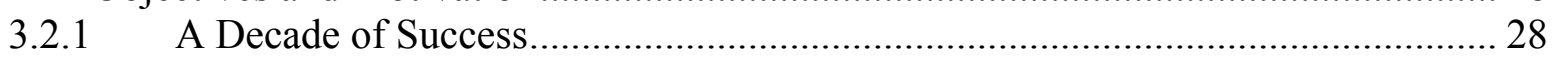

3.2.2 Social Objectives and the Private Sector ……………......................................... 31

3.3 The New Indian Patent Regime ………………….................................................... 34

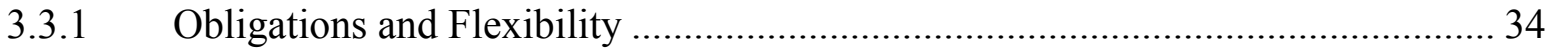

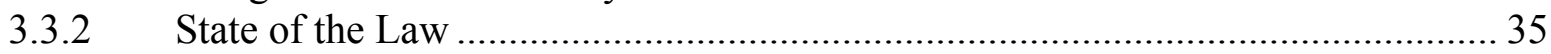

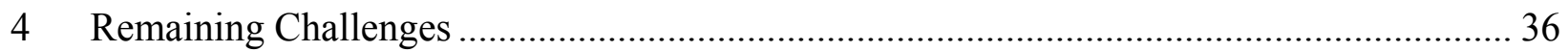

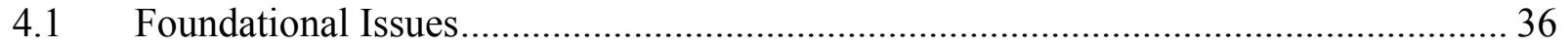

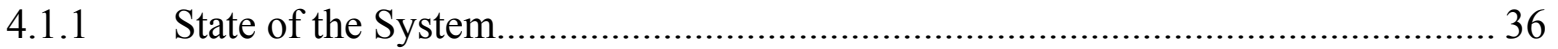

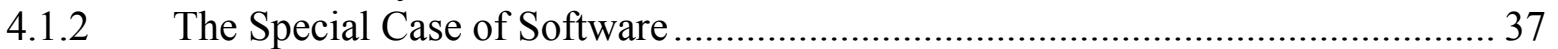

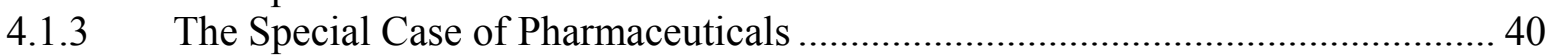

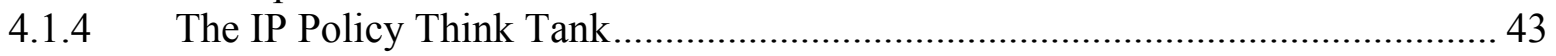

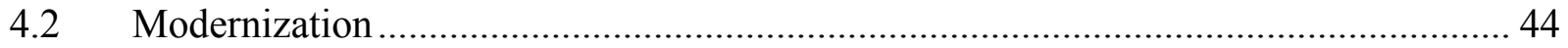

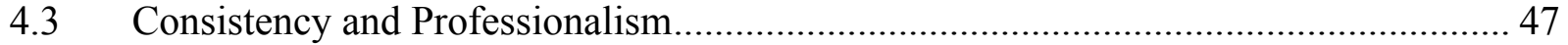

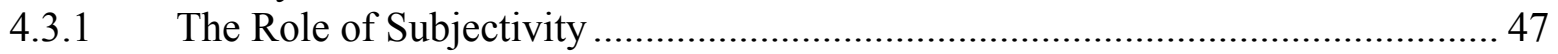

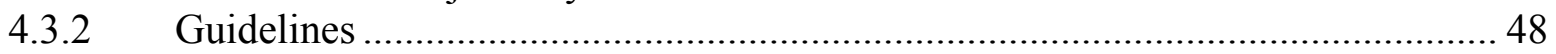

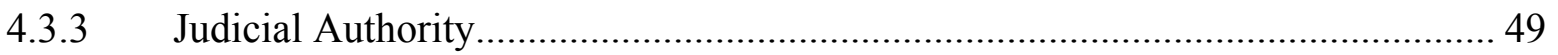

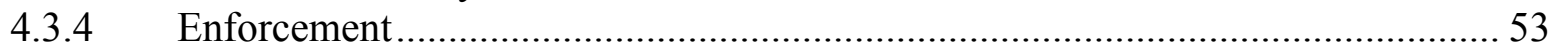

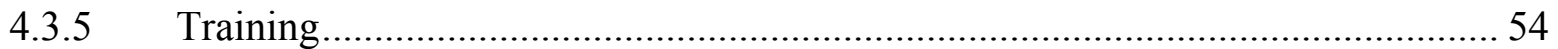

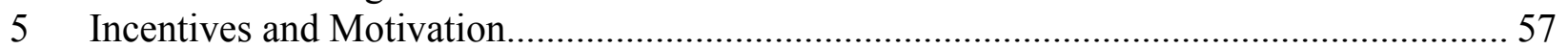

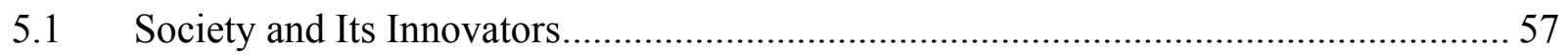

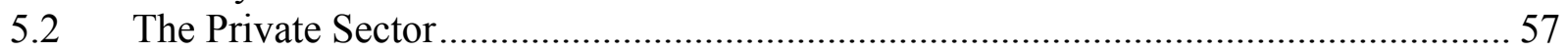

5.2.1 Multinational Corporations and Large Indian Companies.................................... 57 
5.2.2 Small and Medium-size Enterprises and Individual Inventors ............................. 58

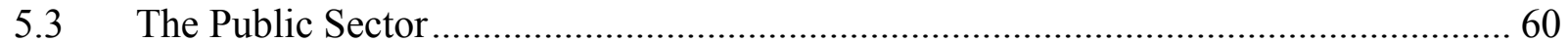

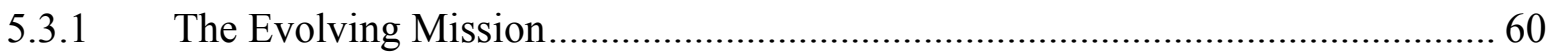

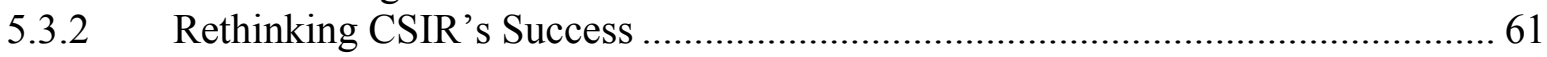

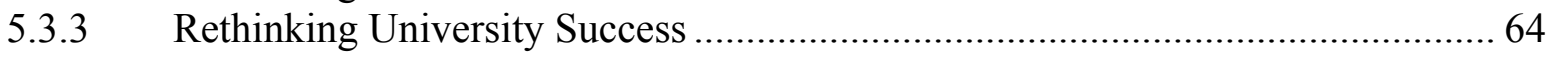

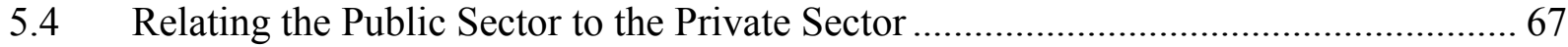

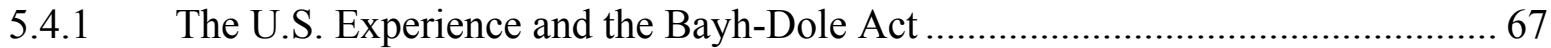

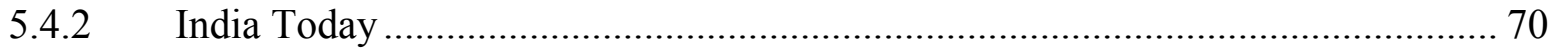

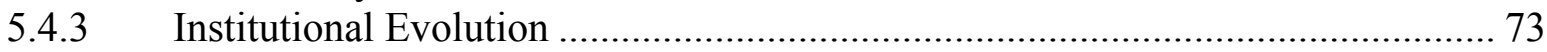

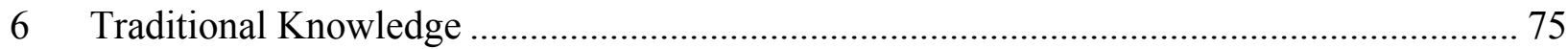

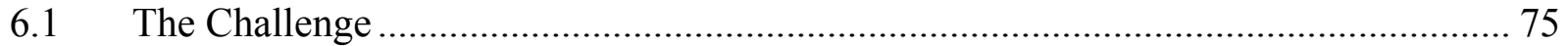

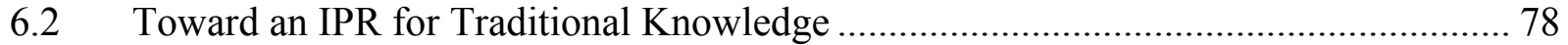

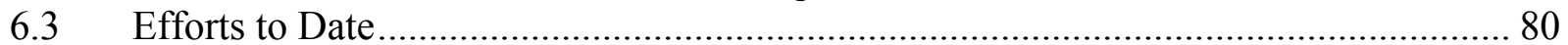

6.4 Possible System Structures for Traditional Knowledge IPRs.................................... 83

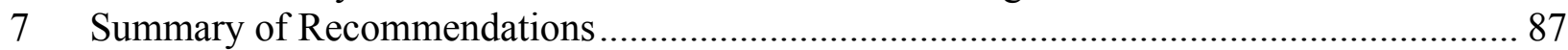

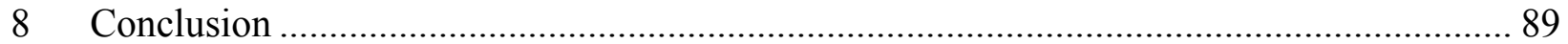




\section{Executive Summary}

This study describes recent advances in Indian patent law and discusses the steps that India must take to complete its journey to an effective patent system. It is part of a broader, ongoing World Bank inquiry into India's efforts to rethink its economic policies in light of early- $21^{\text {st }}$ century realities, with an emphasis on policies related to knowledge, information, innovation, and technology. This study informed, was informed by, and published concurrently with the Bank's Unleashing India's Innovation Potential.

A country's patent system is but a part of its overall regime regulating intellectual property rights (IPRs). IPRs have long played important roles in the innovation systems of most advanced economies. India - like many developing economies — began reexamining its approaches to IPRs when the World Trade Organization's Trade-Related Aspects of Intellectual Property (TRIPS) agreement became effective in 1995.

Though TRIPS obligations may have been the immediate impetus for this reassessment, many of the steps that India has taken stand on their own merits. Robust systems of IPRs can motivate investment, foster innovation, revolutionize industries, improve product quality, reduce consumer prices, expand educational opportunities, increase the demand for skilled labor, and promote economic development. As market mechanisms, however, the paths that they beat to any of these goals are often unpredictable. IPRs thus promise explosive, expansive, unplanned economic growth and its consequent benefits. Research on the economics of innovation indicates that IPRs are the best ways to motivate innovation and that free-market innovation, in turn, is the best way to promote growth.

Because the basic structure of India's patent regime is relatively new, many of the recent changes remain controversial, and many proposals relevant to implementation and augmentation remain. Still, efforts over the past decade - culminating in the 2005 amendments to the Patent Act of 1970 - have constructed a solid foundation for a vibrant, fully functioning patent system. Significant work remains to build such a system atop that foundation. This study describes the steps remaining for India to continue its journey from a patent system that looks good in theory to one that works well in practice.

\section{Intellectual Property Rights}

To many people the term intellectual property (IP) means patents and copyrights. Developing countries contemplating the introduction or reform of their IP systems understand that a certain amount of harmonization with international norms is needed for their full integration with the global economy - and, in particular, for building the investor confidence required to attract foreign direct investment (FDI). By and large, though, they tend to see the development of IP systems as a concession to richer countries.

While such a focus on patents and copyrights is correct, it is also incomplete. The basic "IP bargain"-namely, that society benefits when it allows those with special access to valuable ideas to securitize those ideas - is little more than an extension of the bargain that successful 
capitalist economies have long offered to owners of real property. Much as deeds and titles allow homeowners to leverage their houses into investment capital for entrepreneurship, patents allow innovators leverage their ideas into commercial ventures. This basic bargain should be as applicable to those whose special knowledge arises from the traditional economy as to those whose knowledge lies at the cutting edge of the modern economy.

India's IP analysts understood this broad view of IPRs when they designed India's previous patent regime, effective with the Patent Act of 1970. Any discussion of India's future patent system must be mindful of this past. Perhaps the most important lesson of that past is that good intentions are insufficient. India's earlier patent regime emerged from analyses that asked the right sorts of questions and that sought answers capable of motivating and rewarding innovation while simultaneously promoting production, distribution, commercialization, and job growth. With the notable exception of the pharmaceutical industry - an industry characterized by an unusual combination of large capital requirements for innovation and simple, easily replicable products - the previous regime did neither.

India asserts that its 2005 amendments brought its patent laws into full compliance with TRIPS. These amendments have had dramatic effects:

- India has extended the life of its patents from a 5-14 year scheme to a TRIPS-mandated 20 years.

- India now grants product patents on a range of pharmaceutical and therapeutic innovations, including exclusive marketing rights (EMRs) on drugs. Previously only process patents and weak rights were available.

- India preserved its right to turn normally exclusive patent rights into compulsory licenses, but accepted TRIPS limits on circumstances where such actions were possible. Under current law, India's Controller of Patents may grant a compulsory license only if the claimant can show that exigent circumstances implicate national security, public health, or other emergency circumstances, and that the patented product is not already available to the public in sufficient quantities at reasonable prices.

- India introduced limited patentability for software. The new law continues precluding patents on standalone computer programs, mathematics, algorithms, and business methods. But for the first time, it permits patents on applied software or software embedded in or combined with hardware.

The giant of Indian patenting is the Council of Scientific and Industrial Research (CSIR), a government research institute. CSIR has also played a huge role in raising IP awareness in India. Along with the Patent Facilitating Center (PFC), a program of the Technology Information Forecasting Assessment Council (TIFAC) of the Department of Science and Technology (DST), CSIR has created something of a "patent chic" in India. Some IP lawyers even describe calls from farmers inquiring about the patentability of large vegetables - indicating significant awareness of patents, though limited understanding of their scope.

This broad awareness points to two conclusions. First, it highlights the tremendous successes that these organizations have enjoyed over the past decade. Second, it highlights the need for a new 
task. For the past 11 years the leaders of India's patent community have emphasized basic education, awareness, and social achievements. There seems to be little more for them to do along these dimensions. The time has come for them to shift to the next stages of educationnamely, to emphasize the partially appropriable rewards that patent systems harness to motivate individual innovation and investment.

\section{System Design}

The Government of India must add flesh to its new statutory structure. Despite its overriding concern with TRIPS compliance, the government retains significant leeway in system design. Although TRIPS enshrines principles of patent law and of copyright law that may or may not be appropriate for a country at India's level of economic development, it also affords its members a fair degree of flexibility in determining how to interpret and apply its requirements. The government should carefully evaluate the various possibilities that this flexibility provides. The most likely path to an effective Indian patent system is to tailor a system to the country's needs and then enforce it effectively. An IP regime designed without appropriate analyses risks being a poor system that incurs transaction costs, promulgates uncertainty, and works to the detriment of society.

TRIPS mandates a "unitary" patent system that does not discriminate among industries. Within this system, all signatory countries must provide patent protection on all patentable inventions that are suitably "novel" and "nonobvious." Patentability, novelty, and nonobviousness are imprecise terms. Each country must determine its own definitions, and all chosen definitions should respond to the goals that a country sets for its patent system. The analyses underlying such determinations inject flexibility into national patent systems. India has and should continue to avail itself of that limited flexibility wherever appropriate. As India moves toward refining and completing its IP system, its policymakers must remain aware that numerous analytic questions are relevant to the types and amounts of innovation that its IP system can motivate.

Thus the government must approach the completion of its patent system design by investing the potentially significant time and policy resources needed to create an enforceable system responsive to the country's needs. If it does so, India will likely find that the gains from increased domestic innovation exceed the losses from TRIPS compliance, and that it is thus better off with TRIPS and TRIPS-induced amendments to its patent law than it was without them. Indians will also find that compliance with and enforcement of their patent system can lead to a position of international leadership and generate welfare gains greater than those available to countries that insist on free riding international innovations.

System design begins with choosing between a registration system and an examination system. Flexibility flows from there. In a registration system, government patent offices grant patents for the asking, and leave complicated determinations to courts adjudicating the relatively few patents that generate litigation. In an examination system, administrators at the patent office determine the propriety of patenting before granting a requested patent.

The choice between a registration and an examination system is of more than merely administrative significance. Judges in a registration system and examiners in an examination 
system set the rules that separate patentable from unpatentable subject matter, novel inventions from incremental advances, and obvious innovations from nonobvious ones. These rules thus absorb virtually all the flexibility that remains to individual nations even in a TRIPS-compliant framework.

Decisions about patentability can alter both the investments in innovation that India experiences and the types of commercial development that arise. Expansive patent scope in areas like software and pharmaceuticals can attract significant investments from multinational corporations (MNCs) in Indian research, education, and training facilities, but may hamper the development of low-cost Indian producers as suppliers of choice to the developing world (particularly to countries without their own IP systems).

Decisions about novelty and nonobviousness can have similar consequences. Is the development of a six-hour pill a novel advance over its previous four-hour version? Is the application of a known algorithm to a new setting obvious? Investors care deeply about the answers to these questions. The answers that India's patent system chooses to provide will dictate those investors' responses.

Even at the "merely administrative" level, the choice between registration and examination systems is stark. A pure registration system will convert examiners to file clerks, but mandate better training for judges - thereby motivating the development of a specialized bench. A pure examination system will require detailed guidelines to train technically competent examiners. Judges, particularly trial judges, will likely receive less training-thereby motivating the development of an appellate court with significant expertise.

Every country must evaluate its needs and advantages in deciding what type of behavior to motivate. Wise decisions on these and related issues will allow India to take advantage of the flexibility remaining under TRIPS to encourage behavior likely to attract appropriate amounts of FDI without imperiling either workers or consumers.

The best route for India would be to assess these issues early in the development of its new patent system. India will want to enforce a patent system tailored to its needs - one that increases investor confidence and strengthens the rule of law. A poorly conceived patent system that fails to serve India's interests is likely to result in lackluster performance and undermine investor confidence.

In analyzing the needs of its patent system, India must recognize that as a large, poor, liberal democracy with a large educated class, its needs are likely to be unique. Assessments conducted elsewhere - whether in the developed or developing world - should inform the analysis but not dictate its outcome. Only determinations of patentability, novelty, and nonobviousness relevant to India's needs can lead to an effective patent system.

All the issues discussed in this study - completing India's statutory reform, developing the guidelines and training programs needed to make the reformed system effective and enforced, rethinking the litigation and judicial resolution of patent disputes, assessing the incentives that the new patent system provides to public and private innovators, and considering the potential of 
a new IP system tailored to traditional knowledge - requires its own calculus. On each, India's decisionmakers must consider which industries and which parts of society are most likely to feel the effects, and whether the gains from domestic innovation and commercialization outweigh the lost potential from free-riding on international innovation.

These questions hardly lend themselves to monolithic answers. In some cases, India's decisionmakers have already reached answers and must now gain experience to learn whether further changes are needed. In others, this study points in directions where appropriate resolutions are most likely, but recognizes that further analysis is needed before India can chart an appropriate policy. In still others, only further inquiry-both within India and on India's behalf by international advisers - will provide meaningful answers.

\section{Key Needs}

India's patent system is at a critical juncture. The 2005 amendments marked the end of a decadelong movement toward compliance with TRIPS. The new statutory framework reflects a thoughtful balance of TRIPS compliance and national needs. It combines the general principles of awarding patents to all inventions that cross yet-to-be determined thresholds of novelty and nonobviousness, with special sensitivity to therapeutic treatments and traditional knowledge. It also includes important procedural safeguards that many patent systems of longer standing lack - notably pre- and post-grant challenge procedures and emergency mechanisms for forcing compulsory licenses.

The statutory changes adopted in 2005 represent reasonable policy choices on the major issues. Like all policy choices embodied in law, India needs to monitor the empirical performance of its laws at achieving its stated policy objectives. At the moment, however, India has to allow that empirical evidence to accumulate. It must put into practice the tradeoffs embodied in the 2005 amendments. It must also begin to appreciate the flexibility that TRIPS leaves at the margins, both in determining specific thresholds for the various conditions of patentability and in determining how India wants to treat some of its most important industries, such as hightechnology information and communications and health.

The key to a functioning patent system lies in how it motivates scientists, technologists, and innovators to develop ideas and products that benefit society. Consistency is the most basic requirement of any motivational system: all behavior rests on reasonable expectations. If innovators cannot predict how they will fare when they seek to obtain and enforce their patent rights, they will not use the system - or at the very least, they will not use it appropriately. Thus the most important implementation challenge that India faces is promoting consistency and predictability in its patent system.

Promoting professionalism, competence, consistency, and predictability is hard work, but the keys to doing so are hardly secret. They lie in clear regulations, well-trained personnel, and constant monitoring. Appropriate regulations and new training institutes will add flesh to the skeletal statutory infrastructure. With these pieces in place, India will have a consistent patent system capable of generating business expectations as reliable as those generated anywhere on the planet. It will have a clear set of rules, a single line of rulemaking, and trained personnel 
capable of applying and enforcing those rules. When it comes to monitoring, a stable of trusted advisers housed in an IP-focused policy institute or think tank should provide the government with policy advice. These scholars would monitor both the performance of India's patent system as implemented and global trends in IP scholarship, policy, implementation, administration, adjudication, and enforcement.

Beyond these structural concerns, the next set of questions involves the incentives in play and the extent to which they motivate target audiences to enter the system and use it appropriately. At the examiner and enforcer level, the challenge is clear: civil service systems that set realistic performance goals, reward success, and penalize failure are most likely to yield successful regulatory systems. The challenges of devising such incentives are well known, but they are essentially questions of government organization rather than of IP. The government should consider them primarily within that context.

At the innovator level, the questions are more complex. They relate to the incentives that India plans to offer its innovators, the ways that innovators will perceive those offers, and the behaviors they are likely to exhibit in terms of investing their capital, time, and effort in innovative pursuits in response to those incentives. Of particular importance are the incentives for key participants in India's economy: MNCs and large Indian companies, small and mediumsize enterprises (SMEs) and individual inventors, research institutes and universities, and poor people. Each group plays a different role in India's economy and innovation system, each responds to distinct incentives, and each has a different level of understanding of how to conceptualize, use, and integrate IP.

In thinking about the needs of these groups, some issues rise immediately to the fore. One involves developing an appropriate framework for collaboration between public and private researchers. The United States led the international community in rethinking this issue with the successful Bayh-Dole Act of 1980. In the quarter-century since this act became law, many countries - including India - have seen it as a template for improving university technology transfer programs and promoting collaboration between academia and industry. But every country contemplating analogous legislation has a legal, cultural, and institutional framework that differs from that of the United States prior to 1980. Appropriate analogs must assess the Bayh-Dole Act's strengths within these frameworks.

In India, CSIR and PFC have circulated voluntary guidelines that some ministries have adopted. Future guidelines, regulations, and legislation should preserve many of their essential elements. The voluntary guidelines:

- Encourage universities and research institutes to patent all patentable discoveries.

- Allow these institutions and private corporations that develop patentable innovations jointly to own the patents jointly.

- Encourage these institutions to share patent revenues with individual inventors, but do not mandate a specific formula for that sharing.

- Require these institutions to set aside a portion of royalty revenues for updating innovation, filing new patent applications, litigating, licensing, and raising IP awareness and competence. 
- Require these institutions to provide detailed information about all patented innovations to the agencies that funded the underlying research.

- Grant the Government of India a royalty free license.

Any future guidelines, regulations, or legislation should also consider another provision that neither these guidelines nor the Bayh-Dole Act incorporate:

- A portion of royalties that an institution receives from patents derived through public research grants should flow back to a national public innovation fund to fund future research.

This last provision should confer much of the motivational strength of Bayh-Dole while also creating a pool for future sponsored research. Still, the key to crafting appropriate guidelines remains a focus on institutional cultures and rules of governance. Bayh-Dole worked in the United States because the primary obstacle to successful technology transfer was legislative. India's main obstacles lie elsewhere.

A second critical motivational issue relates to India's poor, the possessors of traditional knowledge. How can India bring the benefits of IPRs to its poor citizens living traditional lifestyles? IPRs promote growth by leveraging ideas and knowledge into securities, securities into capital, capital into investments, and investments into growth. India's traditional communities may possess considerable knowledge unknown to modern industry-much of which has potential commercial value in the modern world. How can the government help these communities and their members attain the sorts of growth that IPRs generate? Can India's policy advisers craft a new IP regime for traditional knowledge - a system capable of applying the same sorts of leverage to traditional knowledge that patents, copyrights, and other existing IPRs apply to contemporary science, technology, art, and expression?

Numerous volunteer organizations have laid the groundwork for such a system, and the government has invested significant resources in a catalog called the Traditional Knowledge Digital Library (TKDL). But such efforts are only precursors to a new IP regime for traditional knowledge. How should such a regime be crafted and administered? Four alternatives warrant consideration: a direct national traditional knowledge analog to the patent system, an international direct traditional knowledge analog to the patent system, a blanket license for traditional knowledge, and a voluntary fund to which MNCs are encouraged to contribute. Each imposes its own costs and promises distinct benefits. Full consideration of these alternatives is a key task for the proposed think tank of IP policy advisers.

\section{Recommendations}

This study examines several areas that India needs to address in the short to medium term. Work is already under way in many of these areas. Some, such as Patent Office modernization, may soon be complete. Others, notably the development of a functioning IP system for traditional knowledge, will require several rounds of proposal, notification, and comment - a process likely to take several years. Together these key needs point to two inescapable conclusions: India must fill the gaps in its statutory framework, and the government must build a think tank to house an IP policy advisory board. 
This study offers two sets of recommendations: The government has already conducted the analyses needed to achieve the first set. Work on many of these recommendations is ongoing. All that remains is an allocation of necessary resources and a commitment to action. Those in the second set require further analysis and input.

The first set of recommendations is that the government take the following actions as soon as possible:

- Establish an IP policy think tank staffed with Indian and foreign IP scholars, and charged with assessing the likely impact on India's public of contemplated IP policies. As part of the think tank, an expert committee on patent guidelines should be created to consider frequent revisions, amendments, and additions.

- Complete the statutory framework of India's new patent laws.

- Finish modernizing the Patent Office. Efforts should focus on enabling automated applications and online searching and on launching a prior art database and connecting these databases and search engines with as many foreign patent offices as possible.

- Identify the extent to which enforcement of court-ordered IP remedies fall short of general enforcement standards, and provide training for customs and police personnel engaged in enforcing orders related to IPRs.

- Implement the government's plan to upgrade its IP training institute into a full-blown staff training college. Curriculum should be developed for staff - examiners and enforcers - but private practitioners should be encouraged to enroll as well.

- Adopt the current government proposal to launch a management-oriented education and research facility. This facility's curriculum should focus on issues related to patent exploitation - licensing, negotiating, and litigating - to convert patents into revenue streams.

- Launch the TKDL as soon as it is complete and suitable for international consumption. In addition, negotiations should continue on building international respect for IPRs for traditional knowledge.

The second set of recommendations requires more thought before the best courses of action become clear. This study outlines many questions and delineates many tradeoffs, but resolution must lie with a trusted cadre of IP advisers who combine an understanding of IP theory with an intimate awareness of India's sociopolitical environment. The proposed think tank would thus begin with many critical questions. Once such an institution exists, the government should charge it with:

- Assessing the relative merits of a patent registration system and a patent examination system - determining the class of patents most likely to best serve India's needs and drafting substantive and procedural guidelines for the Patent Office oriented toward that class.

- Developing a workbook, or catalog of illustrations, drawn from a variety of disciplines, taken from foreign experiences, to accompany the guidelines. 
- Exploring the interrelationships among registration systems, examination systems, and specialized tribunals, and with crafting recommendations to ensure that India chooses a judicial configuration for patent litigation consistent with its administrative decisions on the evaluation of patent applications.

- Investigating the best ways to promote juridical consistency in patent laws, including the practicality and desirability of creating specialized patent tribunals or appellate courts.

- Considering the ramifications of two-tier filing fee structures and maintenance fees designed to limit the ability of underused patents to impede progress.

- Examining the institutional governance issues surrounding either the incorporation of profitdriven analyses into India's research institutions or the transfer of direct management of public sector patent portfolios to patent licensing corporations.

- Promoting patenting and patent exploitation among individual inventors and SMEs, and considering government-sponsored or -subsidized loan programs and prosecution clinics to facilitate foreign applications.

- Reviewing institutional governance at India's leading research institutions.

- Drafting legislation requiring all government agencies issuing research grants to motivate universities, research institutes, and their individual researchers to seek and exploit patents, and to engage in technology transfer programs with industrial concerns.

- Studying variants of a new category of IPRs that would motivate appropriate sharing of traditional knowledge.

\section{Conclusions}

India's new statutory framework appears to have achieved TRIPS compliance. Its provisions for challenging patents and forcing licenses promise to eliminate the most egregious anecdotes that fueled the previous antipathy to patenting. Remaining policy and legislative debates will round out the compromises needed to promote domestic innovation in drug-related industries without impeding the government's commitment to public health.

The recommendations outlined in this study can take the process the rest of the way. Clear guidelines, better training, a single appellate path, and professional enforcement will promote coherence and consistency throughout the patent system. Improving public awareness of revenue-generating mechanisms and subsidies on filing fees will enhance incentives for individual and SME participation in the patent system. Formalizing guidelines for patents derived through government research funds - if coupled with needed changes in institutional governance-will enhance prospects for technology transfer from laboratories to commercial markets. Compensation schemes for traditional knowledge will extend the benefits of IPRs to the poorest members of society - those for whom participation in the existing patenting system is both impractical and inappropriate. And perhaps most important, a new think tank focused on IP policy will provide the government with independent guidance and analysis as it tries to understand the best ways to leverage IPRs to meet the challenges facing India's development.

In today's global information age, innovation systems will play an increasingly important role in dividing winners from losers. India's innovation system is poised to reap significant returns - not 
only for Indian innovators, but also for their neighbors - who will benefit from the positive externalities of increased innovation. This study's recommendations, if followed, will help India achieve both a fully functioning patent system and a mechanism for ensuring that poor Indians living traditional lifestyles receive their share of the societal gains that a working innovation system can confer. 


\section{Introduction}

\subsection{Purpose of This Study}

Saraswati, the goddess of knowledge, and Laxmi, the goddess of wealth, have been familiar figures in India for thousands of years. The Government of India has recently brought them together in a new and very human form: a modern patent system. Patents, by their very nature, allow people with innovative ideas to leverage their knowledge into wealth, tracing the route from Saraswati to Laxmi. This study describes the recent advances in Indian patent law and discusses the steps that India must take to complete its journey to an effective patent system.

This discussion of India's patent system is part of a broader, ongoing World Bank inquiry into India's efforts to rethink its economic policies in light of early- $21^{\text {st }}$ century realities, with a particular emphasis on policies related to knowledge, information, innovation, and technology. The Bank started this inquiry with work that led to a June 2005 report, India and the Knowledge Economy. ${ }^{2}$ In that report the Bank recognized the importance of helping India identify the most effective ways to foster increased innovation for productivity growth and poverty reduction. That effort led to a recent follow-up Bank study of India's innovation system - the institutions, rules, and procedures governing how India, its citizens, and multinational corporations (MNCs) doing business in its borders acquire, create, disseminate, and use knowledge - titled Unleashing India's Innovation. ${ }^{3}$ This study informed, was informed by, and published concurrently with that report.

A country's patent system is but a part of its overall regime regulating intellectual property rights (IPRs). IPRs have long played important roles in the innovation systems of most advanced economies. The Bank's June 2005 report recommended that India "effectively enforce and implement IPRs to create confidence among domestic and foreign innovators on protection of their innovations in the country" in order to strengthen its innovation system: ${ }^{4}$ The report also said that:

Protection of IPRs is becoming increasingly important in knowledge-based economies. This is being driven by the mounting costs of R\&D [research and development] for new products or processes, shortening of the product life cycle, rapid growth in international trade in high-tech products, and internationalization of the research process. To move ahead in the global innovation race, India too needs to have progressive patent laws and a robust IPR regime. ${ }^{5}$

The 2005 report further noted that this recommendation would not require a fundamental change in India's thinking about its future. India started the hard work of ensuring the robustness of its regimes regulating IPRs more than a decade ago. The Bank's primary recommendations on IPRs

\footnotetext{
${ }^{2}$ See Carl Dahlman and Anuja Utz, India and the Knowledge Economy (World Bank, 2005).

${ }^{3}$ Mark Dutz, ed., Unleashing India's Innovation: Toward Sustainable and Inclusive Growth (World Bank, 2007).

${ }^{4}$ See Dahlman and Utz, supra n. 2 at 100.

${ }^{5}$ Id.at 92.
} 
were thus that India accelerate its movement along the path that the country had already chosen, and that it maintain its vigilance for barriers and hurdles along that path. This study is an attempt to help the Government of India identify those barriers and hurdles, recommend steps most likely to remove them, and help India achieve its goal of leveraging IPRs into a powerful innovation system - and in turn robust economic growth.

\subsection{Intellectual Property Rights as Motivators}

India was hardly alone in beginning to reexamine its intellectual property (IP) systems a decade ago. Since TRIPS (Trade-Related Aspects of Intellectual Property), the intellectual property adjunct to the World Trade Organization (WTO) treaty, became effective in January 1995, numerous countries have reassessed the role that IPRs can play in their development. Though treaty obligations may have been the immediate impetus for this reassessment, many of the steps that India and other developing countries have taken stand on their own merits. Research on the economics of innovation indicates that IPRs are the best-known ways to motivate innovation, ${ }^{6}$ and that free-market innovation, in turn, is the best way to promote growth. ${ }^{7}$

That free-market orientation is critical to appreciating the power latent in an effective IP system. Awards, grants, contracts, and prizes can promote innovation, but with a notable difference from the innovation that springs from IPRs. These other mechanisms can motivate innovators both inside and outside government to direct their efforts and investments toward specific goalstypically socially beneficial objectives that government has identified as being worthy of attention. Only IPRs channel market forces toward innovation in unplanned directions.

The "space race" between the United States and the Soviet Union during the 1950s and 1960s provides a classic example of innovation impelled more by awards, grants, contracts, prestige, and national pride than by IPRs. India's development of its Institutes of Technology (IITs) into world-class educational institutions in engineering, science, and technology provides a subtler illustration of the same phenomenon. By way of contrast, market forces rather than government planning powered the growth of the commercial Internet and the emergence of genetic therapies and genetically modified crops. IPRs loomed large in these recent explosions of innovative activity channeled toward socially productive ends, as they have in most industries whose sudden innovative upheavals have generated massive growth and disproportionate increases in societal welfare.

IPRs thus play a unique role in promoting innovation: they are the mechanisms that channel market forces into technological progress and impel technology-driven economic growth. Robust IP systems can motivate investment, foster innovation, revolutionize industries, improve product quality, reduce consumer prices, expand educational opportunities, increase the demand for skilled labor, and promote economic development. But as market mechanisms, the paths that they beat to any of these goals are often unpredictable. IPRs thus promise explosive, expansive, unplanned economic growth, and its consequent benefits.

\footnotetext{
${ }^{6}$ See generally, Suzanne Scotchmer, Innovation and Incentives (MIT Press, 2004).

${ }^{7}$ See generally, William J. Baumol, The Free-Market Innovation Machine (Princeton University Press, 2002).
} 
Research and empirical experience have shown that though the other motivators may be better at promoting planned growth, IPRs can promote maximum growth - but only if designed and implemented appropriately. Poorly designed IPRs can actually impede innovation, commercialization, and progress. Poorly implemented IP systems are as prone to patronage, corruption, misuse, and abuse as are all other regulatory programs. As a result, one of the critical questions underpinning the World Bank's investigation into India's innovation system is whether its revised IP laws do - or are soon likely to-motivate the sorts of innovation capable of powering economic growth throughout Indian society.

\subsection{Types of Intellectual Property Rights}

National IP systems combine numerous types of rights and varying bodies of law. The common theme uniting IPRs is that they convey certain exclusive rights in an idea-rights that, under the proper set of circumstances, can generate significant revenues for their owners. At first glance, this notion of idea exclusivity may appear both unnecessary and counterproductive. After all, ideas are "nonrivalrous"- meaning that one person's use of an idea in no way diminishes another person's use of it. Free-market economics, and in some cases broad moral considerations, seem to suggest that society would benefit if all ideas were shared freely and disseminated widely.

But such an approach works only after new ideas are known and understood. It does little to motivate the creation of new ideas, the teaching of new discoveries, or the significant investments in time and capital typically needed for idea creation and dissemination. In other words, if we all shared all new discoveries freely and immediately, there would be fewer of them to share, and we would not disseminate them as effectively. Experience has shown that, if employed correctly, the various forms of "idea exclusivity" embodied in IPRs can help promote innovation, invention, creativity, consumer protection, and education - all important parts of a country's innovation system.

The most common, and by far best known, categories of IPRs are patents, copyrights, trademarks, and trade secrets, though other types of IPRs exist both in theory and in practice. Each of these categories serves a different goal. Under a traditional IPR taxonomy, patents promote invention and the dissemination of knowledge, copyrights promote creativity and dissemination of expression, trademarks protect consumers by conveying reputational information from and about producers, and trade secrets respect an individual's right to withhold original information from the public. (This taxonomy is only "traditional" because the growth of digital copyrights - particularly the uncomfortable extension of copyrights to protect softwarehas pushed contemporary copyright law far beyond the boundaries of pure expression and well into the realm of the functional. $)^{8}$

\footnotetext{
${ }^{8}$ Many of the most challenging issues currently roiling copyright experts around the planet deal with the incompatibility of traditional copyright concepts and the technologies and economics of the information age. See, for example, Pamela Samuelson, Randall Davis, Mitchell Kapor and J.H. Reichman, "A Manifesto Concerning the Legal Protection of Computer Programs," 94 Columbia L. Rev. 2308 (1994); Bruce Abramson, "A First Principles Approach to Intellectual Property Reform," 8 Boston University Journal of Science and Technology Law, 75 (2002).
} 
Though trade secrets are an important part of every nation's innovation system and often a critical component of its industrial development, trade secret law is not particularly interesting from the perspective of IP analysis. Such laws typically prohibit industrial espionage, and lack the economic calculus or motivational components that animate most studies of IPRs. ${ }^{9}$

Copyright law and trademark law integrate this calculus, and present challenging issues relevant to motivating innovation and industrial development. But India's laws on copyrights and trademarks have long followed the basic contours familiar around the world. By all accounts, India's copyright and trademark systems function well, and there do not appear to be any pressing national issues that would motivate significant revisions to these bodies of law. In the area of Indian trademark law, most observers report that reforms enacted in 1999 cleared up some longstanding problems; at the moment the system does not appear to need any further significant changes.

In the area of copyright law, issues brewing around the globe suggest that all national copyright systems, including India's, may have to undergo considerable reassessment and reform within the next few decades. These issues relate to the challenges that digital data and the information age pose for traditional copyright concepts. In the popular imagination, the war over music downloads best exemplifies this tension (though IP scholars have long viewed the software industry as its central battleground). ${ }^{10}$ In many developed countries peer-to-peer (P2P) file sharing systems have drawn battle lines between "technologists," who wish to ease the transfer of files, including copyrighted files, and "content owners," who seek to impede the transfer of their copyrighted data. Though both technologists and content owners play important roles in the Indian economy, at least parts of the Indian content industry appear to be more comfortable with file-sharing technology than are their European, Japanese, and U.S. counterparts. In late 2003, for example, Yash-Raj Films distributed the Hindi Bollywood gangster movie Supari through KaZaA - making it the first movie ever authorized for online P2P distribution. ${ }^{11}$ Nevertheless, it seems unlikely that India will forever avoid the global battles over the erosion of copyrights in the digital age. At the moment the apparent harmony in India suggests that a reassessment of copyright law for the digital age is not a priority for shaping India's IP system or broader innovation system.

The priorities for India's IP community involve patent law. Until fairly recently, India maintained an atypical patent regime that recognized the concept of granting patent rights to innovators, but tried to tailor those rights to promote production rather than innovation. ${ }^{12}$ This regime, in place from 1970-95, led to some remarkable successes - particularly in generic drug manufacturing - but failed to spur significant innovation or industrial development throughout

\footnotetext{
${ }^{9}$ See, for example, William M. Landes and Richard A. Posner, The Economic Structure of Intellectual Property Law (Harvard University Press, 2003) at ch. 13.

${ }^{10}$ See Bruce Abramson Digital Phoenix: Why the Information Economy Collapsed and How it Will Rise Again (MIT Press, 2005) at chs. 7-8 for a discussion of the P2P battles and their relationship to the challenges of protecting software.

${ }^{11}$ See Anand Parthasarathy, "Indian Film in Internet Distribution Wave," The Hindu, December 11, 2003, http://www.hinduonnet.com/thehindu/2003/12/11/stories/2003121104582200.htm.

${ }^{12}$ See Shondeep Banerji, "The Indian IP Rights Regime and the TRIPS Agreement," in Clarisa Long, ed., IP Rights in Emerging Markets, (The AEI Press, 2000).
} 
the economy. (Though it is unfair to single out a well-conceived, if experimental, patent system for a failure endemic to the broad, statist economy in which the government embedded it.)

This atypical regime also failed to generate much interest in India's patent system: India issued relatively few patents, and even fewer valuable ones, under its auspices. Between 1975/76 and 1984/85, for example, the Indian Patent Office received an average of about 3,000 applications a year and issued an average of fewer than 2,000 patents a year. ${ }^{13}$ According to most accounts, few if any of those patents created lucrative business opportunities that would not have existed absent IPRs, generated significant licensing fees, or even led to infringement litigation. By way of contrast, the U.S. Patent and Trademark Office (USPTO) issued an average of 56,500 patents a year during that same decade ${ }^{14}$ — many of which led to businesses, licenses, and litigation — even though most observers of U.S. patent law view that period as the tail end of a weak patent era during which U.S. corporations downplayed the potential of patents as mechanisms for enhancing revenues and profits. ${ }^{15}$

\subsection{Goals of This Study}

Over the past 15 years, India's thinking about economics in general and patents in particular has undergone radical change - change that the numerous amendments to India's patent laws since 1995 both reflect and helped herald. Several factors have induced this change, including the shift from a planned economy to a more liberal one, WTO accession and India's acceptance of TRIPS, and India's recognition of the role that its knowledge industries and technology companies will play in fostering the country's economic development. These factors-and likely several others - have impelled India to enact radically amended patent laws, and to create the regulatory and adjudicatory bodies needed to make them work. These laws have already begun to play an important role in India's integration with the global economy and in India's emergence as an increasingly important player in the global knowledge economy.

Because the basic structure of India's patent regime is relatively new, many of the recent changes remain controversial, and many proposals relevant to implementation and augmentation remain. Of greater significance to the overall study of India's innovation system, however, is that the overhaul of India's patent system is incomplete. The past decade's efforts - culminating in the 2005 amendments to the Patent Act of 1970 - have constructed a solid foundation for a vibrant, fully functioning patent system. But as virtually every member of India's small, young, patent community recognizes, significant work remains to build such a system atop that foundation. This study describes the steps that remain for India to continue its journey from a patent system that looks good in theory to one that functions well in practice.

In particular, this study discusses several pressing issues that India has yet to resolve in its journey toward an effective patent system:

- The remaining statutory gaps critical to regulating ideas in the quintessential information age industries of software and health care. In software, India must consider the relationships

\footnotetext{
${ }^{13}$ Compiled by CSIR from Annual Reports of the Controller General of Patents, Designs and Trademarks.

${ }_{15}^{14} \mathrm{See}$ http://www.uspto.gov/go/taf/issuyear.htm.

${ }^{15}$ See generally, Fred Warshofsky, The Patent Wars, (Wiley, 1994).
} 
among the motivations inherent in varying IPRs and the needs of industry participants. In health care, India must balance the interests of MNCs in pharmaceutical and related therapeutic industries - whose investments and innovations lead to new cures and therapies - with those of impoverished patients who need those therapies, and the low-cost producers who serve them.

- The need to reduce discretion and increase consistency in all areas of patenting, patent law, and patent enforcement, to ensure that a predictable patent system motivates the desired behavior-namely, investment in innovation and subsequent commercialization.

- The cultural, legal, and behavioral changes needed to motivate India's SMEs, individual inventors, universities, and institutional researchers, first to direct their inquiries toward innovations likely to promote industrial development and job creation, and then to leverage their discoveries into the marketplace.

- The sorts of mechanisms capable of bringing the benefits of IPRs to India's poor rural communities by compensating them for transferring their functional traditional knowledge into the commercial arena.

The study also provides pointers on the directions most likely to maximize success. Most of these are intended as bases for further analysis rather than as definitive answers. Complete analyses and ultimate answers must rest on specific inquiries into the needs of India's innovators and businesses. The appropriate locus for such analyses is a new institution, whose founding is this study's most important — and most definitive — recommendation. The government should establish an independent think tank or advisory board focused on IP policy capable of providing trusted expertise, analysis, and advice.

Before addressing any of these prospective matters, however, the study discusses two necessary background topics: the theory underlying IPRs as generators of both innovation and growth, and the history of India's patent system.

\section{Intellectual Property Rights}

\subsection{Basic Theory}

\subsubsection{The Broad View of IPRs}

To many people the term intellectual property (IP) means patents and copyrights (and occasionally trademarks and trade secrets), more or less as conceived by European, Japanese, U.S., and increasingly international economic law. Developing countries contemplating the introduction or reform of their IP systems understand that a certain amount of harmonization with these international norms is needed for their full integration with the global economy-and, in particular, for building the investor confidence required to attract foreign direct investment (FDI). By and large, though, they tend to see the development of IP systems as a concession to richer countries. ${ }^{16}$

\footnotetext{
${ }^{16}$ See, for example, Sanjaya Lall, "Indicators of the Relative Importance of IPRs in Developing Countries" (UNCTAD/ICTSD, 2003) at 7-8, citing "Intellectual Property: Balancing Incentives with Competitive Access," in Global Economic Prospects, 129-150 (World Bank, 2001).
} 
While such a focus on patents and copyrights is correct, it is also incomplete. Patents and copyrights are critical components of any contemporary IP system, but they are not synonymous with IPRs. In fact, it is precisely the equation of IPRs with existing patents and copyrights that encourages the misconception that IP serves only the rich. In terms of innovation economics, patents and copyrights promote technology creation - the fundamental advances in science in which developed economies retain their greatest advantage over their developing competitors. Patents and copyrights also play a significant role in technology adaptation - the application of known technologies to novel and new uses, and an area where developing economies are beginning to challenge the traditional supremacy of the developed world. Patents and copyrights play almost no important role in technology adoption - the incorporation of known technologies into the contexts and challenges facing developing countries with large, poor, undereducated populations living traditional (and often subsistence) lifestyles.

Nevertheless, the basic "IP bargain"-namely, that society benefits when it allows those with special access to valuable ideas to securitize those ideas - is little more than an extension of the bargain that successful capitalist economies have long offered to owners of real property. Much as systems of deeds and titles allow homeowners to leverage their houses into investment capital for entrepreneurship, patents allow innovators leverage their ideas into commercial ventures. ${ }^{17}$ This basic bargain should be as applicable to those whose special knowledge arises from the traditional economy as it is to those whose knowledge lies at the cutting edge of the modern economy. Extending this bargain to those most in need of development assistance therefore necessitates a new, broader view of IPRs. This broadening leads to an immediate and unanswered question: What type of IPR, if any, could channel commercial profits to the appropriate contributors of traditional knowledge, while incurring only the minimal transaction costs that residents of the traditional economy can bear?

\subsubsection{First Principles}

Perhaps the best place to start any inquiry into the applicability of IPRs beyond their common realm in the developed world's advanced industries is with a return to the "first principles" of IP.

As a matter of basic theory, the classic characterization of innovation, and the role that IPRs can play in motivating it, dates back to Joseph Schumpeter's analysis of "creative destruction" more than 60 years ago. ${ }^{18}$ IPRs allow markets to reward truly powerful creativity with extraordinary returns. Consumer demand turns genuine innovators into powerful incumbents. Because the best way to defeat such an incumbent is to produce a far superior product, competition drives the next generation of innovators to "destroy" the incumbent's market position by "creating" those nextgeneration innovations. IPRs thus allow small innovators to leverage their ideas into legally protected rights that enable them to compete with much larger (and wealthier) incumbents.

Over the past decade or so, Harvard Business School Professor Clayton Christensen has applied Schumpeter's theories in empirical studies of several large (and once-successful) companies that were overtaken by competing startups - along with the startups. ${ }^{19}$ He noticed that low-end

\footnotetext{
${ }^{17}$ See Hernando de Soto, The Mystery of Capital (Basic Books, 2000).

${ }_{11}$ See Joseph A. Schumpeter, Capitalism, Socialism and Democracy (Harper, 1975) [orig. pub. 1942].

${ }^{19}$ See Clayton Christensen, The Innovators Dilemma (Harvard Business School Press, 1997).
} 
startups often managed to surpass their larger, established rivals even though the incumbents had adopted sound business practices and reasonable strategic plans. He posited that the downfalls were almost inevitable consequences of how the entrants' new technologies had rendered the incumbents' existing products and brands obsolete-fulfilling Schumpeter's predictions, and demonstrating the potential for IPRs to help small, underfunded businesses grow into major players and significant employers. Indian companies may be able to avail themselves of these lessons as they seek ways to compete with MNCs.

Professor William Baumol, of Princeton University and New York University, also built on Schumpeter's theories to draw interesting implications about the role that innovation focused through an IP system can play in improving societal welfare. He posited that entrepreneurial activity exists - in roughly comparable amounts - in all societies. In many societies entrepreneurs try to outperform expectations in antisocial ways, through crime, corruption, or rent seeking behavior that maximizes their own returns while reducing overall societal welfare. The constant need for change in market economies impels innovation, productivity, competition, and efficiency. Baumol posited that market economies, specifically those that reward innovation using IPRs or other related mechanisms, provide a socially beneficial outlet for entrepreneurial behavior. ${ }^{20}$ In Indian society a functioning IP system could thus help draw many people from informal, unproductive, and possibly even criminal activities into the formal sector-and thus male them significant contributors to the country's economic growth.

\section{$\underline{\text { 2.1.3 }}$ Flexibility in IPR Design}

Beyond these basic theories about the potential benefits that functioning IP systems confer on societies that adopt them, dual practical concerns about the global competition for FDI and the emerging harmonization of IP concepts pursuant to international treaties have impelled most countries to explore the potential of domestic IP systems. These explorations are more than idle exercises designed to justify a preordained conclusion. Even within the current environment of increasingly harmonized international IP norms, individual countries retain a fair amount of leeway in interpreting and applying these norms.

In patent law, for example, TRIPS obligates parties to offer patents on "any inventions, whether products or processes, in all fields of technology, provided that they are new, involve an inventive step and are capable of industrial application." 21 None of these key concepts - newness (or novelty), inventiveness (or nonobviousness), and applicability — are amenable to a single fixed meaning. In $20^{\text {th }}$ century U.S. patent jurisprudence alone, some inventions that would have passed the requisite threshold of novelty and nonobviousness in some decades would have failed it in others, boundaries delineating which accused products infringe from those that do not have shifted, attitudes toward repairing patented products to create a competitive market have changed, rules governing third-party "inducement" to infringe remain in flux, the applicability necessary to differentiate unpatentable mathematics from patentable algorithms has changed, and the resolution of conflicts between IP law and other legal regimes (notably but not exclusively competition law) have swung back and forth.

\footnotetext{
${ }^{20}$ See Baumol, supra n. 7.

21 TRIPS Art. 27.1.
} 
Other developed economies have exhibited similar tendencies to reassess the meaning of IP law without attacking the underlying language or conceptual fidelity to either novelty or nonobviousness. Developing countries encountering these issues for the first time thus face an array of implementation models, ranging from those that viewed IPRs as an occasionally necessary evil to those that viewed IPRs as valuable engines of growth. This array of alternative interpretations, and potentially new additions to it, should enable decisionmakers in India and throughout the developing world to think creatively, and to craft regimes applicable to their countries' specific economic, industrial, and human needs (Box 1).

\section{Box 1 India and TRIPS}

In many ways TRIPS enshrines principles of patent law and copyright law that may or may not be appropriate for a country at India's level of economic development. Nevertheless, TRIPS does afford its members a fair degree of flexibility in determining how to interpret and to apply its requirements. The Government of India should expend significant time evaluating the various possibilities that this flexibility provides. The most likely path to an effective Indian patent system is to tailor a system to India's needs and then enforce it carefully. An IP regime designed without appropriate analyses risks being a poor system that incurs transaction costs, promulgates uncertainty, and works to the detriment of society.

In particular, the challenge of selecting appropriate interpretations from a sizable candidate set should push developing country governments to ask how turning ideas into concrete securities that individuals can then leverage into financial capital can best help them develop their own national human capital. This question, even if set within the context of patent and copyright law, should help broaden the thinking of developing country governments and advisers beyond the current confines of those laws, into the general goal of understanding how to leverage knowledge into development as the world enters the information age.

Such a new, broad, and ultimately more complete view of IPRs is critical to appreciating their potential for development. At best, developed country approaches to patents and copyrights in the early 1990s - the approaches that TRIPS essentially enshrined as international law-were appropriate for advanced industrial economies. It is now long overdue to inquire which components of these systems are equally appropriate for the developing post-industrial economies of the early information age. The thoughtful changes that India has incorporated into its patent statute over the past decade suggest that the new law's drafters understood both the general need for harmonization and the specific concerns that India's economy poses.

\subsubsection{IPRs as a Response to Market Failure}

Any assessment of the proper role for IPRs to play in India's innovation system must therefore begin by recognizing that patents and copyrights are simply two high-profile realizations of an economic theory about progress and development. The basis of this theory is straightforward: it lies in market failure.

In a true free-market economy (or, for that matter, in most variants of nonmarket economies), anyone who grasps an idea can employ it. Genuine pioneers may be in an excellent position to exploit new ideas; prestige, training fees, and first-mover advantages in the commercial arena may all flow from a reputation for innovation or creativity. But without a guaranteed return to such pioneers, second movers, imitators, and reverse engineers may be able to reap many of the 
returns without having had to invest in experimentation and innovation. This outcome is a classic example of the market failure known as the free rider.

Not all free riding is problematic. Many actions convey positive externalities that promote positive free riding by enhancing a general environment. Homeowners who maintain beautiful gardens, for example, may enhance their neighbors' enjoyment of their own homes, and possibly even raise the value of neighboring properties. Most homeowners recognize that their neighbors will not pay them for that increased value. They thus decide whether or not to beautify their gardens based entirely on a personal calculus: if the value of having a beautiful garden exceeds the costs of maintaining it, homeowners will beautify, generate externalities, and allow their neighbors to free ride on their investment.

Free riding becomes problematic when a potential investor can only justify investing by reaping a greater portion of the returns than the free market would normally allow. Many settings that require significant R\&D investments fall into this category. In such cases, free riding reduces the incentives for investing in research (to develop new ideas), education (to disseminate those ideas), and often even commercialization (to turn new ideas into marketable products).

A regulatory system of "rights in ideas" that provides innovators with guaranteed opportunities to generate returns without free riders' interference provides a way around this market failure. "Partial appropriability" allows innovators to internalize some benefits that would otherwise be externalities. These rights thus allow innovators to appropriate some - but never all —of the benefits that their innovations generate. Of course, such partially appropriable rights do not emerge cost-free. Any set of rights that society grants to innovators necessarily translates into restrictions on someone. Few if any IP systems impose those restrictions universally. Governments typically reserve the right to use patented or copyrighted items under "necessary" circumstances. The U.S. Copyright Act exempts libraries from selected restrictions. Private U.S. universities long believed that they were similarly exempt from parts of the patent laws; a recent court ruling to the contrary has sent them scrambling for a statutory exemption. ${ }^{22}$

Comparable issues abound everywhere because many countries feel less comfortable about restricting behavior at government, nonprofit, and educational institutions than they do about restricting commercial activity and individual use. Perhaps most significantly, IPRs are all territorial; they have no legal force beyond the borders of the country that granted them (barring specific treaty agreements to the contrary). Thus, for example, an MNC that holds a U.S. patent, a Japanese patent, and no other patents on a given innovation may restrict production and use of the patented innovation in the United States and Japan - and importation of that innovation from any third country into the United States or Japan-but possesses no other legal right to interfere with anyone choosing to implement the patented innovation beyond the borders of those two countries.

The recognition that IPRs need not restrict everyone to be effective plays a subtle yet critical role in the aforementioned overdue inquiry into the applicability of advanced industrial IP concepts to the developing economies of the early information age. The only valid justification for allowing IPRs to interfere with normal market principles is their potential for correcting the market failure

${ }^{22}$ See Madey v. Duke Univ., 307 F.3d 1351 (Fed. Cir. 2002). 
of insufficient innovation. The stronger are the rights on offer to potential innovators, the greater is the "price" that the public is paying to promote that innovation. The relationship between price and "quality," however, is rarely linear, and there is no reason to believe that innovation is among the few rare exceptions. As a result, theory suggests - and experience reinforces - that IPRs can become so strong that they begin to interfere with innovation, investment, education, and commerce. Before they reach that point, however, they can also enter a range where the public pays progressively higher prices while receiving only diminishing returns.

\subsubsection{Optimality in IPR Design}

In economic terms, rights stronger than those necessary to motivate the societally optimal quantum of innovation constitute a form of producer surplus. All else held equal, every country that adopts a new IP system broadens the potential market in which the holder of an IPR can reap a return without interference from free riders. This expanded market increases incentives for the innovator. If the incentives on offer from other countries had been suboptimal, the market expansion will benefit everyone by motivating increased innovation and consequent commercial activity and growth. If the incentives on offer already were optimal, the increase represents a public overpayment. (And, finally, for the sake of completeness, if the global public was already overpaying, the market expansion exacerbates a bad situation.)

The implicit analysis requires a fair amount of explanation as a matter of theory, and even more discussion as a matter of policy guidance. In particular, it must consider two distinct questions: What is a societally optimal IP regime? And what are the pros and cons of free ridership?

In answer to the first question, the abstract concept of a "societally optimal" IP regime flows from some standard economic definitions. Any society that adopts IPRs chooses to trade unfettered access to a small innovation pool for more limited access to a larger innovation pool. The stronger the rights granted, the more restricted the access - and hopefully, the larger the pool. The societal value of an IP regime is the net difference between the costs that society bears to develop and run the regime and the benefits that society accrues by establishing the regime. The societally optimal regime is the one that maximizes societal value.

Societal optimality is an elusive concept, likely to be more important in theory than in practice. Even in practical terms, however, the questions guiding the search for societally optimal regimes also play critical roles in guiding policy choices. Any country contemplating IP reform must remember that the regulation of ideas is subject to a cost-benefit analysis that may apply in different ways to different industries and to countries at different levels of economic development. The goal of any such analysis must be to strike the appropriate balance between motivating innovation and commercialization on the one hand and maintaining the public's right to integrate new knowledge into competitive markets on the other. Sound policies should reflect an attempt to maintain this balance; as experience about their effectiveness mounts, occasional reforms should rebalance as necessary.

A series of illustrations set in closed societies may make the notion of optimality a bit more concrete. ${ }^{23}$ In the current era of globalization, analyses of closed societies have lost much of

\footnotetext{
${ }^{23}$ I discussed this issue in considerably greater depth in Abramson, supra n. 8.
} 
whatever salience they might once have had. Knowledge will know few borders in the information age, but IP laws may continue to respect them. Developing countries - including but hardly only India - must therefore weigh the merits and demerits of joining the parts of the world providing motivation for innovators versus joining the parts of the world free-riding on the motivation that others supply. Nevertheless, a closed-society illustration retains its ability to solidify abstract concepts.

Consider first the situation that prevails in a country that confers no IPRs - say, for example, the former Soviet Union. Under such circumstances, some people will innovate for the sake of innovation (that is, they may simply enjoy the intellectual stimulation inherent in innovation), while others will innovate to address their own personal needs. In a market economy without IPRs (which the Soviet Union was not), ${ }^{24}$ some market factors - such as the first mover advantage (that is, that the first firm in a market is often able to establish a market niche that later competitors are unable to shake) or the rewards available for teaching and training-provide further incentives to innovate despite the lack of IPRs. Other sorts of awards, including grants and prizes, can also motivate innovation. Even a society unwilling to offer broad IPRs may still hire innovators with research grants (or salaries) or motivate them to compete for valuable prizes - as the Soviet Union did, with some notable successes. Some commentators believe that these other motivators have the potential to generate as much innovation as patents, but there is no empirical evidence to support their hypothesis. Most observers of innovation agree that grants and prizes can play a useful role in motivating innovation in conjunction with patents, but not in their stead. ${ }^{25}$ These inherent motives for innovation do ensure, however, that even a country without IPRs will not be a country devoid of innovation—as, in fact, the Soviet Union was not.

The innovations generated in such a "no IPR" country thus define a base level of innovation. Because any country could gain access to these base-level innovations without awarding any private rights, the rights granted to private innovators in these goods constitute pure costs that are not strictly necessary. Countries that refuse to recognize any IPRs are thus conservative, riskaverse societies that refuse to regulate the flow of ideas in any way. The public does not invest in innovation directly, but remains willing to free ride on the investments of private innovators. With no investments and likely positive returns, such regimes confer positive (or at least nonnegative) value. This value, however, is unlikely to be very large; countries willing to incur some risks by absorbing some costs should be able to generate greater positive returns.

Next consider a country that recognizes only weak IPRs, as India did under the 1970-95 patent regime. The public in such countries absorbs immediate additional costs by rewarding base-level innovators for tasks that they would have undertaken even in the absence of IPRs. Such countries are thus immediately worse off than those that recognize no rights - unless the rights on offer motivate the diversion of private resources toward further successful innovation. Successful diversion will generate a collection of new, useful ideas above the base-level innovations. If that diversion occurs, these countries' publics will accrue restricted benefits (that is, uses that do not

\footnotetext{
${ }^{24}$ Though many of the Soviet Union's most successful innovation arose in the areas of space and military technology, where the combination of secrecy and competition with the United States mimicked some salient features of market-driven innovation.

${ }^{25}$ See generally, Brett Frischmann, "Innovation and Institutions: Rethinking the Economics of U.S. Science and Technology Policy,” 24 Vt. L. Rev. 347 (2000); Scotchmer, supra n. 6.
} 
conflict with the private rights granted and the ability to buy the other rights back from the right holder) to both the base-level innovations that existed even in the absence of IPRs and the second-level innovations that exist only because of the weak IPRs. In exchange, however, the public of a country conferring weak IPRs must cede the difference in utility between unrestricted and restricted use of the base-level innovations. If the value of restricted use of the second-level innovations exceeds the reduced value of the base-level innovations, weak IPRs will yield a higher return in net societal value than did no IPRs. Considerations along these lines likely led to India's 1970 decision to preserve the concept of patents to reward and promote innovation, while nevertheless weakening them relative to prevailing international norms.

A country that chose to confer strong IPRs would then undertake the same calculation. Once again, the incremental increase in the private value (that is, the value that strong IPRs confer on private parties that weak IPRs did not) will motivate at least some additional potential innovators to develop third-level innovations. The public of countries conferring strong IPRs will thus accrue a net societal benefit equal to the amount that the newly-restricted rights on the three levels of innovation exceeds the less-restricted rights on the first two levels of innovation. The U.S. undertook an analysis along these lines in the late 1970s and early 1980s. Its decision to work toward a strong, predictable patent system at that time played a significant role in reversing its industrial decline of the 1970s and in invigorating the subsequent technology-driven booms of the 1980s and 1990s.

This pattern of costs and benefits will continue as the conceptually incremental process of strengthening private IPRs progresses - to a point. Early in the strengthening process, increased rights are likely to provide added incentives that spur additional innovation. Eventually, however, the rights may become so expansive that they block innovation. New entrants may become discouraged when virtually anything that they discover infringes a right that society has already granted to someone else. Thus, societies that grant increasingly strong rights may gain increasingly restricted use of a growing pool of innovations - or they may deter future innovation.

As each strengthening proposal is considered, society must ask itself whether the pool is likely to grow or to contract; and if it is expected to grow, whether the increased restrictions across the larger pool are likely to result in a net gain or net loss. Proposals that promise a net gain should be adopted; those that promise either a net loss or a smaller pool of innovations should be rejected. When no available proposals promise to yield a net benefit, the regime in place is societally optimal. (Though as a technical matter, this situation describes a local optimum, not necessarily a global optimum.)

A country that finds this elusive hypothetical optimum has no reason to absorb the further costs implicit in granting increasingly restrictive IP rights. Countries that do so anyway are overpaying for innovation. Those that see available net benefits in increasing IP rights but fail to do so are understimulating innovation. Either one represents misregulation. Countries that adopt all proposals that promise a net positive return - and only proposals that promise a net positive return - are regulating innovation optimally. At least, such is the analysis for closed societies. 
These illustrations answer the question about societally optimal regimes. They thus lead into the second question about the pros and cons of national free ridership - a question that becomes relevant when the analysis shifts from the theoretical world of closed societies to the real, interconnected world of the global information age.

\subsubsection{The IPR Enforcement Conundrum}

One of the greatest challenges facing any country in developing sound economic policies is the tension between interest group politics and economic analysis. Policies derived in part in international arenas tend to exacerbate this tension. In the negotiations leading to TRIPS, for example, everyone understood that a successful IP treaty would increase the scope and the strength of IPRs by expanding the size of the market without free riders. Everyone thus also understood, at least implicitly, that the purpose of the negotiations was to increase the overall global incentives for innovation. There is no indication, however, that anyone ever asked whether such an increase represented a move toward optimality or a move away from it - and if the latter, how to amend the emerging international patent system's other dimensions to compensate for the strengthening inherent in increased market size. Furthermore, even if someone did ask the question, there is no indication that such an analysis had any effect on the treaty's final form.

Stated somewhat more bluntly, developing countries may feel that statutory compliance meets their requirements under TRIPS, and that effective enforcement would be a cumbersome expense with few consequent benefits. From that perspective, though there are excellent reasons to believe that effective patent systems will motivate potential domestic innovators to increase their investments in innovation - as the closed-system analysis suggests — it is not at all clear that India's new patent system will motivate MNCs to increase their investments in local innovation.

To Indian policymakers analyzing the costs and benefits of a truly effective patent system, all non-Indian innovations define the base level for which India could gain unfettered access without any IPRs. India's patent system trades this unfettered access for restricted access to this international base level plus the projected larger pool of domestic innovation. Is this tradeoff wise? The Government of India must ask itself several challenging questions to determine the wisdom of the tradeoff (Box 2).

\section{Box 2 The Enforcement Conundrum}

- Was India better off without TRIPS and the TRIPS-induced amendments to its patent law?

- Will the gains from increased domestic innovation exceed the losses from TRIPS compliance?

- Should India now strive to implement its new statutory system effectively?

- Should India invest significant time and policy resources into availing itself of the flexibility that TRIPS affords to create an appropriate enforceable system? 
- Should India try to remain as much of a free rider on international innovation as is possible without violating its international obligations?

The analysis necessary to answer these questions drives a neat wedge between India and many other developing countries. Though India may not be unique along any single relevant parameter, it does occupy a unique niche. Countries with large populations necessarily possess greater potential pools of innovation than do smaller countries. When countries that share cultural similarities also adopt comparable innovation systems, the sizes of their innovation pools tend to more or less reflect their populations. Thus, much as France and Germany produce more innovation than do Austria and Belgium, India's domestic innovation pool will dwarf those of Nepal and Sri Lanka under any scenario in which all three countries adopt comparable innovation systems. That difference alone suggests that India's calculus may lead it and its neighbors in different directions.

But population is only a crude measure of potential. National commitment to education, particularly to scientific and technological education, is even more important - explaining why tiny Israel and Singapore are innovation heavyweights while huge Egypt, Indonesia, Nigeria, and Pakistan are not. In this respect too India stands apart from most other developing countries: its commitment to world-class science and technology education has been laudable and longstanding, though its non-elite primary, secondary, and tertiary education systems continue to lag those of many other countries. Investment, however, requires financial capital, and India remains considerably poorer than any of the other developing countries that can boast both sizable populations and sizable educated cohorts, such as Brazil, China, Mexico, South Africa Thailand, and Turkey.

Yet another relevant parameter may appear surprising, but is not: it lies in the form of government. India is a mature, stable, liberal democracy. While authoritarian states rule through fear, liberal states govern through respect. As a result, unenforced legal regimes and unusable rights undermine both the legitimacy and the authority of a liberal government to a much greater extent than they do an authoritarian one. The stakes to India of marrying its new statutory IP laws to a lackluster enforcement regime are thus much higher than they are in authoritarian states. The flip side of being a liberal democracy, however, is that India's commitment to the rule of law - and its demonstration of this commitment throughout the commercial environmentwill give India a significant advantage over its authoritarian competitors in the race for international investment capital. This criterion thus strongly argues in favor of India's developing TRIPS-compliant approaches to patent scope, novelty, and nonobviousness that make sense in the framework of its economy, and of then enforcing the resulting regime.

Finally, India - like all countries - must remember that its IP systems are an important foundation for its broader innovation system (Box 3). Robust IPRs will invite FDI, with spillovers into education, research, and high-end industrial development. These spillovers will help avoid a brain drain, enhancing growth even further. Thus the calculus surrounding the understandable impetus to free ride must also consider these spillovers. 
In analyzing the needs of its own patent system, India must recall that as a large, poor, liberal democracy with a sizable educated class, its needs are likely to be unique. Assessments undertaken elsewhere, either in the developed world or in the developing world, should inform the analysis but not dictate its outcome. Only determinations of patentability, novelty, and nonobviousness relevant to India's needs can lead to an effective Indian patent system.

India is a very large, very poor, mature liberal democracy with a sizable educated, technologically sophisticated cohort poised to generate a large domestic innovation pool, and an even larger spillover throughout its innovation system and its broader economy. Though India probably does not need a system identical to that of the United States, it needs an effective IP system to gain net benefits greater than those available through free riding. The trick is to craft a system capable of achieving those benefits without paying too high a price.

Complicating the analysis even further is that a patent system is a monolithic legal body that applies to all of a country's industries even though societal optimality invariably varies throughout society. There is no reason to believe that a single set of rights will work for software and pharmaceuticals - or, for that matter, for the commercialization of traditional knowledge and cutting-edge technologies. Sector-specific peculiarities can lead to widely divergent conclusions. In particular, differences related to the notion of an "originator" (that is, a scientist working in a lab versus the residents of a village or region), necessary capital investment, prospects for success, the ability to divert effort into nevertheless productive ventures in case a competitor earns the desired IPR, regulatory hurdles necessary to market a product, time to return on investment, lifetime of commercial viability the cost and ease of obtaining an IPR, the cost and ease of copying a product that an IPR protects, and the cost and ease of enforcing an IPR are all relevant to the calculus.

This observation about variances among industries and across strata of society is hard to put into practice, but not impossible. International experience suggests that countries retain greater flexibility when thinking through the modern technologies of software, medicine, and biotechnology than they do in more traditional industries, and the absence of any provisions in traditional patent law governing traditional knowledge give India significant leeway in thinking through new IPRs that it might choose to pioneer.

\subsubsection{The Challenge of a Unitary Patent System}

Perhaps the greatest challenge that patent law poses to country-specific tailoring is that it is "unitary": it applies a single set of standards and provides a single set of rights to patents and patentees from all industries and all parts of society. TRIPS enshrines unitary patent systems into international law: "patents shall be available and patent rights enjoyable without discrimination as to ...the field of technology..." ${ }^{26}$ subject to a few provisos and exceptions that provide countries with a bit of room for experimentation at the margins.

Some U.S. patent scholars, notably Law Professors Dan Burk and Mark Lemley, argue that even in a unitary system, courts can maintain the flexibility to massage rules and standards in different

\footnotetext{
${ }^{26}$ TRIPS Article 27.1.
} 
ways for different industries. ${ }^{27}$ But that assertion remains controversial even within the United States, where it emerged from an empirical analysis of a well-developed patent system. Even proponents of such judicial tinkering concede that legislative changes would be preferable, but argue that the current political economy in the United States makes such legislation unlikely. To the extent that nascent patent systems, like India's, attempt to incorporate industry-specificity, they should do so through legislation where possible, through regulation otherwise, and through judicial interpretation only as a last resort.

Furthermore, even within a unitary patent system, different words can assume different meanings in different legal systems. In the United States, for example, the operative patent law is still the Patent Act of 1952. Despite numerous amendments in the more than 50 years since the act's passage, many of its terms and provisions remain unchanged. But regulatory and judicial interpretations of at least some of these terms and provisions have changed dramatically over time. In fact, most observers of the U.S. patent system describe the 1960s and 1970s as an era of weak patents and the past 25 years as one of strong patents.

Critics of the U.S. patent system argue that it has grown too strong, and that it now threatens to impede more innovation than it motivates. Two prominent such critics, Economics and Business Professors Adam Jaffe and Josh Lerner, gave voice to a view that many of their colleagues share: "[P]atents serve an important social function, and some recalibration in the direction of stronger patent protection was probably due given the long twentieth century decline. But...the strengthening of patent rights has now gone beyond recalibration to reach troubling proportions." 28 They present ample empirical support for their claims about four significant changes in the implementation of U.S. patent law. They show that since 1980, penalties for infringement have stiffened, the scope of patentable invention has grown, the threshold for obviousness has dropped, and the prevalence of juries for the factual components of patent disputes has grown.

Without getting into the controversy surrounding their critique (or discussing other scholars who believe that U.S. patents are not too strong), Professors Burk, Lemley, Jaffe, and Lerner presumably believe that the earlier, weaker U.S. patent system, the current stronger system, and the reformed systems that they propose are all consistent with the basic parameters of U.S. statutory law and applicable international treaties. Their discussions and critiques thus highlight some areas of remaining flexibility even within a TRIPS-compliant unitary patent system. In short, some flexibility remains in the design of country-specific IP systems (Box 4).

\section{Box 4 Flexibility in IPR Design}

TRIPS mandates a unitary patent system that does not discriminate among industries. Within this system, all signatory countries must provide patent protection on all patentable inventions that are suitably "novel" and

\footnotetext{
${ }^{27}$ See Dan L. Burk and Mark A. Lemley, "Is Patent Law Technology-Specific?” 17 Berkeley Tech. L.J. 1155 (2002); Dan L. Burk and Mark A. Lemley, "Policy Levers in Patent Law," 89 Va. L. Rev. 1575, 1577 (2003). ${ }_{28}$ Adam Jaffe and Josh Lerner, Innovation and its Discontents: How Our Broken Patent System Is Endangering Innovation and Progress, and What to Do About It," (Princeton University Press, 2004) at 125-26.
} 
“nonobvious." But patentability, novelty, and nonobviousness are imprecise terms. Each country must determine its own definitions, and all chosen definitions should respond to the goals that a country sets for its patent system. The analyses underlying such determinations inject flexibility into national patent systems.

Different countries apply starkly different rules to innovative software and medications. Some scholars contend that numerous policy levers can allow different countries to use their patent systems to attain different goals. India has, and should continue to, avail itself of that limited flexibility whenever appropriate. As India moves toward refining and completing its IP system, its policymakers must remain aware that numerous analytic questions are relevant to the types and amounts of innovation that its IP system can motivate.

Each of the issues this study discusses - completing India's statutory reform, developing the guidelines and training programs needed to make the reformed system effective and enforced, rethinking the litigation and judicial resolution of patent disputes, assessing the incentives that the new patent system provides to public and private innovators, and the potential of a new IPR tailored to traditional knowledge - requires its own calculus. On each of these issues, India's decisionmakers must consider which industries and which parts of Indian society are most likely to feel the effects, and whether the gains in domestic innovation and commercialization outweigh the lost potential of free-ridership on international innovation.

These questions hardly lend themselves to monolithic answers. In some cases, India's decisionmakers have already reached answers, and must now gain experience to learn whether further changes are needed. In others, this study points in directions where appropriate resolutions are most likely, but recognizes that further analysis is needed before India can chart an appropriate policy. In still others, only further inquiry - both within India and on India's behalf by international advisers - will provide meaningful answers. This brief discussion of the theory of IP provides a framework for applying the unique calculus that India's new patent system deserves.

\subsection{Historical Inquiries}

The history of patent reform in India suggests a history of decisionmakers attuned to the appropriate analysis of IP law. This understanding dates to the country's earliest days as a modern independent nation-state. In 1947 the newly independent India inherited the Indian Patents and Designs Act of 1911, a British law that incorporated definitions, norms, and rules comparable to those that prevailed throughout the developed world. For 23 years, various Indian commissions and commentators debated the propriety of such a law to India's economic needs. The most influential of these commissions, chaired by Justice Rajagopala Ayyangar, emphasized the wisdom of rewarding innovation while nevertheless recommending a narrow scope of innovations eligible for such rewards. ${ }^{29}$

The Ayyangar Commission's report demonstrated careful consideration of the bargain that the public was striking with innovators when it granted them exclusive rights in exchange for their innovations. Ayyangar had studied and reviewed the patent systems of various countries, including Germany, the United Kingdom, and the United States. These inquiries led him to some nonstandard conclusions and recommendations. In particular, he concluded that Germany's

\footnotetext{
${ }^{29}$ See Banerji, supra n. 12 at 62-69.
} 
weaker patent laws had helped promote its chemical industry to a position of world leadershipand recommended that India follow Germany's lead. The Commission asserted that India's strategic and public policy interests in food and medicines mandated weak protection for innovations in those areas, and proposed allowing patents only for process improvements, not for new products. It also recommended provisions that would make it easy for India to convert the exclusive rights originally (and typically) inherent in a patent grant into a compulsory license, provisions that would require that a patentee work his invention in India to retain the patent, and a patent life as short as 5 years in some cases, and never more than 14 years. India's Patent Act of 1970 enacted all those recommendations into law. ${ }^{30}$

The dawn of the modern patent era in the United States provides another good illustration of appropriate analyses - and one with many lessons applicable to India today. In the late 1970s many observers noted that though the United States retained its global lead in scientific and technological research, it was losing its edge in manufacturing and commercialization. They identified weaknesses in the patent system as one of the causes of this seeming anomaly. Over just a few years - from 1980 to 1984-four major legislative changes and two Supreme Court rulings altered the contours of the U.S. patent system without overhauling the Patent Act of 1952. The six issues that led to these changes are instructive because five of them remain alive and controversial in India today.

One inquiry considered the challenge of motivating universities to engage in the sorts of technology transfer needed to leverage their research into marketable products. The Bayh-Dole Act (1980) responded by allowing universities to patent inventions developed wholly or partly through federal research grants. ${ }^{31}$

A second inquiry assessed the relationship among branded drug companies, generic drug producers, and their federal regulator, the Food and Drug Administration (FDA). The HatchWaxman Act (1984) allowed the branded companies to extend their patents to reclaim some of the time lost to long regulatory reviews, but eased the way for generic producers to experiment and develop products that they could launch as soon as those patents expired. ${ }^{32}$

A third inquiry identified inconsistency among appellate courts as a significant source of uncertainty hanging over the entire patent system. The Federal Courts Improvement Act (1982) created the U.S. Court of Appeals for the Federal Circuit and gave it exclusive appellate jurisdiction over all patent rulings, whether administrative or judicial. ${ }^{33}$

\footnotetext{
${ }^{30}$ See Id.

${ }^{31}$ See David Mowery, Richard Nelson, Bhaven Sampat, and Arvids Ziedonis, Ivory Tower and Industrial Innovation: University-Industry Transfer Before and After the Bayh-Dole Act (Stanford University Press, 2004).

${ }^{32}$ See, for example, Landes and Posner, supra n. 9 at 314-15.

${ }^{33}$ See, for example, Daniel J. Meador, "Origin of the Federal Circuit: A Personal Account," 41 American University Law Review 581 (1992); Pauline Newman, "Origins of the Federal Circuit: The Role of Industry," 11 Federal Circuit Bar Journal 541 (2001). I discuss the history of the Federal Circuit in considerable detail in the forthcoming Bruce Abramson, The Secret Circuit: The Little-Known Court Where the Rules of the Information Age Unfold (Rowman \& Littlefield, 2007).
} 
Meanwhile, the Supreme Court considered two new classes of inventions-laboratorysynthesized microorganisms and algorithms encoded as software - and concluded that both were eligible for patent protection. ${ }^{34}$

These five issues - university technology transfer programs, the balance between drug innovators and low-cost drug producers, the internal consistency and predictability of patent law, the patentability of microorganisms, and the extension of patent law to software and algorithms - all remain alive today, and all remain subjects of controversy and debate in India and around the world. The U.S. experience at addressing these issues should inform India's debate, but not dictate its outcome. India needs to be asking similar questions. The particulars of India's economy will help guide it to its own set of answers.

The sixth significant issue that the U.S. addressed in the early 1980s is relevant to India today only indirectly. At that time, the United States identified its microchip industry as a source of particular concern; it was a critical, strategic industry that appeared ill served by the standard patent regime. In response, the U.S. drafted a sui generis IPR for semiconductors. ${ }^{35}$

In India today, a parallel concern arises when thinking about traditional knowledge. Such knowledge plays an important role in the Indian economy, as well as in its sense of national pride. It also comprises a body of knowledge whose possessors are in desperate need of development assistance. Many Indians (and others in the developing world) have expressed an interest in developing an IPR to help convert such knowledge into a viable revenue stream - and once again, conventional patent rights seem ill suited to the task. Just as the United States invented a new IPR to protect semiconductors, India is contemplating the creation of a new IPR to protect traditional knowledge. Because TRIPS is silent on the creation of new IPRs, any system that Indian law treated it as a distinct IPR subject to its own legislation rather than as an adjunct to its patent system subject to provisions of India's Patent Act would likely be TRIPScompliant.

Parallels aside, these illustrations show the sorts of analyses that countries should undertake when contemplating IP reform. Appropriate analyses are no guarantees of success, as both the Indian and U.S. experiences demonstrate. India's Patent Act of 1970 led to some notable successes - particularly in the growth of India's generic drug companies into global leaders and important players in the pharmaceutical industry. But it failed to promote widespread innovation, industrial development, and growth. The U.S. reforms of the 1980s led to successful technology transfer programs, faster releases of generic drugs, and increased consistency in patent law. At the same time though, it did little for the semiconductor industry and unleashed an ever-growing morass of questionable software patents unlikely to have increased innovative software development. The recent amendments to India's patent laws suggest that India undertook an appropriate analysis when drafting its new legislation, and that it learned many empirical lessons

\footnotetext{
${ }^{34}$ See Gottschalk v. Benson, 409 U.S. 63, 67 (1972); Diamond v. Chakrabarty, 447 U.S. 303, 308 (1980); Diamond v. Diehr, 450 U.S. 175, 185 (1981). The specific microorganism that motivated the U.S. Supreme Court to announce that the patent laws covered synthetic life forms was a bacterium capable of digesting crude oil. Its inventor, Ananda Chakrabarty, is an Indian-American who received his Ph.D. from the University of Calcutta and was working for General Electric at the time.

3517 U.S.C. $\$ \S 901-904$.
} 
from both its own experiences and those of the United States. The remaining challenges all relate to India's ability to leverage these analyses beyond legislation and into a fully functioning patent system.

\section{Patenting in India}

\subsection{Data and Trends}

\section{$\underline{3.1 .1}$ Trends in Indian Patents}

Any discussion of the future of India's patent system must be mindful of its past. Perhaps the most important lesson of that past is that good intentions are insufficient. The Ayyangar Commission asked the right sorts of questions and conducted thoughtful, detailed analyses. It returned with recommendations that it believed would motivate and reward innovation while also promoting production, distribution, commercialization, and job growth. With the notable exception of the pharmaceutical industry - an industry characterized by an unusual combination of large capital requirements for innovation and simple, easily replicable products - the Commission's changes did neither. During the years that its recommendations shaped India's patent system, India's patent system was insignificant. Few innovators applied for patents, the Patent Office issued few patents, few Indian patents generated even moderate revenues, virtually no infringement claims made it to court (leading to a dearth of serious Indian patent jurisprudence), and few Indians gained the knowledge and experience needed to engage fully in the international patenting arena.

Between 1975 and 1984 about 1,000 Indian applicants and 2,000 foreign applicants filed for Indian patents each year. Between 1985 and 1994 the number of Indian applicants remained about the same while the number of foreign applicants increased slightly, though there were still fewer than 3,800 total applicants a year, on average. Applications increased markedly - to more than 7,000 - as soon as India joined the WTO in 1995. When India began accepting applications through the Patent Cooperation Treaty (PCT) in 1999, many applicants began using this route to seek patent protection in India (Box 5). Over the past decade the number of Indians filing patent applications has skyrocketed. By 2004/05 there were more than 3,500 Indian applications for Indian patents, more than 3,000 foreign applications for Indian patents, and more than 10,500 PCT filings directed at India (Figure 1 and Table 1).

\section{Box 5 The Patent Cooperation Treaty}

\footnotetext{
${ }^{36}$ See http://www.wipo.int/pct/en/treaty/about.htm.
} 
The Patent Cooperation Treaty (PCT) allows inventors file "international" patent applications that can then help them seek patent protection simultaneously in many countries. The treaty was concluded in 1970, amended in 1979, and modified in 1984 and 2001. It is open to all states that are parties to the Paris Convention for the Protection of Industrial Property (1883). The World International Property Organization (WIPO) administers the PCT through an Assembly to which all member countries belong. India became a party to the PCT in late 1998. By mid-2006 the PCT Assembly had 133 member states. The Assembly is responsible for issuing and amending regulations and for fixing fees for international filings.

The PCT also assigns various major national patent offices responsibility for conducting international searches for each international application. An office thus appointed assumes the status of an International Searching Authority (ISA). An ISA issues international search report listing citations that might affect the patentability of the invention claimed in the international application, and prepares a written opinion on patentability. These documents help applicants determine which national patent applications to pursue and which to withdraw. If the applicant decides to pursue an international application, WIPO publishes it, along with the search report, but not the ISA opinion.

The PCT confers significant advantages on patent applicants, national patent offices, and the general public:

- It extends filing deadlines up to 18 months in many member countries, and eases various formalities associated with the nuanced filing requirements that individual patent offices maintain.

- The ISA opinion provides valuable information that can help applicants make informed decisions about which national patents to pursue.

- The international search report can ease workloads on national patent offices, conserving public resources and speeding processing times. It can also help members of the public form well-founded opinions about the patentability of the claimed invention, and conform their behavior accordingly.

Figure 1 Patent Applications Filed in India, 1999-2005 ${ }^{37}$

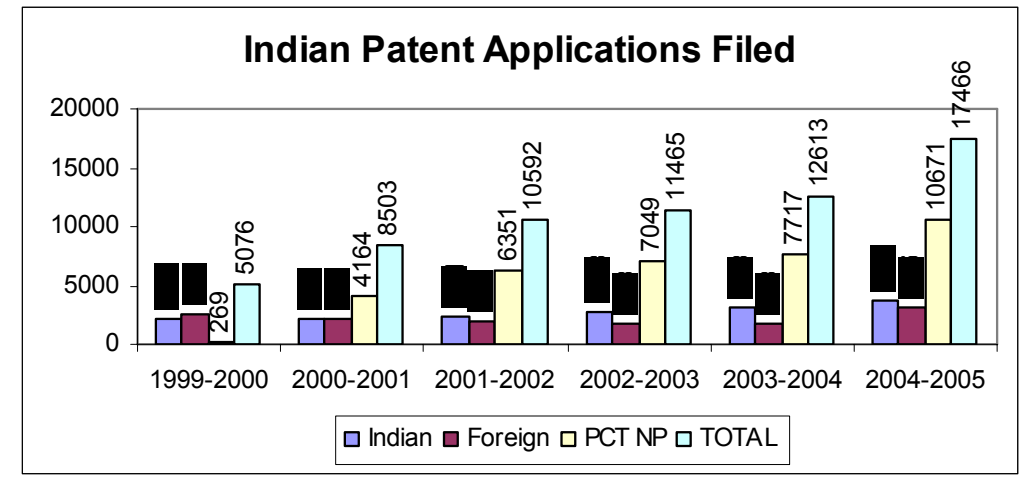

${ }^{37}$ Compiled by CSIR from Annual Reports of the Controller General of Patents, Designs and Trademarks through 2001/02, and from the Patent Office, New Delhi, for subsequent years. 
Table 1 Patent Applications Filed and Granted in India, 1975-2005

\begin{tabular}{|c|c|c|c|c|c|c|}
\hline \multirow{2}{*}{ Year } & \multicolumn{3}{|c|}{ Applications } & \multicolumn{3}{|c|}{ Patents Granted } \\
\hline & Indian & Foreign & PCT & Total & India & Foreign \\
\hline $1975-76$ to $1984-85$ (annual average) & 1,119 & 1,918 & & 1,758 & 459 & 1,299 \\
\hline $1985-86$ to $1994-95$ (annual average) & 1,164 & 2,608 & & 1,939 & 498 & 1,441 \\
\hline 1995-96 & 1,606 & 5,430 & & 1,533 & 415 & 1,118 \\
\hline 1996-97 & 1,661 & 6,901 & & 907 & 293 & 614 \\
\hline $1997-98$ & 1,926 & 8,229 & & 1844 & 619 & 1,225 \\
\hline 1998-99 & 2,247 & 6,707 & & 1,800 & 645 & 1,155 \\
\hline $1999-2000$ & 2,206 & 2,601 & 269 & 1,881 & 557 & 1,324 \\
\hline $2000-01$ & 2,179 & 2,160 & 4,164 & 1,318 & 399 & 919 \\
\hline $2001-02$ & 2,371 & 1,870 & 6,351 & 1,591 & 654 & 937 \\
\hline 2002-03 & 2,693 & 1,723 & 7,049 & 1,379 & 494 & 885 \\
\hline 2003-04 & 3,218 & 1,678 & 7,717 & 2,469 & 945 & 1,524 \\
\hline 2004-05 & 3,630 & 3,165 & 10,671 & 1,911 & 764 & 1,147 \\
\hline
\end{tabular}

\subsubsection{Indian Patenting Abroad}

A few more data help place these numbers in context. Table 2 shows data from the USPTO showing the number of applications that it received from both U.S. and foreign inventors between 1995 and 2004. Statistics on U.S. filings are critical to understanding India's patent community. As Professor Rakesh Basant has noted:

The IP regime in the U.S. (or other Western nations) may be more important for the Indian IP creating firms than the regime in India. Most Indian firms that do create IP, either on their own or through alliances with foreign firms, tend to protect their IP in the U.S. and other large markets and not necessarily in India...This is essentially due to two reasons. One, it is essential to protect the invention where the market is, and most of the IP in India is being created for the Western markets. Two, some IT related inventions (like algorithms, business methods) are not patentable in India. ${ }^{39}$

The original USPTO data contain a complete breakdown by country from 1965 through $2004,{ }^{40}$ but even the summary data in Table 2 tell an interesting story. During a decade when applications for Indian patents grew by almost 250 percent, applications for U.S. patents grew by a bit more than 67 percent. U.S. patent applications from Indians, though small in numbers, showed a marked increase - both in raw numbers, where they grew more than 14-fold, and as a percentage of all filings and of foreign filings. Indian applications grew from 0.04 percent of total applications in 1995 to 0.37 percent in 2004 - and from 0.10 percent of foreign applications in 1995 to 0.78 percent in 2004.

\footnotetext{
${ }^{38}$ Compiled by CSIR from Annual Reports of the Controller General of Patents, Designs and Trademarks through 2001/02, and from the Patent Office, New Delhi, for subsequent years.

${ }^{39}$ Rakesh Basant, "Intellectual Property and Innovation: Changing Perspectives in the Indian IT Industry," 29

Vikalpa: The Journal for Decision Makers 69 (2004).

${ }^{40}$ See ftp://ftp.uspto.gov/pub/taf/appl_yr.pdf.
} 
Table 2 U.S. Patent Applications by Origin of First-Named Inventor, 1995-2004 ${ }^{41}$

\begin{tabular}{|c|c|c|c|c|c|c|c|c|}
\hline Year & Total & $\begin{array}{l}\text { United } \\
\text { States }\end{array}$ & Foreign & Indian & $\begin{array}{c}\text { U.S as } \\
\text { o of } \\
\text { Total } \\
\end{array}$ & $\begin{array}{c}\text { Foreign } \\
\text { as \% of } \\
\text { Total } \\
\end{array}$ & $\begin{array}{c}\text { Indian } \\
\text { as } \% \\
\text { of } \\
\text { Total } \\
\end{array}$ & $\begin{array}{c}\text { Indian } \\
\text { as } \% \text { of } \\
\text { Foreign } \\
\end{array}$ \\
\hline 1995 & 212,377 & 123,958 & 88,419 & 91 & 58.37 & 41.63 & 0.04 & 0.10 \\
\hline 1996 & 195,187 & 106,892 & 88,295 & 115 & 54.76 & 45.24 & 0.06 & 0.13 \\
\hline 1997 & 215,257 & 120,445 & 94,812 & 137 & 55.95 & 44.05 & 0.06 & 0.14 \\
\hline 1998 & 243,062 & 135,483 & 107,579 & 180 & 55.74 & 44.26 & 0.07 & 0.17 \\
\hline 1999 & 270,187 & 149,825 & 120,362 & 271 & 55.45 & 44.55 & 0.10 & 0.23 \\
\hline 2000 & 295,926 & 164,795 & 131,131 & 438 & 55.69 & 44.31 & 0.15 & 0.33 \\
\hline 2001 & 326,508 & 177,511 & 148,997 & 643 & 54.37 & 45.63 & 0.20 & 0.43 \\
\hline 2002 & 334,445 & 184,245 & 150,200 & 919 & 55.09 & 44.91 & 0.27 & 0.61 \\
\hline 2003 & 342,441 & 188,941 & 153,500 & 1,164 & 55.17 & 44.83 & 0.34 & 0.76 \\
\hline 2004 & 356,943 & 189,536 & 167,407 & 1,303 & 53.10 & 46.90 & 0.37 & 0.78 \\
\hline
\end{tabular}

The years 1995-2004 are particularly significant, and not merely because they are the most recent ones for which data are available. India was hardly the only country to undertake a major rethinking of its IP laws upon joining the WTO. Nearly every country-including the United States - had to revise its IP laws upon WTO accession. Many of these countries, like India, took the opportunity to promote reassessments of their innovation systems. The numbers for U.S. patent applications suggest that India has been more successful than most; its share of a growing pie has expanded during a period of intense international competition.

Statistics on U.S. patents granted are a bit harder to decipher because different applications move through the application process at different speeds. USPTO data, for example, continue to show patents granted to citizens of Czechoslovakia and the Soviet Union-long after the demise of those two countries. As a result patents issued in any given calendar year necessarily lag changes in national cultures, IP laws, and innovation systems. Nevertheless, the data remain instructive.

Table 3 shows that India remains a small but growing recipient of U.S. patents. A ranking of U.S. patents issued by country from 1995-2004 places India $24^{\text {th }}$ of 36 enumerated. Most of the top 23 economies are OECD members with fully developed patent systems. Among non-OECD members, only Taiwan (China), Israel, Singapore, Hong Kong (China), China, and Russia place ahead of India - and of these six, all but China have had significant advanced scientific, technological, and industrial bases in place for at least several decades.

${ }^{41}$ See ftp://ftp.uspto.gov/pub/taf/appl_yr.pdf. 
Table 3 U.S. Patents Granted by Nationality of First-Named Inventor, 1995-2004 ${ }^{42}$

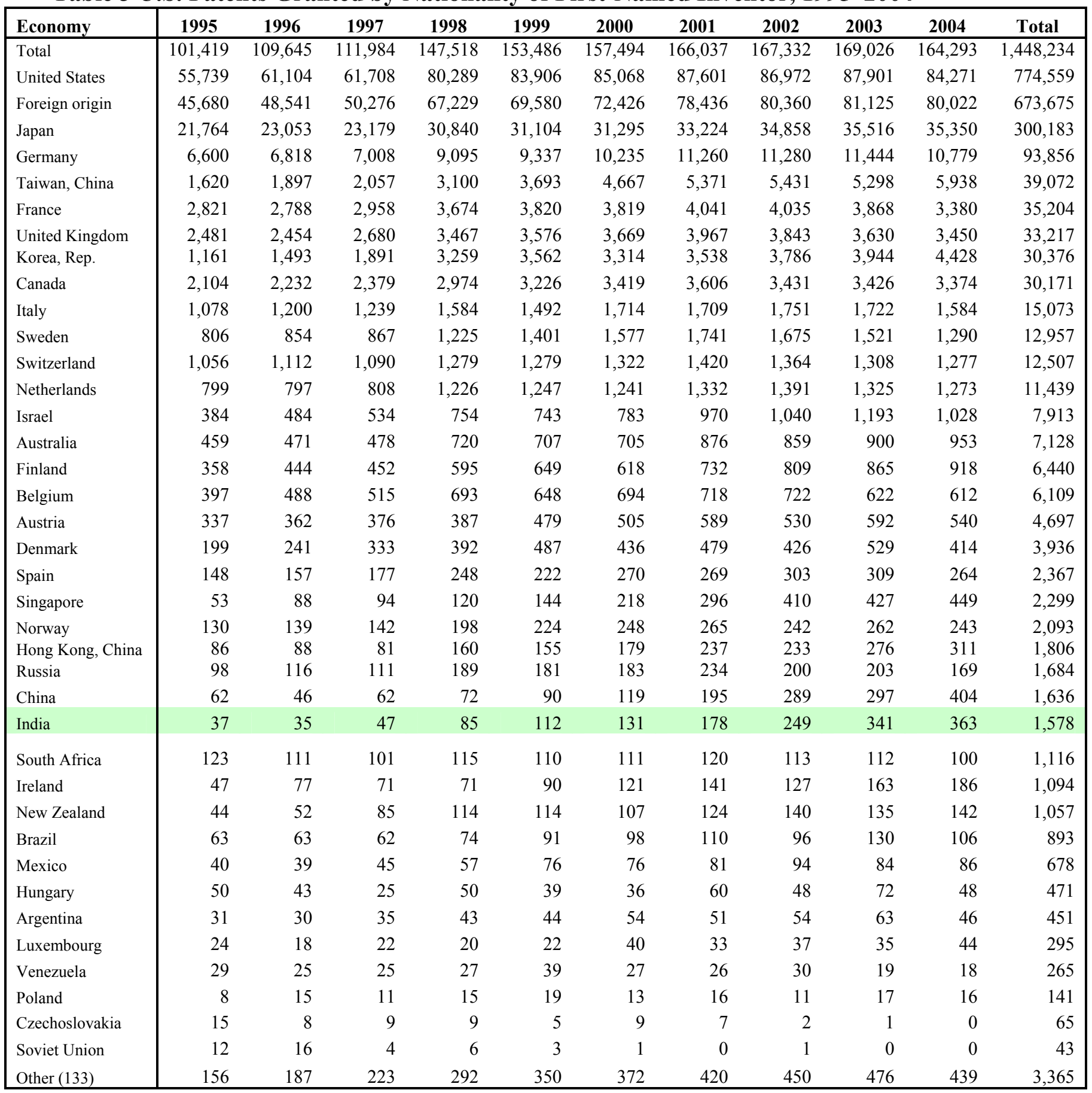

${ }^{42}$ See ftp://ftp.uspto.gov/pub/taf/all_tech.pdf. 


\subsubsection{India's Applicant Pool}

The growth of patenting in India has yet to translate into anything suggesting that the new rewards available to Indian innovators are motivating much additional innovation —or even that India's private sector innovators understand how to leverage patents into tangible rewards.

Table 4 lists the most active applicants for Indian patents over 1995-2005. Forty-four of the top 49 applicants are either fully foreign, MNCs who do business in India, or Indian majority-owned or wholly owned subsidiaries of MNCs. Three are Indian government agencies (CSIR, IIT, and the Ministry of Defense), and one is a public corporation (Steel Authority of India). Only two of the top applicants, Ranbaxy and Dr. Reddy's, come from India's homegrown private sector-and both belong to the generic drug industry that fared well under the previous patent regime.

Table 5 tells a similar story. The USPTO provides reports, based on the year in which it granted patents, on the patents issued to inventors resident in each country, along with the organizations or institutions to which they assigned their patents, at least initially. Once again, CSIR emerges as the dominant player: it was the first-named assignee on 43 percent of U.S. patents granted to Indian inventors and 70 percent of U.S. patents that Indian inventors assigned to Indian organizations or institutions. Nearly twice as many Indian inventors assigned their patents to MNCs as to domestic private companies, providing a rough estimate of comparative investments in in-country R\&D. Nevertheless, these data are encouraging. Recent trends show a marked increase in patent activity in all areas of assignation - and as noted, data on patent grants lag $R \& D$ outlays by a potentially significant amount.

The data in Tables 4 and 5 also raise a subtler point: MNC investments in India's scientific community are significant and increasing. The more confident these investors are in the integrity of India's IP systems, the more likely they are to invest. From this perspective, India cannot afford to develop a reputation as a country whose patent system reads well at the statutory level, but collapses in practice.

Table 4 Top Applicants for Indian Patents, 1995-2005 ${ }^{43}$

\footnotetext{
${ }^{43}$ Compiled by CSIR from TIFAC database (Ekaswa A) on Indian patent filings.
} 


\begin{tabular}{|c|c|}
\hline Applicant & Number of applications \\
\hline Council of Scientific and Industrial Research (CSIR) New Delhi & 2,760 \\
\hline Procter \& Gamble & 1,865 \\
\hline Siemens & 956 \\
\hline Hindustan Lever (a majority-owned subsidiary of Unilever) & 892 \\
\hline Honda & 631 \\
\hline BASF & 599 \\
\hline Bayer & 523 \\
\hline Daewoo & 465 \\
\hline General Engineering Services & 465 \\
\hline Sony & 437 \\
\hline Samsung & 427 \\
\hline Matsushita & 411 \\
\hline IBM & 407 \\
\hline Lucent & 405 \\
\hline Motorola & 403 \\
\hline Novo Nordisk & 361 \\
\hline Pfizer & 359 \\
\hline Praxair & 329 \\
\hline Glaxo SmithKline & 320 \\
\hline Qualcomm & 288 \\
\hline Maschinenfabrik Rieter & 262 \\
\hline Mitsubishi & 251 \\
\hline Ericsson & 251 \\
\hline Indian Institute of Technology (IIT) & 245 \\
\hline Hoechst & 241 \\
\hline British Telecom & 234 \\
\hline Dow Chemical & 213 \\
\hline Shell & 206 \\
\hline Societe D'exploitation des Procedes Marechal (SEPM) & 201 \\
\hline Kabushiki & 199 \\
\hline Hoffman La-Roche & 196 \\
\hline Koninklijke PTT & 190 \\
\hline Johnson \& Johnson & 188 \\
\hline Ranbaxy Laboratories & 185 \\
\hline American Tool & 183 \\
\hline Steel Authority of India & 178 \\
\hline Bosch & 177 \\
\hline Kimberly-Clark & 175 \\
\hline Merck & 171 \\
\hline LG Electronics & 161 \\
\hline Ministry Of Defense, India & 161 \\
\hline Astra Aktiebolag & 158 \\
\hline Ciba Specialty Chemicals & 155 \\
\hline Corning & 152 \\
\hline University Technologies International (University Of Calgary) & 149 \\
\hline Asea Brown Boveri & 148 \\
\hline Dr Reddy's Research Foundation New Delhi & 148 \\
\hline Eaton & 145 \\
\hline Eli Lilly & 143 \\
\hline
\end{tabular}


Table 5 U.S. Patents Granted to Indian Inventors, 1996-2005 ${ }^{44}$

\begin{tabular}{|c|c|c|c|c|c|c|c|c|c|c|c|c|}
\hline First-Named Assignee & 1996 & 1997 & 1998 & 1999 & 2000 & 2001 & 2002 & 2003 & 2004 & 2005 & Total & Type \\
\hline CSIR & 10 & 18 & 25 & 36 & 37 & 58 & 120 & 133 & 127 & 117 & 681 & Public \\
\hline Texas Instruments & 2 & 6 & 3 & 3 & 7 & 9 & 8 & 17 & 22 & 25 & 102 & MNC \\
\hline Other MNC & 2 & 2 & 6 & 5 & 6 & 4 & 10 & 12 & 14 & 31 & 92 & MNC \\
\hline IBM & 0 & 0 & 0 & 0 & 0 & 8 & 8 & 18 & 28 & 26 & 88 & $\mathrm{MNC}$ \\
\hline General Electric & 0 & 0 & 2 & 4 & 5 & 6 & 9 & 10 & 22 & 24 & 82 & $\mathrm{MNC}$ \\
\hline Ranbaxy & 1 & 2 & 5 & 4 & 4 & 8 & 7 & 8 & 11 & 7 & 57 & Private \\
\hline Other Indian private & 1 & 1 & 1 & 2 & 6 & 5 & 5 & 12 & 8 & 6 & 47 & Private \\
\hline Dr. Reddy's & 0 & 1 & 2 & 7 & 7 & 3 & 7 & 8 & 3 & 5 & 43 & Private \\
\hline Dabur & 0 & 0 & 0 & 1 & 3 & 5 & 5 & 7 & 1 & 6 & 28 & Private \\
\hline Indian Oil & 0 & 0 & 2 & 2 & 4 & 4 & 3 & 5 & 2 & 4 & 26 & Private \\
\hline STMicroelectronics & 0 & 0 & 0 & 0 & 0 & 0 & 1 & 7 & 4 & 14 & 26 & $\mathrm{MNC}$ \\
\hline Unilever & 1 & 0 & 0 & 3 & 2 & 4 & 3 & 3 & 7 & 3 & 26 & MNC \\
\hline Cypress & 1 & 0 & 0 & 0 & 1 & 1 & 3 & 10 & 2 & 4 & 22 & $\mathrm{MNC}$ \\
\hline Orchid C\&P & 0 & 0 & 0 & 0 & 0 & 0 & 2 & 5 & 6 & 5 & 18 & Private \\
\hline Hewlett-Packard & 0 & 0 & 0 & 0 & 0 & 1 & 1 & 6 & 7 & 2 & 17 & $\mathrm{MNC}$ \\
\hline Other Indian public & 0 & 0 & 0 & 0 & 2 & 2 & 6 & 2 & 2 & 1 & 15 & Public \\
\hline Panacea Biotech & 0 & 1 & 1 & 4 & 2 & 3 & 2 & 1 & 0 & 0 & 14 & Private \\
\hline Honeywell & 0 & 0 & 0 & 0 & 0 & 0 & 0 & 0 & 2 & 10 & 12 & MNC \\
\hline Indian Petrochem & 0 & 1 & 1 & 0 & 5 & 0 & 0 & 1 & 2 & 2 & 12 & Private \\
\hline Lupin Labs & 1 & 1 & 5 & 2 & 1 & 1 & 0 & 0 & 0 & 1 & 12 & Private \\
\hline Nat. Inst. Immun. & 0 & 0 & 2 & 3 & 1 & 3 & 2 & 0 & 0 & 0 & 11 & Public \\
\hline Natreon & 0 & 0 & 0 & 0 & 2 & 3 & 2 & 1 & 1 & 1 & 10 & $\mathrm{MNC}$ \\
\hline \multicolumn{13}{|l|}{ Totals } \\
\hline Total Indian public & 10 & 18 & 27 & 39 & 40 & 63 & 128 & 135 & 129 & 118 & 707 & \\
\hline Total Indian private & 3 & 7 & 17 & 22 & 32 & 29 & 31 & 47 & 33 & 36 & 257 & \\
\hline Total Indian & 13 & 25 & 44 & 61 & 72 & 92 & 159 & 182 & 162 & 154 & 964 & \\
\hline Total MNC & 6 & 8 & 11 & 15 & 23 & 36 & 45 & 84 & 109 & 140 & 477 & \\
\hline Individually owned & 7 & 9 & 15 & 16 & 12 & 18 & 12 & 14 & 16 & 12 & 131 & \\
\hline
\end{tabular}

\subsection{Objectives and Motivation}

\subsubsection{A Decade of Success}

The giant of Indian patenting is CSIR, ${ }^{45}$ a government research institute that accounted for almost 15 percent of the applications filed by the top applicants and more than 75 percent of those filed by the six fully Indian entities shown in Table 4. In addition to simply applying for patents, CSIR has played a huge role in promoting IP awareness in India. Along with the Patent Facilitating Center (PFC), ${ }^{46}$ a program of the Technology Information Forecasting Assessment Council (TIFAC) of the Department of Science and Technology (DST), CSIR has created something of a "patent chic" in India. Some IP lawyers even describe calls from farmers inquiring about the patentability of large vegetables - indicating significant awareness of patents, though limited understanding of their scope.

\footnotetext{
${ }^{44}$ See http://www.uspto.gov/go/taf/asgstca/inx_stc.htm. Geographic regions are determined by the residence of the first-named inventor, and listed by first-named assignee.

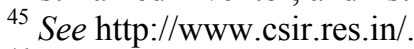

${ }^{46}$ See http://www.indianpatents.org.in/.
} 
India's lead public patenting organizations have thus been spectacularly successful at the task that they set for themselves a decade ago - namely, promoting general awareness of the patent system. They must now meet their next challenge with equal skill: promoting an understanding of the ways that a functioning patent system harnesses market mechanisms to expand private investment and innovation, thereby impelling economic growth. To achieve this task, the leaders of India's young patent community will have to rethink the role that they have assumed in the Indian patent system, the way that they educate the public, and the institutions that they use to promote both patenting and technology transfer.

This new task will also require India's patent evangelists to reconsider how they measure and describe their successes and achievements. Most of their presentations to date have emphasized the sorts of metrics that typically represent success in the public sector, and have trumpeted the social objectives that patenting has helped them achieve. When facing a challenge of promoting awareness, these presentations were quite powerful. When facing the new challenge of motivating India's private sector, however, public sector successes are unlikely to suffice. As CSIR, PFC, and other government agencies shift the objective of their IP education campaigns from awareness to understanding, they will have to recast their metrics and successes in terms likely to appeal to private entrepreneurs. To see the sort of shift necessary, consider first CSIR's description of its R\&D output:

Competence is essentially linked to the intrinsic knowledge-base of the organisation on which it can base its growth. Similarly the major achievements of a scientific research organisation are primarily reflected in its research publications and the intellectual property rights it holds. The research papers emanating from CSIR's laboratories are noted for their quality with average impact factor/paper being 1.75 (2003-2004). In the field of IPR, CSIR's track record is enviable given its rather recent entry into the area. Of the 229 US patents granted in 2004-05 to Indian inventors (excluding foreign assignees), CSIR has 140 (61.1 percent). Even if one considers Indian inventors including foreign assignees, CSIR's share is still 28.3 percent. $^{47}$

Discussions with government officials similarly measure patent success in terms of portfolio size. References to the "broad social goals of patents" abound. CSIR's descriptions of its successes (or technically, the successes of its constituent laboratories) typically report benefits in terms of job creation, environmental enhancement, and other socially important government objectives. These descriptions rarely discuss licensing revenues, spinoffs, commercial opportunities, returns on investment, or other metrics likely to motivate private investment. Those that do mention them suggest that they have been relatively small - certainly far too small to motivate the private sector to invest in the sort of R\&D needed to have generated them.

\footnotetext{
${ }^{47}$ http://www.csir.res.in/External/Utilities/Frames/outputs/main_page.asp?a=topframe.htm\&b=leftcon.htm\&c=../.././ Heads/outputs/csir_outputs.htm.
} 
Box 6 Examples of the Many Successful Programs at CSIR Labs That Led to Patents ${ }^{48}$

- The Institute of Microbial Technology (IMTECH) earned a process patent that improved the production efficiency of STPase, a drug that alleviates vascular blockage by dissolving blood clots. CSIR licensed the patent to Cadila Pharma, whose consequent cost reductions led to a significant reduction in drug prices. Under the license terms, CSIR receives royalties subject to an agreed series of milestones.

- The National Chemical Laboratory (NCL) has collaborated with General Electric (GE) since 1993. Between 1994/95 and 2003/04 the NCL received about \$8.5 million in funding from GE from this partnership. GE, in turn, has received a half-dozen patents from work conducted with the NCL and its scientists. The relationship also led to a process patent for the synthesis of high-grade polycarbonates with particularly desirable properties. The new process, licensed to Excel, introduced competition into a market that Hoechst Celanese had previously monopolized. Between 2001 and 2003 Excel's exports totaled roughly Rs 30 crore (more than \$6 million).

- Scientists at the NCL also patented a water purification process that reduced the cost of removing bacteria and viruses from water, and recently licensed the method to industry.

- The Central Salt and Marine Chemicals Research Institute (CSMCRI) licensed to Pepsico its patented method for the production of carrageenan and liquid fertilizer from fresh seaweeds. Following trials in Punjab, Andhra Pradesh, and Gujarat, various government departments are now promoting seaweed cultivation as a way to generate muchneeded revenues for poor rural communities.

- CSMCRI has a patent pending on biodiesel production, and has entered into a memorandum of understanding with Rajasthan State Mines and Minerals Ltd., Udaipur, on a demonstration plant.

- CMSCRI, Bhavnagar, and Gujarat Narmada Valley Fertilizers Company (GNFC) have collaborated on research that has already led to two U.S. patents on technology for converting calcium carbonate rich in inorganic by-product material to industrially useful, high-quality, value-added products that have both improved the environment and created jobs.

- The Central Institute of Medicinal and Aromatic Plants (CIMAP) developed several new variants of the mint plant and obtained U.S. plant patents to protect them. These varieties helped turn India into a major player in the global market for mint oil, and generated many new jobs across the agricultural sector.

Detailed discussions show a similar elevation of general education above motivating investment - an emphasis that may have been necessary in 1995, but is becoming less so with each passing year. For example, R.K. Gupta, the head of CSIR's Intellectual Property Management Division, compiled a compelling list of successful patenting projects at CSIR's constituent labs (Box 6). ${ }^{49}$

CSIR's role in developing technologies that improve India's employment situation, agricultural yields, and environment is highly appropriate for a government research institution. In fact, it is an almost perfect role for a public institution whose mission is "to provide scientific industrial R\&D that maximises the economic, environmental and societal benefits for the people of India." ${ }^{50}$ At the same time, CSIR's emphases and presentations typically omit the sorts of results critical to motivating private investment. Many of its presentations provide little or no information about how much (if any) revenues CSIR itself has seen, and whether or not it has engaged in licensing intended to generate such revenues. Given all these wonderful successes,

\footnotetext{
${ }^{48}$ See Id.

49 See R.K. Gupta, "Valorization of Intellectual Property from Publicly Funded Organizations: A Case Study of the Council of Scientific \& Industrial Research (CSIR), India," 10 Journal of Intellectual Property Rights 406 (2005).

Mr. Gupta provided further details in discussions and interviews with the author.

${ }^{50} \mathrm{http}: / /$ www.csir.res.in/External/Utilities/Frames/aboutcsir/main_page.asp?a=topframe.htm\&b=leftcon.htm\&c=../../

../Heads/aboutcsir/about_us.htm.
} 
CSIR has indicated only that the National Chemical Laboratory (NCL) received a $\$ 50,000$ licensing fee and about \$1 million in royalties from General Electric, that CSIR recently licensed its technologies for isolating plant extracts to treat various diseases to a small Indian company and an MNC, and that CSIR recently licensed four U.S. patents (plus one pending) on anticancer compounds to a U.S. biotech research firm.

\subsubsection{Social Objectives and the Private Sector}

The important social objectives that CSIR's constituent labs have achieved are unlikely to excite those driven by the profit motive. Private investment is likely to follow the public sector lead only when Indian businesses and entrepreneurs see lucrative commercial opportunities in patenting.

It is entirely possible that some or all of CSIR's IP successes generated the types of revenues that motivate private investment. But because CSIR's focus remains - appropriately — on its public sector missions, so do the metrics by which it measures success and the terms that it chooses to emphasize when describing those successes. This approach to discussing IP must change as India's patent educators graduate from promoting awareness to promoting understanding - even if all of the activities underlying these successes remain unchanged.

Furthermore, as noted, the current approach to discussing IP leaves a gaping hole in the presentation. As presented, an observer could easily conclude that CSIR might have achieved many if not all of these important social objectives even in the absence of a patent system-and that it might have achieved them more efficiently. Recall that as a matter of IP theory, the mere introduction of a patent system imposes immediate administrative costs on society. Every patent application filed drains public and private resources during its examination. Every patent issued is a potential impediment to commerce. When patentees either practice their patents or license them to commercial ventures that practice them, the consequent new or improved products impel commerce forward. Under such circumstances the analysis of the patent system is straightforward: if the commercial benefits that new products confer exceed the costs of administering the system and impeding commerce, the system is a net societal boon. Otherwise, it is a bane.

In India's case, as in other developing countries that have introduced robust statutory IP systems pursuant to their TRIPS obligations, this tradeoff is particularly important (Box 7). By granting rights in India to MNCs, India has accepted restricted rights on an enormous pool of international innovation. These restrictions, coupled with administrative costs, mean that India's new patent system imposes real costs on Indian society. If it does not also confer benefits in the forms of increased FDI to sponsor innovative activities in India and increased domestic innovation - and specifically, increases that would not have occurred absent a TRIPS-compliant patent statute, and that will dissipate in the absence of enforcement of that statute- the system is a pure cost. 


\section{Box 7 Tradeoffs Inherent in Complying with TRIPS}

Any country contemplating IP reform must conduct a cost-benefit analysis. For countries that have typically had weak IP regimes, stronger IPRs will lead to new inventions and innovations. A country should pursue the contemplated reforms only if the commercial benefits that new products confer exceed the costs of administering the system and impeding commerce.

When India became a party to TRIPS and strengthened the rights that it offers to MNCs, it accepted restricted rights on an enormous pool of international innovation. These restrictions and the necessary administrative overhead impose real and immediate costs on Indian society. Its promised benefits arrive in two forms: MNCs should increase their investments in innovative activities in India, and India's domestic innovators should increase their own investments and activity. If these benefits do not offset the costs in ways that would have been unlikely had India refused to adopt a TRIPS-compliant patent system, the decision to join TRIPS was a mistake.

India's new patent system will only benefit the country as a whole if its increases in domestic innovation (whatever the sources of funding), plus the consequent improvements to commercial activity, product availability, training, education, and other spillovers throughout the innovation system, exceed the costs of administering the system and of restricting access to international innovation. This observation does not detract from the hard and successful work that CSIR, PFC, and the others at the vanguard of India's patent community have achieved over the past few years - but it does emphasize the need for redirection as they move into the future. Social objectives of the sort that CSIR highlights are boons to Indian society-but they are only boons attributable to the patent system if India could not have achieved them without its recent wave of patent reforms.

As CSIR evolves, and the focus of its patent education campaigns moves from general awareness to appropriate motivation, its leaders must consider where patents were critical to achieving its social objectives, and where other mechanisms for creating and disseminating knowledge might have been just as effective. Scholarly publications, for example, can be as effective as patents both at preventing third-party patenting and at dedicating knowledge to the public. Even selfpublished pamphlets can achieve the same goals without the costs and delays inherent in patenting.

Where dedication to the public is the primary objective, patenting is an inefficient approach. CSIR must be prepared to revisit, rethink, and recast its past successes as it revises the focus of its patent education campaign. Its leaders must be prepared to partition its successes as the sorts of social objectives that justify the outlay of public funds from its commercial successes of the sort likely to motivate private investment and entrepreneurship. India's innovators need to hear more stories about the ways that private patenting and private investment yield private profits, and fewer stories about how government-held patents can help the government do its job.

Fortunately, such anecdotal support is beginning to appear. CSIR's R.K. Gupta has also circulated a personal statement from some recently successful patent applicants (Box 8). In this statement, Dr. Alka and Dr. Atul Kumar, two surgeons from Jaipur who credit CSIR with helping them to patent a process for improving hysteroscopic surgery, hit a more appropriate tone. They describe an important message that Dr. Mashelkar, CSIR's long-time Director General, conveyed in a public address: He exhorted Indians to worship Saraswati and Laxmi simultaneously — a potentially powerful cultural allusion that could help people reassess their 
thinking about IPRs, and the one with which this study opened. Following Dr. Mashelkar's address, the surgeons approached him, described the difficulties that they had faced in even thinking about patenting, and enlisted his personal support and CSIR's institutional support in their drive toward patent protection — and perhaps soon to patent-driven revenues.

\section{Box 8 A Personal Success Story ${ }^{51}$}

Uterine distension is the most difficult and complicated part of hysteroscopic surgery; the liquid used for distending the uterus may enter the patient's blood circulation and endanger her life. This phenomenon, known as intravasation, has been an obstinate impediment to optimal performance in hysteroscopic surgery. Our invention maintains a predictably clear endoscopic visualization so that the surgeon always knows the real-time rate of the intravasation into the patient's blood circulation. The invention is also applicable to arthroscopic surgery.

Loaded with these ideas, we had only two options: to publish our work or apply for a patent. We almost decided in favor of the first option due to fear of the unknown and to ill-founded fears associated with the seemingly arduous patenting process. Our visit to some R\&D organizations only confused us further and made us even more fearful of patenting.

By chance, we heard Dr. Mashelkar, CSIR's Director General, deliver his oration, "Nation Building Through Science \& Technology" at Birla Auditorium, Jaipur, in July 2003. He pointed out that many technocrats like us first publish and then think of patenting; in this manner, we lose our intellectual property to foreigners who exploit our ideas and at our cost, leading to an individual as well as a national loss.

Following this inspiration and a meeting with Dr Mashelkar, we traveled to New Delhi. There we received seemingly God-sent help from R.K. Gupta, the Head of CSIR's IP management division. He explained the concepts of non-disclosure agreements (NDAs), licensing, and corporate communications, leading us to prepare more than a dozen additional patents, along with critical assistance preparing our PCT application.

In July 2004, we filed our PCT application (available at http://ep.espacenet.com, publication number WO2005077435). In August 2004 we entered into an NDA with a few U.S.-based companies and eventually selected one as a prospective collaborator.

No one wanted to lose any time. The scientists of the U.S.-based company visited us in India and both sides participated in academic discussions. In December 2004 our American collaborators hosted us in the United States. In May 2005 we licensed more than half a dozen technologies in the United States, and the final products are also expected to be available in global markets in the near future.

These private sector surgeons seem to have grasped the worship of Laxmi in the way that CSIR, PFC, and the rest of India's patent community must emphasize when they address the private sector. The surgeons' account of their CSIR-inspired drive toward a patent relates not only the work toward patenting, but also their recent licensing agreements leading to several products that will soon be available around the world. ${ }^{52}$ India's innovators need to hear more such stories if they are to internalize the motivation that the patent system is supposed to confer.

\footnotetext{
${ }^{51}$ See CSIR, Intellectual Property and Technology Management Scheme, forthcoming. Edited and paraphrased by author from draft personal statement of Dr. Alka and Dr. Atul Kumar provided by CSIR.

${ }^{52}$ See Id.
} 


\subsection{The New Indian Patent Regime}

\subsubsection{Obligations and Flexibility}

India's recent cultural shifts and increases in patent activity all derived from the same motives as its recent fundamental changes in the law - not to mention from the new laws themselves. The past decade has been a very active one for India's patent community. Though Indian patent law today looks very different from the system that the Ayyangar Commission proposed, the Patent Act of 1970 remains in force — albeit subject to a series of significant amendments.

Beyond the statutory level, the administration of India's patent system falls within the jurisdiction of the Department of Industrial Policy and Promotion (DIPP) and its subordinate Office of the Controller General of Patents, Designs, and Trademarks (CGPDTM). ${ }^{53}$ India's Patent Office is spread across the country, with the head office in Kolkata and regional offices in Mumbai, Delhi, and Chennai. These offices process both direct applications for Indian patents and international applications filed under the Patent Cooperation Treaty (PCT) designating India. Modernization efforts are under way at all four locations, and the Government of India is working to improve automation, training, and staffing to meet the challenges inherent in turning its new statutory system into an engine of economic growth.

India's accession to the WTO in January 1995, and specifically its status as a TRIPS signatory, obligated it to harmonize many aspects of its patent system with standards prevalent in the developed world. TRIPS compliance, however, does leave room for experimentation at the margins - and in patent law, the effects of such marginal experimentation can be significant. In particular, as noted, these margins allow countries to apply sui generis rules to industries that they believe warrant special considerations. Though such rules do not alter the unitary nature of patent law as a matter of law (that is, the same Patent Act applies to all patents), they do alter it as a matter of fact (that is, different rules apply to different patents).

The United States exploited this loophole when it passed the Hatch-Waxman Act and introduced a de facto industry-specific regime for pharmaceuticals - though because Hatch-Waxman predates TRIPS, this deviation from a unitary patent system was not technically a loophole at the time that the United States exploited it. Because Hatch-Waxman essentially overturned a court ruling against the generic drug manufacturer Bolar, the rules that it introduced allowing generic producers to experiment with patented drugs during the lifetime of the patent are known internationally as "Bolar provisions." 54

The WTO has ruled that the Bolar provisions incorporated into Canadian patent law are TRIPS compliant, though on grounds sufficiently narrow and technical that other implementations may still be subject to challenge. ${ }^{55}$ India's new laws similarly incorporate Bolar provisions - and even further changes are being considered that would magnify the differences between Indian pharmaceutical patents and other Indian patents.

\footnotetext{
${ }^{53} \mathrm{http}: / /$ did.nic.in/ipr/cgpdtmain.htm.

${ }^{54}$ See Roche Products, Inc. v. Bolar Pharmaceutical Co., 733 F.2d 858, 863 (Fed. Cir. 1984).

55 See WTO Panel Report, WT/DS114/R, 17 March 2000 "Canada_Patent Protection of Pharmaceutical Products. Complaint by the European Communities and their member States." http://www.wto.org/english/tratop_e/dispu_e/7428d.pdf.
} 


\subsubsection{State of the Law}

The core of the new laws, however, was TRIPS compliance - not experimentation at the margins. The first significant wave of amendments toward achieving compliance came in 1999, followed by further amendments in 2002 and 2003, with many of the changes made retrospective to January 1995. India asserts that its 2005 amendments brought its patent laws into full compliance with TRIPS. The net effect of these amendments has been dramatic: ${ }^{.56}$

- India has extended the life of its patents from Ayyangar's 5-14 year scheme to a TRIPSmandated 20 years.

- India now grants product patents on a range of pharmaceutical and therapeutic innovations, including exclusive marketing rights (EMRs) on drugs. Previously only process patents and weak rights were available.

- India preserved its right to turn normally exclusive patent rights into compulsory licenses, but accepted TRIPS limitations on the circumstances in which such actions were possible. Under current law, India's Controller of Patents may grant a compulsory license only if the claimant can show that exigent circumstances implicate national security, public health, or other emergency circumstances, and that the patented product is not already available to the public in sufficient quantities at reasonable prices.

- India introduced limited patentability for software. The new law continues precluding patents on standalone computer programs, mathematics, algorithms, and business methods. For the first time, however, it permits patents on applied software or software embedded in or combined with hardware.

Beyond these core changes, the recent amendments also allowed India to avail itself of TRIPS's flexible margins. In addition to the Bolar provisions, India's patent laws now incorporate various provisions to protect public health from vagarious exercises of patent rights on important drugs; require patentees to disclose the source of the knowledge underpinning their applications pursuant to the Convention on Biodiversity (CBD) ${ }^{57}$ though not necessarily all prior art; and allow both pre- and post-grant challenges to patents. ${ }^{58}$

The recent amendments also established an Intellectual Property Appellate Board (IPAB) and delineated the board's makeup, powers, and governing procedures. ${ }^{59}$ The IPAB now has sole appellate jurisdiction over all rulings emanating from the Controller of Patents-but not over infringement litigation, which is brought in standard civil trial courts.

Together these provisions demonstrate fidelity to both the goals of TRIPS compliance and the broader societal concerns that Justice Ayyangar raised four decades ago - and that for the most part still characterize Indian society. Neither the lengthening of patent life nor the strengthening

\footnotetext{
${ }^{56}$ See Archana Shankar, "India," in Patents in 27 Jurisdictions Worldwide (Law Business Research, Ltd., 2006) at 78; Laura Thomson, "Changing Times for Patenting in India," http://scientific.thomson.com/news/newsletter/2005$02 / 8263720 /$.

${ }^{57}$ See Cynthia M. Ho, "Disclosure of Origin and Prior Informed Consent for Applications of Intellectual Property Rights Based on Genetic Resources: A Technical Study of Implementation Issues," UNEP/CBD/WG-ABS/2/INF/2, 29 September 2003, http://www.biodiv.org/doc/meetings/abs/abswg-02/information/abswg-02-inf-02-en.pdf.

${ }^{58}$ See Shankar, supra n. 56.

${ }^{59}$ See Id; $\S \S 116,117$ of the Indian Patents (amendment) Act, 2005.
} 
of pharmaceutical rights was negotiable; TRIPS requirements are clear on both counts. ${ }^{60}$ The possibility that TRIPS allows of reducing those patents to compulsory licenses in emergency cases, however, protects the Indian public from the most egregious of the potential abuses that motivated Ayyangar to recommend against patenting any pharmaceutical products. ${ }^{61}$

Pre- and post-grant challenges and the CBD disclosure requirements will make it harder for anyone to patent either traditional knowledge or incremental advances that are known widely in a substantive field, but that the literature may not reflect. Pre- and post-grant challenges also promise to reduce the number of improvidently granted patents, add certainty to the likely validity of patents that are granted, and reduce consequent litigation over validity. Many countries lack any such procedures, and many of the challenge procedures that do exist do not work well.

The basic premise behind open challenges is that competitors will move to squelch the threat of future patent litigation by helping examiners ensure that only earned patents are granted. That insurance should make those patents that are granted more likely to be valid — and thus upheld in court if challenged. Furthermore, administrative proceedings are typically less expensive than is full-blown litigation, preserving both public and private resources. Nevertheless, good challenge procedures seem to be hard to draft and harder to implement. India's decision to introduce both pre- and post-grant challenges demonstrates a commitment to maintaining the integrity of the patents that the Patent Office does grant. Only empirical evidence will determine whether these procedures will succeed where others have failed.

In short, it appears that the drafters of India's new patent laws have analyzed the situation carefully and balanced the imperatives of TRIPS compliance in a globally competitive world with the concerns of India's companies, consumers, patients, and possessors of traditional knowledge.

\section{Remaining Challenges}

\subsection{Foundational Issues}

\subsubsection{State of the System}

India's patent system is at a critical juncture. The 2005 amendments marked the end of a decadelong movement toward compliance with TRIPS. The new statutory framework reflects a thoughtful balance of TRIPS compliance and national needs. It combines the general principles of awarding patents to all inventions that cross yet-to-be determined thresholds of novelty and nonobviousness with special sensitivity to therapeutic treatments and traditional knowledge. It also includes important procedural safeguards that many patent systems of longer standing lack - notably pre- and post-grant challenge procedures and emergency mechanisms for forcing compulsory licenses.

\footnotetext{
${ }^{60}$ See TRIPS Article 27 on patentable subject matter; TRIPS Article 33 on patent length.

${ }^{61}$ See TRIPS Article 27.1.
} 
By all accounts, India's small but growing patent community has used the past decade to promote IP awareness effectively. Since 1995 the PFC has sponsored over 300 IP seminars in locations across India. It also operates numerous local advisory centers and a full-blown facilitation center in New Delhi, where it and CSIR help innovators prepare applications for both Indian and foreign patents. ${ }^{62}$ Indian research institutes, universities, and companies have begun to build portfolios of Indian and international patents. Individual inventors and SMEs have also entered the fray, and appear to be showing increasing interest in patenting. According to Anjan Das, Senior Director of the Confederation of Indian Industries (CII), Indian industry today is "pro-patent." But as noted, there seems to be considerably more awareness of the patent system than understanding of the behavior that it is supposed to motivate.

India's movements over the past decade indicate a commitment to building a fully functioning, effective patent system. Its statutory law reflects a coherent policy decision to use patents to promote innovation, motivate commercialization, harmonize with the developed world, embrace treaty obligations, and address local concerns. Its public education campaigns have raised awareness of patents throughout the domestic technical and legal communities, as well as throughout the public at large. Nevertheless, considerable work remains to grow from a wellconceived patent system to a fully functioning one.

The statutory changes adopted in 2005 represent reasonable policy choices on the major issues. Like all policy choices embodied in law, India needs to monitor the empirical performance of its laws at achieving its stated policy objectives. At the moment, however, India needs to allow that empirical evidence to accumulate. It must put into practice the tradeoffs embodied in the 2005 amendments. It also must begin to appreciate the flexibility that TRIPS leaves at the margins, both in determining the specific thresholds for the various conditions of patentability and in determining how India wants to treat some of its most important industries - namely, hightechnology information and communications and health.

\subsubsection{The Special Case of Software}

This need for monitoring is particularly acute in the software and information technology (IT) industries. Until 2005, Indian law prohibited software patents. The 2005 amendments maintained the explicit prohibition on patenting computer programs, mathematics, and business methods per se, but expanded the scope of patentability to include software applied to specific industrial problems and software incorporated with hardware as part of a single innovation. ${ }^{63}$

In many ways this distinction adopts a situation that most observers of U.S. patent law believed existed between a U.S. Supreme Court ruling in 1972 announcing the patentability of applied industrial software and two rulings of the U.S. Court of Appeals for the Federal Circuit in the 1990s that broadened the scope of patentable software to include nearly all novel and nonobvious algorithms and business methods. ${ }^{64}$ All three of those rulings, however, represented departures from the situation that most U.S. observers believed existed throughout the 1950s and 1960s-

\footnotetext{
${ }^{62}$ See the Patent Facilitating Center Website, http://www.tifac.org.in/.

${ }^{63}$ See Shankar, supra n. 56 at 80.

${ }^{64}$ See Gottschalk v. Benson, 409 U.S. 63 (1972); In re Alappat, 33 F.3d 1526 (Fed. Cir. 1994) (en banc); State Street Bank \& Trust Co. v. Signature Financial Group, Inc., 149 F.3d 1368 (Fed. Cir. 1998).
} 
namely, that software was not patentable subject matter. The upshot of this history is that patents, copyrights, and trade secrets simultaneously protect software in the United States today. This triple protection has generated a complex legal environment and a business environment that scholars are still trying to fully understand. ${ }^{65}$

The U.S. experience with software patents - either in their narrow form prior to the mid-1990s or in their current expansive form - has been far from positive. Numerous critics have argued that patents do little to motivate innovation in software, ${ }^{66}$ there is little if any evidence that patenting has contributed to the robustness of the U.S. software industry (and some evidence that it has deterred R\&D), ${ }^{67}$ and even possessors of potentially valuable software portfolios, such as Amazon.com's Jeff Bezos, have conceded that the current U.S. system of patenting software does not work appropriately and might warrant structural reform. ${ }^{68}$

Advocates for "open source" software argue that the entire structure of the U.S. software IP regime is misguided, and has led to a misallocation of resources throughout the global software industry. They contend that the commercial software industry should assume a service rather than a product orientation. ${ }^{69}$ In their view, software developers who place their products - or partial products - in full public view will simultaneously solicit input that improves their products with minimal development costs and enhance their reputations in ways that generate lucrative opportunities for consulting, advising, and customizing software. Their work has led to some powerful and important commercial products, including the Linux operating system and the Apache Web server. Nevertheless, many questions remain about the viability of open source within the confines of U.S. triple protection.

Litigation currently under way in the United States will begin to resolve these questions. The ramifications of these lawsuits are likely to reverberate worldwide — in no small part because they will provide an unusually clear illustration of the relationship between IP policy and the shape of industrial development. India's policy advisers should pay close attention to the debate over open source and the proper shape of the software industry as they consider the best ways to leverage Indian IP policy into an increasingly powerful and important Indian IT industry.

Partly because of the U.S. experience and partly due to other reasons, software patents are unavailable in the European Union - though that could change. Though the European Parliament rejected a bill that would have introduced software patents by an overwhelming majority of 68414 as recently as July 2005, the issue reportedly continues to surface in Brussels. ${ }^{70}$ The stakes for

\footnotetext{
${ }^{65}$ I explored some of the ramifications of this triple protection, and some likely implications of adopting alternative IP regimes for software in Abramson, supra n. 10 at chs. 2, 8.

${ }^{66}$ See, for example, Samuelson and others, supra n. 8; Abramson, supra nn. 8, 10.

${ }^{67}$ See James Bessen \& Robert M. Hunt “An Empirical Look at Software Patents,” Federal Reserve Bank of Philadelphia Working Papers 03-17 (2004), http://www.researchoninnovation.org/online.htm\#sw.

${ }^{68}$ See, for example, "Patent Wars," The Economist, April 6, 2000.

${ }^{69}$ For an introduction to the open source ideology written by one of the movement's founders, see Eric Raymond, The Cathedral and the Bazaar, (O'Reilly \& Associates, 1999). For a discussion of the movement's history and its implications as a business model, see Abramson, supra n. 10 at ch. 6. For a discussion of the open source approach as a general model of industrial and social organization, see Steven Weber, The Success of Open Source (Harvard University Press, 2004).

${ }^{70}$ See Ingrid Marson, "Lobbyists Prepare for Next Software Patent Battle," ZDNet, UK, http://news.zdnet.co.uk/business/0,39020645,39248676,00.htm.
} 
EU countries can be high. Microsoft reportedly threatened to move Navision - a Danish subsidiary employing 800 software developers - out of the country if the European Union refused to grant software patents. ${ }^{71}$

The stakes for India can be just as high. Over the past 15 years India has developed a large, flourishing, and increasingly important software industry. India's software companies now combine homegrown entrepreneurs and MNCs sourcing work to India-two critical sources of innovation that India must nurture through its IP system. This industry emerged in an environment where India protected software under its copyright laws, its trade secret laws, and to a lesser extent, its trademark laws. The recent amendment extending patent law into some areas of the software world represents a change to a system that seemed to be working - always something of a risk. But as Microsoft's threat to Denmark demonstrates, the culture in the software world is also changing. Legal stasis may not have been an option for India. The need for such adaptation rose to the fore in a recent CNBC-hosted debate, "Conforming to the IPR Regime-Is it a Business Imperative Today?"

In line with demands of the IT industry, the Government has agreed to rigorously implement IPR laws in the sector to enable India to emerge as a knowledge superpower. Department of Industrial Policy and Promotion Secretary Ajay K. Dua has said, "We need to implement greater intellectual property rights laws," while responding to BSA Worldwide President Robert Holleyman's statement that India's track record in implementing an IPR regime is very poor, and that Malaysia and Taiwan are much ahead of India...

According to him, India needs to have IPR infrastructure including IPR managers, IPR attorneys and IPR enforcement machinery. As a recent IDC-BSA Global piracy study said, decreasing India's piracy rate by 10 points from 2002 to 2006 would add 2.1 billion dollars to the GDP, thereby creating more than 48,000 new jobs and generating 92 million dollars in tax revenues. The IT giants realised that ignorance about licensing is a key reason for the high rate of piracy at the corporate level. $^{72}$

Furthermore, many critics of software patents are equally critical of software copyrights; neither type of IPR seems particularly well attuned to motivating software developers. As a result, many of these critics have recommended a sui generis IPR for software. ${ }^{73}$ Because few if any of their recommendations have worked their way into law anywhere, it is impossible to know whether they would lead to a more robust software industry - either globally or in whatever country chose to adopt them.

The ultimate lesson for India's software and IP communities is that all IPRs protecting software remain controversial. Box 9 outlines a number of questions that India's policymakers (along with

\footnotetext{
${ }^{71}$ See "Bill Gates Threatens to Close Navision in Denmark," The Copenhagen Post Online, February 15, 2005, http://www.cphpost.dk/get/85881.html.

72 “Govt to Implement IPR Regime Rigorously: Dua,” 18 September, 2006. http://www.indlawnews.com/3B85675445ADB7E38916409C322F31D1.

${ }^{73}$ See, for example, Samuelson and others, supra n. 8; Abramson, supra nn. 8, 10.
} 
policymakers elsewhere) must contemplate when determining the contours of an IP regime most likely to promote its critical IT industry. These questions also illustrate one of the major areas of flexibility that remains under TRIPS. The world has yet to develop IP norms applicable to many of the "new" industries of the information age. India's policymakers must find a set of answers appropriate to the needs of both India's current IT industry and the IT industry that India would like to build as it moves into the future.

\section{Box 9 Some Key Questions about IPRs in the IT Industry}

- Should any software be considered patentable subject matter?

- Does a combination of copyright law and trade secret law motivate investment and innovation in software?

- Is a combination of copyright law and trade secret law adequate for motivating investment and innovation in software?

- Should software be considered patentable subject matter if and only if it is bundled with hardware?

- Should all algorithms be considered patentable subject matter?

- Should business methods be considered patentable subject matter?

- Will patentability motivate additional investments and innovations in software?

- Should India set thresholds of novelty and nonobviousness high enough to ensure that only significant software innovations will earn patents?

- Should India show any preference for open source software?

- Should India's public sector and educational institutions show a preference for open source software?

- If India's IP laws covering software differ from those of other countries, will the Indian IT industry find itself at a competitive disadvantage (or advantage, depending on the direction of the difference)?

- Should India consider adopting any of the proposed sui generis forms of software IPRs that the scholarly literature proposes?

- What resources should the Government of India allocate to enforcing its software IP regime?

In short, IP protection of software presents a special case. India recently changed a system that enabled and facilitated the growth of a globally important domestic IT industry. The lack of international norms on software IPRs means that India retains considerable flexibility in determining where the thresholds for novelty and nonobviousness lie, and what sorts of evidence to require to distinguish patentable software from prior art. High barriers to patentability would render the effect of software patents negligible, and might placate MNCs seeking software patents. To a large extent, though, the degree to which MNCs are placated will be a factor of trends abroad. India's IP community must monitor international developments in this arena, while simultaneously monitoring the potential changes to its domestic software industry now that some of its innovations are patentable.

\subsubsection{The Special Case of Pharmaceuticals}

Unlike software, where India has made its statutory choices and must now monitor them as they unfold, India's treatment of pharmaceutical and chemical patents remains incomplete. The Department of Industrial Policy and Promotion, the agency that oversees and administers patent laws, has chartered the Mashelkar Committee on Patent Law Issues (chaired by CSIR's Director General, Dr. Mashelkar), and asked it to answer two lingering questions:

- Would it be TRIPS compatible to limit pharmaceutical patents to new chemical entities, rather than to all advances in pharmaceuticals?

- Would it be TRIPS compatible to exclude microorganisms from patenting? 
The Committee issued its report in December 2006: rules limiting patentability solely to new chemical entities or excluding microorganisms from patenting would violate India's obligations under TRIPS. ${ }^{74}$ The government must now decide how to incorporate this advice into law. A different committee, this one under the auspices of the Department of Chemicals and PetroChemicals and chaired by its Secretary, is exploring whether the government may share data that it obtains from branded chemical companies seeking regulatory clearance to sell their products with generic competitors seeking to develop products to launch upon expiration of applicable patents.

In all three cases the government will have to decide, first, which set of policies best serve India's needs; second, whether those policies are consistent with India's international obligations; and third, if they are inconsistent with those obligations, whether or not they confer enough benefits upon India to warrant adopting them anyway.

The implications of India's choices can be significant. Patents on incremental improvements, the eligibility of microorganisms for patent protection, and prohibitions on data sharing will all make India a more attractive business venue for branded MNCs and biotech firms. Narrower concepts of patentability and weak data protection laws will serve the interests of low-cost drug producers. India's policy decisions and eventual legislation in these areas can thus shape the future development of India's pharmaceutical industry: the cost and availability of drugs to consumers, the number and types of domestic research opportunities, the number and types of drug manufacturing facilities that companies choose to locate in India, and the consequent shape of employment throughout the sector.

In other words, these remaining issues implicate precisely the cost-benefit analysis underlying the assessment of all IP regimes - and are thus worth considering in at least some detail. If India decides to grant broad patent rights on drugs and chemicals, it will attract some additional investment from MNCs, possibly motivating them to introduce R\&D facilities in India and move their manufacturing facilities to India.

As The Economist recently reported, India possesses several features that make it a particularly attractive place for at least some forms of medical research:

In pharmaceuticals, the market in outsourced clinical trials, for example, is expected to reach $\$ 1$ billion annually by 2010 . Vasudeo Ginde, of iGATE Clinical Research, one of several dozen firms competing for a share of this cake, says that India has always had three essentials: doctors versed in Western ways, good (in places) hospital facilities, and huge numbers of patients. In addition, since the beginning of last year there has also been stronger patent protection for foreign medicines, so foreign firms are less nervous that conducting research in India will jeopardise their intellectual property. As in other outsourced businesses, speed is as important as cost: if 500 diabetics are needed, they can be found much more

\footnotetext{
${ }^{74}$ R.A. Mashelkar, Chairman, Report of the Technical Expert Group on Patent Law Issues (December 2006).
} 
quickly in India. And there are more inoperable cancers, because fewer are detected at earlier stages. ${ }^{75}$

The stronger patent protection that the 2005 amendments introduced is already helping to attract clinical research. Even stronger forms of protection will likely accelerate that trend, and open the door to broader research facilities with consequent spillovers into domestic education, training, and innovation. Weaker protection, or poor enforcement of the recently added rights, will delay or deter such investments from abroad.

The downside of broader patent protection in these areas, however, is both more immediate and more certain. Indian pharmaceutical patents will raise the prices of drugs in India and reduce the ability of India's low-cost drug manufacturers to export to developing countries that have chosen not to award such patents. The broader are the rights that India grants, the higher these costs will rise. In thinking through these remaining statutory issues, the government must decide whether the benefits of promoting FDI, domestic innovation, and their spillovers into education, training, and commercialization exceed the costs of restricting access to international innovation and reducing the effectiveness of India's producers at serving the low end of the international market (Box 10).

\section{Box 10 Some Key Questions about IPRs in the Pharmaceutical Industry}

- Should India restrict pharmaceutical and chemical patents to newly discovered compounds?

- Should India allow patents on minor pharmaceutical advances, including those that lead to "evergreen" products in which branded drug manufacturers will always maintain an exclusive patent on the most advanced form of their products?

- Should microorganisms or other life forms synthesized in a laboratory be considered patentable subject matter?

- Should genes or genetic therapies be considered patentable subject matter?

- Should branded drug manufacturers be allowed to retain as proprietary the clinical data that they provide to the Government of India when seeking regulatory clearance to market their drugs?

- Should the government share clinical data obtained from branded drug manufacturers with their generic and low-cost competitors?

- Should India adopt a pharmaceutical IP system designed to attract MNC research, including but not limited to clinical research?

- Should India adopt a pharmaceutical IP system designed to motivate domestic drug production?

The choice is stark. India must decide what type of drug and chemical companies it wants: Decisions in one direction will protect but not guarantee India's position as a powerhouse in lowcost drug manufacturing and complicate any desire to move into high-end medicine or medical research. Decisions in the other direction will create the possibility of becoming an important player in medical innovation, but complicate the future of low-cost drug producers. Either approach will make some aspects of India's negotiations with MNCs and foreign governments easier and others harder: narrow patent rights will ensure continued international tension over statutory issues, while broad patent rights will shift the debates from statutory reform to enforcement.

\footnotetext{
${ }^{75}$ The Economist, "If in Doubt, Farm it Out," June 1, 2006.
} 
India's decisions will also put procedural aspects of its new patent system to the test: The 2005 amendments reduced the scope of the procedures allowing the Patent Office to compel a patentee to license its patents. Public health crises remain among the circumstances under which compulsory licenses are still possible. The broader are the patent rights granted on pharmaceuticals, the greater is the likelihood of compulsory licensing. It is a safe bet that every compulsory license hearing will generate international controversy and tension. Finally, and perhaps most significantly, broader patents can harm public health by reducing the availability of patented drugs, or cost the government money by forcing it to subsidize the costs of those drugs for India's poor consumers - though these same broader rights may also speed the introduction of new drugs in India.

The complexity of these costs and benefits notwithstanding, these remaining statutory issues all seem poised for near-term resolution. The drafters of India's current patent laws have demonstrated thought, care, and balance. The Government of India should review the reports that it has commissioned and then make the decisions that, in its judgment, best serve the country's needs. Whatever it decides will remove uncertainty from the patent system and help India's innovators and investors make informed decisions. In any business environment, certainty reduces risk and increases investment. India's most pressing IP policy need lies in providing the innovative and commercial portions of the pharmaceutical and chemical industries with the certainty that they need to make informed investment decisions.

\subsubsection{The IP Policy Think Tank}

These analyses point to two critical needs: India must fill the remaining gaps in its statutory framework, and the government must build a patent policy advisory board. In addition to simply monitoring the performance of the new laws in various critical industries, the government will soon need to make decisions about numerous implementation issues - many but not all of which are discussed below. Each of these decisions may require complex analyses.

The government will need permanent, trusted policy advisers. The best way to develop a cadre of such advisers is to create a government-sponsored, IP policy think tank. Such a think tank must maintain its independence so that it can avoid major personnel shifts and policy shifts following elections. It must also avoid the bureaucratic traps common among civil service institutions. The think tank should consider all the implementation and enforcement issues relevant not only to patents, but also to copyrights, trademarks, and other forms of IP. Each scholar should be invited to participate full-time for a brief period, and part-time for a longer period. The think tank's primary job should be to ensure that all government decisions on IP policy conform to the goal of achieving societal optimality for the Indian public.

Recommendation 1: Establish an IP policy-oriented think tank as soon as possible. Staff it with Indian and foreign IP scholars charged with assessing the likely impact of contemplated IP policies on India's public. The think tank should also review the issues and recommendations delineated in this report. In addition, it should closely monitor developments in the software and pharmaceutical industries to determine the effects and the effectiveness of the policies adopted. 
Recommendation 2: Complete the statutory framework as soon as possible. The completed framework should resolve issues of patentability in the chemical, pharmaceutical, and microorganism arenas, and incorporate clear rules on data protection and sharing.

\subsection{Modernization}

With those policy choices enacted into law, the basic foundation for a modern Indian patent system will almost be in place - but not quite. Statutory frameworks and policy choices are just that: frameworks and choices. The greatest challenges facing India's IP system today relate to implementation.

India has already taken significant steps toward modernizing and professionalizing its Patent Office. New facilities in New Delhi and around the country house examiners and controllers, and their professionalism and relevant expertise have reportedly improved markedly over the past decade. Though the new facilities apparently contain state-of-the-art computing and communication infrastructures, modernization is not yet complete. According to Patent Office personnel, in May 2006 the Office did not yet accept automated applications, full online searches of issued patents were not yet available, the databases needed for prior art searches remained unfinished, and interconnections with foreign patent offices had yet to be established.

Modernization costs money, and it must therefore compete with other budgetary items that may seem more pressing. An effective patent system is a long-term investment, and modernization is a prerequisite for its effectiveness. The government must decide how it wants its own potential entrepreneurs, MNCs, and other governments to perceive it. If India wants the world to view it as a serious place to do business - trustworthy with sensitive innovations, protective of its domestic entrepreneurs and small businesses, and a reliable treaty partner - it must strive to enforce the laws that it passes. Though none of these perceptions are strictly necessary to attract partners or investors, they are necessary for a country hoping to assume a position of global scientific, technological, or commercial leadership.

India's homegrown businesses are beginning to clamor for positions of international leadership. Consider, for example, The Economist's recent discussion with B. Ramalinga Raju, the head of Satyam, an Indian IT firm generating about $\$ 1$ billion in annual revenues.

[Mr. Raju] describes his company's growth as taking place in six "orbits". First came the simple "body-shopping" of the early 1990s, when Indian engineers were hired out to help develop software. Next, thanks to huge improvements in telecommunications, much of this work started to be carried out remotely, on "campuses" in India. Third was a "technical transformation", as firms shunned simple labour arbitrage in a drive for quality. Mr Raju compares the Indian industry with immigrant groups that feel compelled to outshine the indigenous population. Next came a global expansion as firms started building "development centres" in third-world countries, and creating a "global delivery" model. By the fifth orbit, the big Indian firms were dealing with complex integrated projects. 
Now, for its sixth orbit, says Mr Raju, the industry needs to demonstrate "a leadership mindset" and the ability to innovate. ${ }^{76}$

Satyam's "sixth orbit" of international leadership is only possible in an environment that the international business community deems trustworthy. It is hard to see leadership emerging from a country whose enforcement of its laws remains lackluster. If India wishes to assume leadership positions in any of the technologies or industries impelling its economic growth, it will have to act like a leader. At the moment, that means leading the developing world in understanding how to make IPRs applicable to the needs of a poor country in the information age.

The requirements of modernization do not mean that India must mimic the U.S. system of performing a full-blown examination of every patent application, though India might well decide that such a system serves its interests. There is an alternative model, known as a patent registration system, that contrasts with the U.S. model of a patent examination system. Many countries, including Australia, Singapore, and some EU member states, require few substantive inquiries prior to granting patents. Australia also launched another interesting experiment in 2001: an "innovation patent" that provides simple, inexpensive protection for inventions deemed insufficiently inventive to meet the threshold required for standard patents. Though this experiment is too new to have generated meaningful data capable of assessing its merit, India should leverage the inquiries and recommendations leading to such experiments when considering their propriety in the Indian context. ${ }^{77}$ The differences between pure registration and pure examination systems, however, are well enough understood to be immediately informative.

In a pure registration system a country's patent office simply grants patents to all applicants who meet procedural filing requirements, without inquiring into the novelty, nonobviousness, or general suitability of patenting the claimed innovation. These patents then have the force of law, but courts asked to enforce them need show little deference to the expertise latent in the patent office-precisely because the patent office applied little or no expertise prior to granting the patent. The burden of proof thus rests entirely with the patentee, who must convince the court of the patent's validity, as well as of the defendant's infringement.

Under the full-blown examination model that the United States uses, Patent Office personnel apply significant expertise, and courts typically defer to their greater knowledge by presuming that a patent is valid unless a defendant can prove otherwise. The choice of a registration or an examination system has a profound effect on a country's administrative and judicial agencies, as well as on the cost of maintaining its patent system. Registration systems speed applications along, proliferate weak, improvident, and unenforceable patents, reduce administrative time and costs, restrict full examination to the relatively few patents subject to litigation, and increase the demands on the judiciary and the costs of litigation. Examination systems delay patent grants, typically lead to higher-quality patents, ease enforcement, promote negotiated licenses rather than litigation, and reduce the burden on the courts.

\footnotetext{
${ }^{76}$ The Economist, "Virtual Champions," June 1, 2006.

77 See Australian Government, IP Australia, "The Innovation Patent," http://www.ipaustralia.gov.au/patents/what_innovation.shtml.
} 
The proposed IP policy think tank should evaluate the propriety of these approaches as soon as possible. Once India invests further funds in Patent Office modernization and examiner training, the move toward an examination system may be too far along to reverse - even if a detailed policy analysis concludes that a registration system would have been preferable (Box 11).

\section{Box 11 Examination and Registration Systems as the Basis of Flexible Patent Law Design}

The choice between an examination and a registration system is of more than merely administrative significance. Examiners in an examination system, and judges in a registration system, set the rules that separate patentable from unpatentable subject matter, novel inventions from incremental advances, and obvious from nonobvious innovations. These rules thus absorb virtually all the flexibility that remains to individual nations even within a TRIPS-compliant framework.

Decisions about patentability can alter both the investments in innovation that India experiences and the types of commercial development that arise. Expansive patent scope in areas like software and pharmaceuticals can attract significant MNC investments in Indian research, education, and training facilities, but may hamper the development of low-cost Indian producers as the suppliers of choice to the developing world (particularly to countries without their own IP systems).

Decisions about novelty and nonobviousness can have similar consequences. Is the development of a six-hour pill a novel advance over its previous four-hour version? Is the application of a known algorithm to a new setting obvious? Investors care deeply about the answers to these questions. The answers that India's patent system chooses to provide will dictate investor responses.

Even at the "merely administrative" level, the choice between examination and registration systems is stark. A pure examination system requires detailed guidelines to train technically competent examiners. Judges, particularly trial judges, will likely receive less training - thereby motivating the development of an appellate court with significant expertise. A pure registration system will convert examiners to file clerks, but mandate better training for judgesthereby motivating the development of a specialized bench.

Every country must evaluate its needs and advantages in deciding what type of behavior to motivate. Wise decisions on these and related issues will allow India to avail itself of the flexibility under TRIPS to motivate behavior likely to attract appropriate amounts of FDI without imperiling workers or consumers. The best approach for India would be to assess these issues early in the development of its new patent system. India will want to enforce a patent system tailored to its needs, thereby improving investor confidence and strengthening the rule of law. A poorly conceived patent system that fails to serve India's interests is likely to lead to lackluster performance and undermine investor confidence. The choice of a registration system or an examination system is where it all starts. Flexibility flows from there.

By reviewing these and similar questions, the proposed think tank can play a central role in helping not only India, but all developing countries, understand how best to leverage IPRs for the needs of their populations, industries, and innovators. Its recommendations would help India attract high-quality innovation and investment, and assume global leadership in showing developing countries how to leverage IPRs into effective development aids. A failure to implement the new statutory structure effectively, on the other hand, threatens to sentence developing countries to a perpetual brain drain, as their most capable innovators leave seeking more reliable returns elsewhere. The analysis of registration and examination systems, and the modernization and automation of India's Patent Offices to implement whichever type of regime the Government of India chooses, is a small but important step in the right direction. 
Recommendation 3: Charge the proposed think tank with exploring the relative merits of a patent registration system and a patent examination system. Emphasize the need for a rapid response, and take appropriate steps to recalibrate plans for modernization and personnel training to implement the chosen regime.

Recommendation 4: Commit to completing the modernization of the Patent Office as soon as possible. Enable automated applications and online searching. Launch a prior art database and interconnect these databases and search engines with as many foreign patent offices as possible, as quickly as possible.

\subsection{Consistency and Professionalism}

\subsubsection{The Role of Subjectivity}

The key to a functioning patent system lies in how it motivates scientists, technologists, and innovators to develop ideas and products that benefit society. Consistency is the most basic requirement of any motivational system. All behavior rests on reasonable expectations. If innovators (or their legal representatives) cannot predict how they will fare when they seek to obtain and enforce their patent rights, they will not use the system—or at the very least, they will not use if appropriately. The most important implementation challenge that India faces is promoting consistency and predictability in its patent system.

The drive for consistency has been the bane of many patent systems. Every patent application requires an examiner (or in a registration system, a judge) to determine whether the claimed invention crosses the requisite thresholds of novelty and nonobviousness, whether the applicant has distinguished the invention sufficiently from prior art, whether the language is sufficiently clear to describe the invention to others skilled in the art, and whether the claim language is sufficiently precise to delineate the invention claimed. Most applications lead to exchanges between the examiner and the inventor, and subsequently to amended claims. In cases of ultimate rejection, many applicants appeal—requiring the appellate body to reconsider each of the examiner's decisions.

Pre- and post-grant challenges raise all of these validity issues once again, though this time in a more balanced environment, where advocates for both views try to persuade the patent office that they are correct. Infringement litigation raises them in yet another contested setting - along with the new set of issues that emerge when comparing an asserted patent claim with an accused product. Hearings to seek compulsory licenses require judgments about both the criticality of the patent in question and the availability of the products that it covers.

Each of these judgments necessarily embodies a certain amount of subjectivity. Subjectivity, in turn, opens the door to inconsistency, incompetence, and even corruption - in effect, raising once again all the issues that make it important for India to complete the modernization of its Patent Office. Though no patent system can eliminate subjectivity altogether, perhaps the overriding implementation issue separating a functioning system from a nonfunctioning one lies in the role of subjective decisionmaking; the less inherent subjectivity, the better the system. The centrality of such consistency played an important role in the U.S. analysis of the early 1980s: it led to both 
the creation of the U.S. Court of Appeals for the Federal Circuit with exclusive appellate jurisdiction in patent cases and a revised set of guidelines for the USPTO.

Minimizing subjectivity in the patent system is no different from minimizing subjectivity anywhere else. It requires clear, stable rules and competent, honest personnel to apply them. These requirements, in turn, lead to two items whose importance cannot be overemphasized: guidelines and training. But guidelines and training can also be cumbersome and expensive. Once again, then, the consideration of these issues returns the analysis to the question of effective versus lackluster implementation. And once again, that analysis will point to the same answer that it did in assessing the need for modernization - and for all of the same reasons. India can only realize its full potential for growth and leadership if it creates a responsible, predictable legal environment. A business environment rife with subjectivity and corruption may invite certain types of growth, but it will do little to promote the development of India's human capital. Guidelines and training are indispensable if India's patent system is to contribute to such an environment. In the absence of clear guidelines and well-trained personnel, the system will fail, no matter what else India may invest in crafting a functioning system. All other considerations are therefore secondary.

\subsubsection{Guidelines}

There are positive indications on both the guidelines and training fronts, but significant work remains. India's Patent Office issued a new Manual of Patent Practice and Procedure in 2005, providing helpful definitions and useful guidance for both examiners and practitioners. ${ }^{78}$ In May 2006 the Department of Industry and Trade Promotion promulgated a set of rules, adding numerous technical requirements and levels of detail to the stark statutory framework. ${ }^{79}$ According to Secretary Dua, work is reportedly under way on even more detailed guidelines.

Such developments are positive. As work toward full-blown detailed guidelines proceeds, however, it is important to emphasize that the guidelines must detail not only sound procedures, but also techniques to minimize substantive subjectivity and discretion. Sound guidelines must strive to achieve three broad objectives. They must provide clear tests and references to help minimize subjectivity. They must outline procedures that are realistic given both current and projected staffing levels. And they must motivate compliance by both individual and institutional government actors. Though there may be significant numbers of talented Indians capable of drafting such regulations, international assistance can prove invaluable. Countries in the developed world have spent decades refining their patent guidelines based on empirical experience. The best way for India to benefit from that experience is to enlist foreign input in regulatory design. The best recipient of that advice, in turn, is the policy-oriented think tank described above.

Furthermore, substantive guidelines and the laws that surround them will play a large role in determining the scope and the effectiveness of India's patent system. Guideline development provides an opportunity for the Government of India's policy advisers to address definitional

\footnotetext{
${ }^{78}$ See http://ipindia.nic.in/ipr/patent/manual-2052005.pdf.

${ }^{79}$ See http://ipindia.nic.in/ipr/patent/patent_rules_2006.pdf.
} 
questions. TRIPS obligated India to grant patents that are novel and nonobvious. ${ }^{80}$ TRIPS does not, however, mandate a specific definition or a precise determinative test for either term. India's guidelines can help determine whether every invention embodying even a soupçon of novelty is patentable, or a significant inventive step is required to meet the requisite threshold.

Guidelines and their subsequent legal development will allow India to circumscribe the class of inventions eligible for Indian patents - a class that may or may not correspond to the class of inventions eligible for patents in other countries. Policy inputs from the proposed think tank will prove invaluable in determining which classes of patentable inventions will best promote the sorts of innovative activities most likely to propel India's economic and scientific growth. Clear guidelines will ensure that India's patent examiners and controllers - not to mention the Intellectual Property Appeals Board (IPAB) and judiciary - adhere to the policy that the government adopts.

Recommendation 5: Solicit recommendations from the proposed think tank about the class of patents most likely to serve India's needs. Draft a detailed set of substantive and procedural guidelines for the Patent Office oriented toward that class. In the procedural section, delineate all procedures in which the Patent Office engages, including but not limited to examination, reexamination, pre-grant challenges, post-grant challenges, appeals to the IPAB, and petitions for compulsory licenses. In the substantive section, include tests and standards for determining patentability, novelty, nonobviousness, differentiation from prior art, disclosure, and any other issues related to validity. Focus on clear tests that minimize discretion.

Recommendation 6: Accompany the guidelines with a workbook, or catalog of illustrations, drawn from a variety of disciplines, taken from foreign experiences. In this catalog, explain why rejected applications failed the relevant test, why granted applications passed it, and where (if anywhere) Indian law would lead to a different result. Make the guidelines and illustrations available to the public to align expectations and discussions of applicants, prosecutors, and examiners. Elicit the assistance of foreign experts-likely those with experience drafting such guidelines, prosecuting and examining patents, and administering patent systems - to improve product quality and speed completion.

Recommendation 7: Establish a standing expert committee on patent guidelines to consider frequent revisions, amendments, and additions, as part of the new IP policy think tank.

\section{$\underline{4.3 .3}$ Judicial Authority}

The goal of clear substantive regulations is to enforce administrative consistency at the examiner and controller levels. Consistency throughout the rest of the system lies with those who possess judicial authority. Once again, the balance between the requisite levels of administrative and judicial expertise shifts toward the judiciary as patent systems move from examination-based to registration-based.

\footnotetext{
${ }^{80}$ See TRIPS Art. 27.1
} 
Like most countries, India directs IP litigation to courts of general jurisdiction-in India's case, its district courts and High Courts, with ultimate authority vested in the Supreme Court. Over the past few decades a growing number of countries have questioned the efficacy of that approach, and introduced specialized patent courts. Much but not all of this specialization has occurred at the trial level (Box 12).

\section{Box 12 Approaches to IP Litigation around the World ${ }^{81}$}

Many countries treat IP litigation in ways that differ from their treatment of standard commercial disputes. The following list is representative. Numerous other countries take numerous other approaches.

Australia: The Federal Court of Australia, a generalized court, arranges its docket so that specialized IP judges handle IP cases.

Chile: A specialized administrative court in the judicial branch hears appeals from the patent and trademark office.

China: Specialized courts with panels consisting of two technologists and one judge resolve patent cases. A single appellate court in Beijing handles all patent appeals.

Germany: A specialized court hears challenges to patent validity.

Japan: Specialized IP divisions of the national court system, in Tokyo and Osaka, hear patent disputes. Judges typically hire Patent Office personnel as technical advisers.

Panama: Recently introduced specialized trial and appellate courts for IP disputes.

Peru: An administrative review board hears cases related to IP, antitrust, and consumer protection.

Philippines: Special Commercial Courts handle IP cases.

Republic of Korea: The IP Office runs the independent and specialized IP Tribunal, though general trial courts can still resolve selected patent issues.

Singapore: A specialized court draws on a bench with IP expertise.

Spain: Special "sections" review IP judgments appealed from general commercial courts.

Thailand: A special Intellectual Property and International Trade Court presides over all trade and IP issues.

Turkey: Developing a training program for 12 planned specialized IP tribunals.

United Kingdom: The Patents Court of the English High Court, a specialized court in the Chancery Division, has jurisdiction to hear all IP actions.

United States: Generalized federal trial courts hear patent disputes. A single appellate court in Washington, D.C., hears all appeals.

This trend toward specialized tribunals either for patents specifically or for IP broadly remains controversial. Its proponents point to the unusual factual and technological complexity inherent in virtually every patent case and in increasing numbers of copyright cases. In their view a specialized court, staffed with technically trained judges immersed in IP law, can provide litigants with levels of factual understanding typically unavailable among the legally trained jurists who sit on general jurisdiction courts. This argument seems particularly compelling in pure patent registration systems, where the lack of substantive examination requires a detailed judicial inquiry into the technical propriety of the patent's validity under national law. In such cases the specialized bench effectively replaces the specialized administrative agency.

Nevertheless, and even in the absence of a full-blown examination, opponents of judicial specialization point to the possibility of "agency capture" and the undesirability of divorcing patent and IP law from more general legal principles. As they see it, specialized courts risk treating patent law as their proprietary domain, and may develop legal principles incompatible with the rest of the nation's legal system and business environment.

${ }^{81}$ See Ryan Goldstein, "Specialized IP Trial Courts Around the World," 16 International Law 1 (North Carolina Bar Association International Law Section, Sept. 2006). 
The United States has attempted a middle ground, and one to which India should pay close attention given the structural similarities between the U.S. and Indian federal court systems. The USPTO grants patents only after a full examination; as a matter of statutory law, all patents granted are presumed valid. ${ }^{82}$ Patent trials then occur at the general jurisdiction courts that hear all civil litigation, where litigants are free to raise a full range of validity concerns, but the burden falls on defendants seeking to disprove validity. Appeals of those trials then go to a court of special jurisdiction - the United States Court of Appeals for the Federal Circuit-whose docket is heavily, but not entirely, patent cases. The United States instituted this arrangement in 1982 to avoid the problem of "circuit splits," in which federal courts in different parts of the country applied different legal rules to questions of patent law, complicating reasonable business planning and investments in innovation and commercialization.

India has not yet engaged the question of general versus special patent courts. The government should solicit advice from the proposed think tank about the relationship among patent registration systems, patent examination systems, and the propriety of specialized tribunals and appellate bodies before deciding on the relative merits of different judicial configurations. When conducting this inquiry, India's policy advisers should note that India, like the United States but unlike most other countries, must confront the issue of "splits" in federal law. Inconsistency and uncertainty about legal definitions in Indian patent law constructs can prove as damaging to India's attempts to promote innovation and commercialization as they did to the U.S. system prior to the Federal Circuit.

Several observations are possible even before establishing the proposed think tank and charging it to conduct such an inquiry. As noted, India has never had much patent litigation, but it does have a long history of copyright and trademark litigation. In these areas, India's general jurisdiction courts appear to have functioned well. But international experience suggests that though patent litigation bears many similarities to copyright litigation, it also raises enough unique issues to warrant unique treatment. India's current treatment of patent disputes as standard civil litigation suggests the need for significant thought on this issue. In the final analysis, India may decide against instituting special procedures for patent litigation. But given the international trend in the other direction, any country opting to treat patent disputes precisely as it treats other civil litigation should do so because it determines that judicial specialization is inappropriate — not as a simple default mechanism.

An inquiry into the propriety of specialized patent litigation procedures in India may conclude that India's new, TRIPS-compliant patent system is too young to warrant a full-blown specialized trial court system. Because India does not yet know how much patent litigation to expect, it cannot know how large its patent dispute tribunal should be-or where to place these tribunals geographically throughout the world's seventh largest country. The complexity of the new statutory provisions means that few Indians understand it. The lack of suitable guidelines

\footnotetext{
${ }^{82}$ U.S. courts interpret that presumption of validity to place a high burden of proof on defendants contesting patent validity. Many observers of U.S. IP law have begun to criticize that approach. The U.S. Federal Trade Commission, for example, recently recommended that the courts lower the burden considerably — demonstrating yet again the flexibility inherent even within a TRIPS-compliant patent system. See Federal Trade Commission, To Promote Innovation: The Proper Balance of Competition and Patent Law and Policy at 8 (October 2003).
} 
hampering examiner training will similarly hamper judicial training. And even under the best of circumstances - and in countries with well-developed patent systems and ample experience with patent litigation - the array of people who possess both a suitable legal background and a suitable technical background is limited.

In short, even if India decided that it wanted to join the ranks of countries with specialized patent tribunals, it would face a staffing and logistical nightmare. Furthermore, the arguments against severing patent law from general civil law are particularly strong in the case of a new patent system. It thus appears that India may best be served by embedding its patent trials within its general jurisdiction courts - at least until empirical evidence detects a problem with that approach.

At the appellate level, however, the structural similarities between the U.S. and Indian federal court systems suggest that India, like the United States, should benefit from the middle ground of a semi-specialized appellate court. As currently configured, appeals from a Controller's decision go to the newly empowered Intellectual Property Appeals Board (IPAB), whose panels draw from both a judicial bench and a technical bench. IPAB decisions appear to be final, with no recourse available to the judiciary should a party wish to appeal further. The IPAB, an administrative body, therefore has final say over all decisions on patent grants or rejections, preand post-grant challenges, and compulsory licensing.

Meanwhile, infringement litigation will follow a standard civil suit path through the courts, with appellate authority vested in the High Courts and ultimately in the Supreme Court. As noted, however, the structure of the Indian national court system is not conducive to imposing consistency. Each state maintains its own High Court, bound only by its own precedents and rulings of the Supreme Court - not by the rulings of other High Courts. This configuration can and does lead to splits among the High Courts - situations where a single national law is subject to different interpretations in different states.

In many settings such splits are beneficial despite the inconsistency and unfairness. Numerous judges write opinions on their views of the appropriate interpretation, and all such views inform the Supreme Court's ultimate reconciliation and ruling. But in some settings the costs of inconsistency outweigh the benefits of diverse opinions. Empirical evidence has shown that patents are one such area of the law; this problem of appellate inconsistency was precisely the motivation behind the U.S. decision to create its Court of Appeals for the Federal Circuit.

Splits in patent law will lead to differing interpretations of both validity and infringement. Patent prosecutors and examiners will not know which rules to apply when preparing and reviewing patent applications because they will not know which courts may review their work and what rules will govern those reviews. Innovators will have weak expectations because the rules governing their patents will remain in doubt until a plaintiff selects a venue for litigation. Inevitably, some courts will develop pro-patent reputations and others anti-patent reputations. Litigants may race to seek favorable forums when jurisdiction is proper in more than one state's courts. And Supreme Court reconciliations will occur too infrequently to guide the system. 
In the absence of a single appellate court with national jurisdiction, consistency in patent law is unlikely. India needs to rethink its appellate procedures and consider developing a nationwide court whose status, prestige, and personnel parallel those of the well-respected High Courts. One solution would be to follow the U.S. lead, and establish a new High Court with nationwide jurisdiction and a permanent bench. A variation on that theme would staff that new nationwide High Court with a bench drawn from existing High Courts, on a rotating basis, for terms likely lasting two or three years. This approach would not only help promote consistency, but would also help promote patent awareness and understanding throughout the country. But whether the Government of India opts for this route or not, international experience has shown that judicial consistency is a prerequisite for an effective patent system. India must begin exploring the best ways for it to achieve this goal. Once again, this is an appropriate analysis for an IP policyoriented think tank to undertake.

Recommendation 8: Charge the new think tank with exploring the interrelationships among registration systems, examination systems, and specialized tribunals, and with crafting recommendations to ensure that India chooses a judicial configuration for patent litigation consistent with its administrative decisions on the evaluation of patent applications.

Recommendation 9: Charge the new think tank with investigating the best ways to promote juridical consistency in patent laws. Explore the practicality and desirability of creating specialized patent tribunals. Consider forming a new High Court with exclusive nationwide jurisdiction to hear appeals in all patent cases, and possibly judicial review of the IPAB. Consider the relative merits of a permanent bench, and a bench staffed with judges from existing High Courts, rotated onto the new High Court for Patents, in staggered terms.

\section{$\underline{4.3 .4}$ Enforcement}

Indian IP law includes several types of relief for infringement, whether of patents, copyrights, or trademarks. In all three cases, courts can enjoin further infringement, order infringing products impounded, or order a losing defendant to pay damages. ${ }^{83}$ Though patent litigation has been rare, India's courts and enforcers have ample experience with copyright and trademark infringement.

But according to many observers, defendants frequently evade court-awarded remedies. This situation is reportedly at its worst with impoundment and seizure orders. Police and customs agents reportedly often find it difficult to identify infringing items, and are reluctant to seize them even when a prevailing plaintiff provides the necessary identification. Needless to say, poor enforcement can destroy the efficacy of even the best IP system. If IPR holders cannot trust the authorities to enforce even hard-won legal victories, the system will lose all credibility — and perhaps more to the point, it will lose all ability to motivate. India needs to improve its enforcement record to the point that potential innovators believe that the public will respect their IPRs - whether voluntarily or for fear of official enforcement.

The enforcement of IPRs, and of court orders relating to IPRs, is not really an issue of either IP policy or law. It is primarily a matter of government organization and civil service

\footnotetext{
${ }^{83}$ See Shankar, supra n. 56 at 77.
} 
administration. Customs agents and police are likely to show the same levels of integrity and competence in IPR enforcement as they do when enforcing other areas of the law. As a result it is hard to identify concrete steps that could improve IP enforcement that do not relate to enforcement more generally-with one notable exception. To the extent that the complexity of IP law and the difficulty of identifying infringing products degrade enforcement to a level lower than that demonstrated in other areas of the law, improved training promises to correct the situation. With appropriate training, IP enforcement should reach the same levels of professionalism as other aspects of legal enforcement in India.

Recommendation 10: Identify the extent to which enforcement of court-ordered IP remedies may fall short of general enforcement standards. Provide suitable training for customs and police personnel engaged in enforcing IPR orders. Emphasize the importance of professionalism, integrity, and objectivity.

\subsubsection{Training}

Clear and substantive regulations, a unified appellate path, and professional enforcement are necessary prerequisites for a consistent, predictable patent system. But they are not sufficient. An effective patent system also requires trained, competent professionals at all levels, in both the public and private sectors: appellate judges, trial judges, litigators, controllers, examiners, prosecutors, and enforcers. The recent and rapid pace of change in India's thinking about patents - not to mention IP more broadly — essentially guarantees that there can be no more than a small number of well-trained personnel in the country. Education campaigns have raised general awareness, but they are inadequate for providing the detailed, specific training that professionals require.

The shortage of trained examiners, in particular, already makes procedural problems all but inevitable. Promises of fast-track examinations and rapid turnaround times may be incompatible with current workloads. For example, according to S.K. Roy, Assistant Controller of Patents and Designs, fewer than 50 patent examiners now review about 15,000 applications a year cutting across all areas of technology in the New Delhi Patent Office. Those numbers imply that the average examiner receives more than one new application each workday - rendering any hope of a uniform, rapid turnaround unachievable. The system can only work if staffing levels increaseand new hires with inadequate training threaten to make matters worse, rather than better. Clearly, rapid, large-scale training programs and exercises are needed.

The private sector may provide some help, but its interests tend to be too narrow to address the full range of systemic needs. Over the past five years some Indian research firms and law firms have begun to build IP capabilities to receive outsourced work from clients in the developed world. Evalueserve, a leader in this area, employed about 135 professionals in its IP group as of May 2006, mostly engineers and doctors. According to the company, that staff is growing quickly. ${ }^{84}$ Such companies provide their own training, rapidly teaching their professionals the skills needed to draft patents to the standards required for foreign patent filings-including filings at the USPTO and under the PCT, as well as the research, valuation, and advising skills

\footnotetext{
${ }^{84}$ See www.evalueserve.com.
} 
necessary to serve a worldwide clientele. Japan's Patent Office has also reportedly launched a program to train Indian industrialists in the best ways to obtain and enforce patents and IP licenses. ${ }^{85}$

Over time these training programs will build a cadre of patent-savvy, technically trained professionals. Of more direct relevance to the current training needs of the public sector patent system, the experience that the private sector has amassed at curriculum design and training should spill over to help address the broader needs of a public sector curriculum. The government should enlist the support and assistance of these entrepreneurial Indian companies.

Government training programs, however, will have to cover a broader range of issues that do those tailored to the private sector. Broad patent training needs to address not only the drafting, searching, researching, and advising concerns that animate the private sector, but also the entire procedural and substantive underpinnings of the patent system. Examiners in particular need to know what tests to apply to determine the basic criteria of patentability - and how to apply them. In other words, examiners need to internalize the pending guidelines. Unfortunately, the dual needs of regulations and training lead to a chicken-and-egg problem. India needs trained, experienced professionals to draft its regulations. Yet sound regulations are a prerequisite for curriculum development at training institutes. The need to break out of this cycle once again emphasizes the importance of soliciting foreign support in drafting the regulations.

International support and domestic resources will both be critical to improving training. Currently, training and related coursework occurs at the Intellectual Property Training Institute (IPTI) in Nagpur. ${ }^{86}$ Though IPTI may form the core of a new training system, the recent statutory changes, pending regulations, and acknowledged orders-of-magnitude growth expected throughout the IP system indicate that new curricular and institutional approaches are neededas is a rapid scaling up of training efforts.

India is reportedly already enlisting international support in upgrading its training capabilities. According to Secretary Dua, both the World Intellectual Property Organization (WIPO) and Planck Institute have contributed advice and assistance. Still, India does not appear to be fully availing itself of available opportunities. Excellent training programs in national and international patent law exist around the world, in both government-run facilities and at law schools. In addition, many business schools teach strategies for converting IP assets into revenue streams. India should leverage the experiences of these faculties to develop an appropriate program. It should also institute an exchange program to rotate faculty from these institutions to India as visiting faculty members.

At least one specific proposal that the government has already begun to explore suggests that some key players recognize the magnitude of the necessary training task and have identified steps likely to make it succeed. This proposal is to develop two training centers: an expanded

\footnotetext{
${ }^{85}$ The Hindu, "Japan to Train Indian in Patent Rights," September 6, 2006, http://www.hindu.com/2006/09/06/stories/2006090618490500.htm.

${ }^{86}$ See http://www.patentoffice.nic.in/ipr/pis/ipti_trg.htm.
} 
IPTI to serve as a broadly based staff training college and a new, higher-level Intellectual Property Management Institute (IPMI) to train judges and managers. ${ }^{87}$

The new IPTI will solicit international support to develop curriculums and provide at least large parts of the initial faculty. It will emphasize the regulations and rules that examiners, controllers, and enforcers need to follow, and that prosecutors need to understand to draft patents. Its initial charter will also look into the goals of technical modernization that the patent system is undergoing, such as full automation of patent applications and prior art searches. Once the modernization is complete, this new incarnation of IPTI will look for opportunities to expand international collaboration through cross-linked search engines and databases.

The more advanced IPMI will combine high-level training with research capabilities. It will provide legal training to judges and lawyers, and management training to public and private actors who need to understand the licensing and leveraging strategies that can help them convert patents into revenues. It will also provide sector-specific training to interested personnel drawn from all levels of the patent system, conduct research on IP law for government and industry sponsors, and explore international collaboration on higher-level issues. Once in place, it may be worthwhile to consider using the new IPMI as a permanent host institution for the IP policy think tank. Again, international support will be critical to launch such an institute quickly and effectively.

This two-track approach to training is sound. It is unclear, however, how close it is to becoming a reality. It is critical that the government develop a realistic plan capable of launching both institutes, with sound curriculums and initial faculties, as soon as possible.

Recommendation 11: Implement the current government plan to upgrade IPTI into a full-blown staff training college as soon as possible. Draw on international experts for both curriculum development and the initial faculty, as necessary. Design the curriculum for staff, namely examiners and enforcers, but encourage private practitioners to enroll as well.

Recommendation 12: Adopt the current government proposal to launch a management-oriented education and research facility as soon as possible. Focus its curriculum on issues related to patent exploitation -licensing, negotiating, and litigating to convert patents into revenue streams. Draw on faculty from foreign law and business schools for curriculum design and initial faculty. Maintain a constant flow of visiting foreign faculty to build competence, reputation, and international prestige. Consider using this institute as a permanent institutional home for the policy-oriented think tank.

\footnotetext{
${ }^{87}$ The following discussion is based on notes taken during a meeting with Secretary Dua, and on extrapolations from those notes. Secretary Dua did not provide all the details discussed in the text.
} 


\section{Incentives and Motivation}

\subsection{Society and Its Innovators}

Appropriate regulations and new training institutes will add flesh to the skeletal statutory infrastructure. With these in place, India will have a consistent patent system capable of generating business expectations as reliable as those anywhere else. It will have clear rules, a single line of rulemaking, and trained personnel capable of applying and enforcing those rules. The proposed think tank will also give the government a steady stream of policy advice from independent advisers monitoring both the performance of India's patent system at achieving its proclaimed policy goals and global trends in IP scholarship, policy, implementation, administration, adjudication, and enforcement.

The next set of questions must therefore address the incentives in play and the extent to which they will motivate the target audience-India's innovators - to enter the system. At the examiner and enforcer level, the challenge is clear: civil service systems that set realistic performance goals, reward success, and penalize failure are most likely to yield successful regulatory systems. The challenges of devising such incentives are well known. Perhaps the only thing that might make them easier to implement in the patent context than elsewhere is the rapid change that the patent system is undergoing; entrenched interests may be fewer and weaker in the patent community than in other parts of Indian society. Nevertheless, these are essentially questions of government organization rather than of IP, and the government should consider them primarily within that context.

Thus the remaining questions relate to the incentives that India plans to offer its innovators, how innovators will perceive those offers, and the behavior they are likely to exhibit in terms of investing their capital, time, and effort in innovative pursuits in response. In particular, it is important to look at the incentives for key participants in India's economy: MNCs and large Indian companies, SMEs and individual inventors, research institutes and universities, and poor people and possessors of traditional knowledge. Each of these groups plays different roles in India's economy and innovation system, each responds to distinct motivators, each has a different level of understanding of how to conceptualize, use, and integrate IP, and each warrants consideration.

\subsection{The Private Sector}

\subsubsection{Multinational Corporations and Large Indian Companies}

India's private sector contributors to the knowledge economy fall into two categories subject to two sets of motivating factors: MNCs and large domestic companies, and SMEs and individual inventors. The situation of MNCs and large Indian companies is the more straightforward. These companies own the overwhelming majority of Indian patents held by the private sector, and are responsible for the vast majority of Indian patent applications (many filed simultaneously in jurisdictions around the world; see Table 4). 
Few of these patents generate revenues in India, and few are subject to active licensing campaigns. Most Indian patents that large corporations hold play a primarily defensive role in their portfolios; they seek the patents to preclude anyone else from obtaining them and to prevent potential litigation in India. India can expect defensive patenting to increase as its patent system matures. In many industries, particularly software and electronics, defensive portfolios and crosslicensing have become the dominant practices of large MNCs, and thus the primary strategic use of their IP portfolios.

From India's perspective, these patents confer both costs and benefits (beyond the obvious administrative costs inherent in having granted them). Their costs are immediate: they allow the patentees to monopolize protected products, potentially curtailing supply and raising price. This situation would persist even if the large companies chose to pursue licensing programs: Though such licenses might increase supply, the added costs that producers must bear to pay licensing fees will necessarily emerge as higher prices for consumers. The costs of these patents are thus the standard costs always associated with patents: they can lead to higher prices on new products. The standard benefits also accrue: these patents will lead to more new products. In the case of MNCs' defensive patent portfolios, however, India gains another benefit. MNCs who feel protected under Indian law are more likely to invest in India-including investments in experimentation, innovation, and R\&D, with the consequent impact on education and employment.

Without any further development of incentives, India's mere willingness to grant MNCs these patents makes it easier to attract FDI - specifically, high-quality FDI directed toward innovation. Because India's track record at providing this type of protection to MNCs was rather poor until fairly recently, and because the few remaining policy issues relate primarily to the sorts of innovations in pharmaceuticals, therapeutics, and chemicals in which only MNCs excel, many MNCs undoubtedly remain wary of launching innovative ventures or locating their research facilities in India. Such wariness will take time to dissipate. India's main task is to build confidence among MNCs by rigorously enforcing its new laws. When it comes to this class of economic actors, the Indian patent system is already set to function, and it appears likely to work even better if and when the government invests the resources needed to complete the modernization and automation of its Patent Office, develop clear guidelines that reduce subjectivity, and upgrade its training and enforcement programs.

\subsubsection{Small and Medium-size Enterprises and Individual Inventors}

For SMEs and individual inventors, the current situation is neither as settled nor as encouraging. Domestic filing fees represent a hurdle for most individuals, and international filing fees are a significant deterrent. According to key Patent Office personnel, the Patent Office recently came under significant political pressure to reduce filing fees to levels that even individual inventors can bear. This sort of blanket reduction may warrant reconsideration. Filing fees should provide most, if not all, of the Patent Office's operating budget - as they do in the United States and elsewhere. At the same time, it is hardly a bad idea to set fees high enough to deter frivolous filings capable of draining Patent Office resources. There is thus no reason to reduce filing fees for MNCs and large corporations capable of bearing their fair share of funding a Patent Office whose services benefit their businesses. SME reductions or subsidies promise a far superior mix 
of affordability and revenue generation, and are likely to lead to a better-functioning - not to mention self-sufficient—patent system.

Beyond filing fees, some countries also charge patentees significant maintenance fees. These fees represent an attempt to ensure that only commercially viable patents retain exclusive rights, while all others enter the public domain quickly — where innovators other than the original patentee may discover ways to use them to generate private and public value. Some observers of patent systems have suggested that widespread adoption of high maintenance fees would improve the global innovation pool without sacrificing much of the patent system's motivation. The proposed think tank should consider the implications of an Indian policy requiring such patent maintenance fees. And given the goal of ensuring that only genuinely valuable patents remain in private hands, there is no clear reason to subsidize these fees for individuals or SMEs.

Of greater significance to the private sector's perception of incentives than fees, though, is the recent shift of India's successful awareness campaign beyond general patent awareness to licensing, litigation, and revenue generation. These issues are hardly afterthoughts; they are central to the patent system's ability to achieve its goal of promoting innovation. Licensing is the primary way that patentees without their own production facilities can convert their patents into money. The primary reason that licensors take licenses is the implicit (or explicit) threat of infringement litigation. In the absence of a culture promoting licensing and litigation, the patent system will not funnel economic rewards to patentees - and in the absence of economic motivation, few individuals or SMEs will invest the resources needed to seek patents.

This situation thus highlights the need for a private sector education and awareness campaign focused on licensing and litigation. The programs proposed for IPMI are a start, but they are not enough. Expansions of the PFC's seminars and programs are critical. Lessons and anecdotes from abroad - particularly from developed countries with longstanding patent systems — need to be brought into India. As in most such cases, the only way to effect cultural change is through education. Fortunately, the desirability of leveraging patents into revenues is the sort of lesson that people learn easily. A few successful high-profile licensing programs, and a few high-profile lawsuits, are likely to energize a business community already aware of patents and the patent system. The current challenge is simply to get the process started - and make the appropriate educational opportunities available. Though the proposed think tank should certainly study private sector attitudes toward India's IP system, there do not seem to be pressing policy inquiries in this area.

Recommendation 13: Charge the proposed think tank with exploring the ramifications of both two-tier filing fee structures and maintenance fees designed to limit the ability of underused patents to impede progress.

Recommendation 14: Promote patenting and patent exploitation among individual inventors and SMEs. Consider government-sponsored or subsidized loan programs and patent prosecution clinics to facilitate foreign applications. Direct the awareness campaign to emphasize the importance of licensing and litigation. Sponsor seminars on licensing strategies. Circulate publications relating successful SME and individual licensing programs, initially from abroad, and subsequently as they arise in India. 


\subsection{The Public Sector}

\subsubsection{The Evolving Mission}

The next important category of actors is the public sector, or more specifically the portions of the public sector involved in research - namely, government research institutes and universities. (Though much of the discussion also applies to private universities and to other participants in India's nonprofit sector.) These contributors to India's innovation system pose special challenges and warrant considerable attention.

Universities and research institutes are significant players in the Indian patent system - CSIR, as noted, possesses the largest portfolio of Indian patents. Many patents in public sector portfolios have helped serve important public sector objectives. But it is not clear how many have also served the goals that differentiate patents from other mechanisms for disseminating information: rewarding innovative individuals and their employers, and motivating competitors and colleagues to invest in innovation.

This critical unanswered question lies at the heart of the aforementioned transition that CSIR and PFC will have to undertake as the mission of India's patent evangelists evolves from promoting general awareness of IPRs to promoting specific understanding of the ways to leverage IPRs to generate revenues. India's universities and research institutes thus play two distinct and complementary roles in the patent system: they are important sources of innovation in their own right, and they are educators of the private sector. If they are to succeed at continuing to patent or at motivating the private sector, they will have to think and to talk like members of the private sector - the primary audience for the behavior that governments grant IPRs to motivate.

That transition will not come naturally, and it may not even come easily. Many of the same cultural attitudes that have impeded licensing by MNCs, large Indian companies, SMEs, and individual inventors appear to have inhibited the full exploitation of institutionally owned patents. Revenue generating mechanisms like patent licenses, patent sales, and commercial spinoffs provide incentives for institutional technology transfer programs, collaboration between industry and academia, and a culture conducive to entrepreneurship. In the absence of such revenues, patents become little more than a new form of scholarly publication.

If India's innovators, particularly its public sector innovators, fail to see benefits in patenting that they could not accrue with equal ease through publication, they will publish rather than patent, limiting the effectiveness of India's patent system. It is essential that scientists at universities and research institutes commit time to patenting, and that the universities and institutes commit to technology transfer-exploiting those patents by collaborating with companies capable of turning them into marketable products.

At the moment nothing (other than perhaps the novelty of the patent system and pride in patenting) motivates any such behavior. India's leading patent-savvy institutions must ensure that they present patenting in a manner that allows individual innovators to appreciate the potential personal payoffs that the patent system offers, as well the broad societal payoffs. Once again, this challenge will require CSIR in particular to rethink a successful strategy; as the nature of the task changes, so will the metrics for success. 
CSIR - and by all indications, the rest of India's impressive research institutes and universitiestypically elevates the social dimensions of patenting above the commercial dimensions. Such a focus is unlikely to motivate individual innovators appropriately. To appreciate the difference between a social and a commercial focus, consider once again the achievements of CSIR's constituent labs. The brief descriptions that CSIR's R.K. Gupta provided highlighted the points of which CSIR is proudest. ${ }^{88}$ But these descriptions left many questions open-precisely the questions that individual innovators would ask (Box 13).

\footnotetext{
Box 13 Key Questions about Individual Motivation

For public sector innovators:

- Would these achievements generate revenues flowing to my host institution?

- Is there a mechanism that will allow my institution to use these revenues to augment existing programs?

- Can my institution use these revenues to enhance my area of inquiry?

- Will my institution share these revenues with me?

For private sector innovators:

- Would my investment in comparable research have yielded profits significant enough to warrant the investment?

Affirmative answers to questions of this sort provide the motivation necessary for India's patent system to become an effective contributor to global innovation.
}

\section{$\underline{\text { 5.3.2 }}$ Rethinking CSIR's Success}

Most questions about individual motivation make sense only within a context of general patent awareness. India's leading patent institutions have spent the past decade building that awareness. A quick review of CSIR's achievements - and perhaps more significantly, of how it presents its achievement - can illustrate the ways that the next decade's focus must differ from that of the successful awareness campaign. ${ }^{89}$

As its first noteworthy achievement, CSIR described the primary benefit of IMTECH's process patent on STPase as a reduction in drug prices achieved through sole-source licensing. But was this important contribution to society achieved through the research or the patent? Suppose that IMTECH's scientists had published their STPase results rather than patenting them. That publication would have put the technology in the public domain; by entering the prior art, it would have precluded any third party from patenting it, and all pharmaceutical companies would have gained access to it. Because the technology was a process improvement that reduced the costs of drug production, any company selling a drug to which the process was applicable would presumably have adopted it. Widespread efficiency increases in a potentially competitive market would have led to even lower prices than those today. The social objective would have been better served without incurring the public expense of patenting or the negotiations to find a licensing partner.

\footnotetext{
${ }^{88}$ See Box 6 and Gupta, supra n. 49.

${ }^{89} \mathrm{Id}$.
} 
Now suppose that a private research corporation, rather than CSIR, had developed and patented the result in question. Its next task would have been to find a licensing partner. Because the new technology represented an efficiency increase, companies engaged in relevant drug production would have been willing to pay royalties as long as their post-improvement, post-royalty production costs fell below their prior production costs. They would then have reflected this costs reduction in some combination of price reductions and increased profits - though quite possibly entirely in increased profits. Had this scenario prevailed, the private sector would see that patented $R \& D$ can lead to increased profits. The public may or may not have benefited from price reductions.

But CSIR seems to have chosen a middle ground - at least in its presentation, if not its actions. It did not take the steps necessary to guarantee minimum price reductions; those steps would have precluded patenting. At the same time, there is no indication that it worked to maximize its royalties, or used the consequent revenue stream in a way that motivated the contributing scientists to continue patenting. As a result, the private sector may have gained some motivation and the public may enjoy lower prices, but neither effect is as strong as it could have been. This middle ground may have represented a conscious choice, and that choice may have been the most appropriate one given the needs spread throughout the different strata of Indian society. Nevertheless, from the perspective of educating innovators about the personal and commercial benefits of patenting, a revenue maximization drive would have been more effective.

In a second noteworthy success, CSIR reported that the deal between the National Chemical Laboratory (NCL) and General Electric (GE) secured \$8.5 million in funding for NCL over the past decade, earned six patents for GE, injected competition into a previously monopolized product market, and earned NCL about $\$ 1$ million in royalties. The revenue-generating process patent certainly sounds like an appropriate use of the patent system, but the broader issue of the overall NCL-GE deal is hard to understand without a bit more information. GE's average annual investment of $\$ 850,000$ is a pittance. What does it buy GE? If the exchange is that GE receives exclusive — or even preferential — patent rights to the lab's developments, the deal seems hopelessly one-sided. Has GE really received a half-dozen issued patents in a decade? Are any of them valuable? What has GE done with these patents? Though CSIR may know the answers to these and related questions, its use of portfolio size as a success metric stops the story too soon, and its focus on social objectives seems to view this public-private partnership as an end in and of itself. Thus, although the licensing fees represent a legitimate success story, the question remains: how is CSIR (or NCL) using these revenues to motivate either its own scientists or their private sector colleagues to focus on applied, commercializable research? Perhaps there is an answer, but again, CSIR seems to elevate well-deserved pride in having created competition and lowered prices over viewing the patent system as a mechanism for motivating private investors to compete toward achieving these same social objectives.

This deal also suggests another interesting question. Various U.S. research institutes and universities have entered into quasi-cross-licensing agreements with MNCs. Under these agreements the MNCs grant the institutions the use of their entire portfolios for research purposes. In return, the institutions grant the MNCs a right of first refusal to partner with them on all potential commercialization projects to emerge from institutional research within a defined scope of invention. Is the NCL-GE deal such a deal? If not, why? CSIR and its labs need to 
invest greater effort into identifying items of value that they can offer to the private sector-and then negotiate the most favorable terms that they can in return. There is no doubt that GE's cash infusions are valuable. But are they of greater value to a scientific institution than unfettered access to GE's formidable patent portfolio? By thinking like its private partners, CSIR may be able to negotiate deals that will impel its public research mission forward. It is not clear that it is doing so today. And even if it is, its description of the NCL-GE deal illustrates a presentation problem. This deal may represent precisely the sort of story needed to motivate institutional innovation and industrial collaboration. It might be generating revenues that NCL is using to reward its successful innovators and bolster its institutional commitment to their work. But CSIR's discussion of the deal would leave any innovators reading it uninformed about the potential benefits of emulating it.

A third noteworthy accomplishment, NCL's newly patented water purification process,' raises similar questions to those encountered in reconsidering the STPase results and the NCL-GE deal. CSIR cites the social objective of improved health as the primary contribution of the new process. While it is hard to fault a program that increased the availability of clean, safe water in India, it is unclear how patenting helped promote this goal. Why couldn't the process have been put into effect without a patent-saving the public the expense of preparing the patent at CSIR and of examining it at the Patent Office? Without answers to such questions, it is unclear whether or how any private innovators will choose to build on NCL's important work in this area. In other words, if CSIR's reason for patenting is simply to help build an IP-savvy culture, how will it use these patents to motivate private investment?

In two further success stories, CSMCRI's work motivating seaweed cultivation and biodeiseld production sound like they should be a boon to the economies of poor Indian communities - a wonderful achievement for a national laboratory. But it is entirely unclear how patenting the process helped achieve that goal. Again, CSMCRI could have worked with the local governments had it arrived with a publication rather than a patent — and putting that information in the public domain might have spurred private investment as well. It is not clear what patenting accomplished beyond draining public resources, both at CSMCRI to prepare the application and at the Patent Office to examine it.

A sixth presentation of success, CSIR's description of CSMCRI's work on calcium carbonate, raises an interesting issue - namely, foreign patents. The juxtaposition of a U.S. patent and a success metric of environmental improvement and job creation in India seems odd. Because U.S. patents have no legal force in India, there is no reason to believe that it affected local environmental or employment factors in any way. The purpose of obtaining a U.S. patent should have been to license the technology to U.S. companies interested in using it to improve U.S. environmental and employment prospects. Has CSIR engaged in any such licensing? If so, what sorts of revenues have they generated, and how is CSIR using these revenues to motivate CSMCRI's scientists to continue doing patentable research? Once again, CSIR's focus on social objectives seems to stop the story before it reaches its climax.

CSIR's seventh success story, CIMAP's U.S. plant patents, raises similar questions. Their cited benefit lies in catapulting India into a major role in the global mint oil market, and its consequent effect on agricultural improvement in India. Have others outside India attempted to cultivate the 
patented plants? Has CIMAP responded by threatening to litigate? If not, how did the U.S. plant patents help? India could have cultivated these new varieties using only CIMAP instructions or publications. If the patents neither restrain competition in a meaningful way nor generate additional revenues, what do they add?

Finally, CSIR's reports of recent licenses to private companies, ranging from small domestic concerns to MNCs, sound like steps in the right direction. Perhaps in a few years, data capable of measuring success will become available.

Together these cited successes do demonstrate some uses of the patent system capable of motivating private innovators to emulate public innovators. They make it quite clear, however, that CSIR views the social objectives of patenting as primary, and the commercial objectives of patenting as secondary. CSIR's foremost goal remains the development of scientific and technological breakthroughs that serve the broad interests of the Indian public, not the development of marketable, revenue-generating products. Such a goal is highly appropriate for a premier national research laboratory. But it is problematic for a nation's premier patent shop.

The Government of India must determine whether this tension is inherent in the governance of its research labs, its universities, or both — and if so, what to do about it. In a mixed economy, the private sector is supposed to focus on profits, while public institutions focus on societal objectives that may or may not have profit potential - and in a truly successful mixed economy, public institutions will evacuate spaces that promise profitability, leaving competitive market forces to produce superior returns on smaller public investments. In other words, as long as CSIR continues to perform well at the task for which the government founded it and continues to fund it, its ability to demonstrate the patent system's full commercial potential may remain limited. The private sector will invest in researching and developing patentable innovations when it sees that patents can generate increased profits. Private investment is no more likely to chase an example of large public sector patent portfolios than it is to chase an example of large publication portfolios.

\section{$\underline{5.3 .3}$ Rethinking University Success}

CSIR is hardly unique in elevating the social benefits of IP above the commercial benefits. In many ways this prioritization is endemic to public sector thinking. A comparison of the stated IP policies of two engineering-oriented universities - a public Indian institution and a private U.S. institution - shows a stark contrast in emphases and attitudes. Boxes 14 and 15 present the mission statements for the IP policies of IIT Kharagpur and Carnegie Mellon University, respectively.

In simple terms, IIT Kharagpur sees IP as but one tool that it can use to achieve its broad social goals. It recognizes the potential for commercialization and revenue, but treats them almost as an afterthought. The primary purpose of its IP policy statement is to protect the institute and its commitment to the public. 


\section{Box 14 IIT Kharagpur's Intellectual Property Policy ${ }^{90}$}

The goals of the institute's intellectual property policy are to:

- Promote academic freedom and safeguard the IP interests of all those involved in the creation of IP at the institute.

- Further develop the environment, and enhance incentives, for R\&D, the discovery of new knowledge, and innovation, compatible with the institute's educational mission.

- Set and make available a policy for disseminating the institute's IP for commercial use, so that such use imparts the benefits of IP to the public while safeguarding the interests of the creators or licensees of such property, and in the process generates revenue for the institute and the creators.

- Set up and maintain an office that provides services to employees and students for effective commercial use of IP generated at the institute in the interests of all concerned, and oversee the fair distribution of the returns accruing from them in accordance with the policy and its amendments.

- Provide legal support as the institute deems necessary to defend and protect the interests of the institute and creators of IP against unauthorized use of such property.

\section{Box 15 Carnegie Mellon University's Intellectual Property Policy ${ }^{91}$}

The university's intellectual property policy aims to:

- Create a university environment that encourages the generation of new knowledge by faculty, staff, and students.

- Facilitate wide transfer of useful inventions and writings to society.

- Motivate the development and dissemination of IP by providing appropriate financial rewards to creators and the university, and administrative assistance to creators.

- Ensure that financial returns from the development of IP do not distort decisions and operations of the university in ways contrary to its mission.

The policy is based on the following principles relating the university to society:

- The mission of the university remains the generation and dissemination of knowledge.

- IP will be generated within the university, and there is an obligation to disseminate it. An interface is needed if better technology transfer is to be achieved, and the university will provide mechanisms to do so.

The policy is based on the following principles relating faculty, staff, and students to the university:

- IP is created by individuals, or groups of individuals, who are entitled to choose the course of disclosure. Academic freedom of individuals is a higher priority than possible financial rewards.

- There is a historical tradition allowing authors to retain ownership of IPRs from textbooks and works of art.

- The university supports the whole campus community, and so is entitled to share in financial rewards.

- There should be incentives for all parties to pursue financial rewards together, consistent with the expressed goals of the policy. The distribution of these rewards should reflect, insofar as possible, the creative contributions of the creator and the resources contributed by and risks assumed by both the creator and the university in developing IP.

- Since it is often difficult to meaningfully assess risks, resources and potential rewards, negotiated agreements are to be encouraged whenever possible.

Carnegie Mellon, on the other hand, views commercialization as a unique part of its contribution to society. It recognizes that the potential for financial rewards are central to commercialization. The primary purpose of its IP policy is to strike a balance between the short-term individual and societal benefits inherent in technology transfer and commercialization and the long-term

\footnotetext{
${ }^{90}$ Indian Institute of Technology Kharagpur, Intellectual Property Policy at 5-6.

${ }^{91} \mathrm{http} / / / \mathrm{www} . \mathrm{cmu}$. edu/policies/documents/IntellProp.html.
} 
benefits that traditional noncommercial academic research also confers on society, the university, and its individual investigators. Anyone reading the Carnegie Mellon policy would understand immediately how IPRs differ from traditional scholarly publications. Anyone reading the IIT Kharagpur policy would conclude that there is little difference between them.

The presentation choices of CSIR and IIT Kharagpur likely reflect a belief that public sector patents are useful primarily to the extent that they serve the same social objectives as do other government programs, and that occasional commercial spillovers and financial rewards are welcome side effects, but hardly central to their systemic purpose. This attitude reiterates a basic mismatch between public sector and private sector goals - a mismatch in no sense unique to India. National research institutes exist to serve the public. To the extent that government researchers can use their results to promote national or regional employment, education, or environmental concerns, they are succeeding at their mission. By all indications, CSIR and many of its laboratories are models of successful public sector research institutions. Perhaps the greatest relevant question that they must now answer is whether they can absorb enough private sector thinking to lead India's patent system to its next level of effectiveness without compromising the public sector goals at which they excel.

The patent system, like public research laboratories, exists to benefit the public. The internal mechanisms that it employs to do so, however, differ radically from those at play in public sector institutions. The patent system's sole objective is to motivate private investment in practical, commercializable research. Market dynamics and competition fill out the equation to ensure that new products reach the public quickly, that new knowledge reaches competitors who may be able to work around almost as quickly, and that prices decline when patents expire.

Patenting can promote employment growth by motivating private companies to build industries. It can improve the environment by motivating companies fielding competing green technologies to compete for business. It can improve education by placing new technological information into the public domain, even while the commercial exploitation of that information remains proprietary. What the patent system cannot do, however, is guarantee that any of these socially beneficial objectives will unfold when, where, and how the government might wish. At its heart, a government decision to embrace a robust patent regime represents a relinquishment of government control over innovation to the marketplace. It is a vote of confidence in liberal markets.

Universities and research institutes thus play a complex, multifaceted role in India's patent system. They are significant sources of patentable research whose policies must motivate responsible patenting. They are fonts of education and leaders by example for India's SMEs and individual innovators. They are anchors of a national technology transfer systems, and partners of private innovators. And they are public sector institutions charged, as are all public sector institutions, with serving broad societal goals.

The Government of India needs to ensure that its universities and research institutes operate within governing structures amenable to serving all these important roles. With appropriate institutional governance structures in place, positive cultural changes can begin. As things stand, however, India appears to be facing a mismatch between the goals, objectives, and incentives that animate its premier research institutions and those that it would like its patent system to 
achieve - a mismatch that India must correct as these institutions reorient themselves from promoting patent awareness to promoting patent understanding.

Recommendation 15: Charge the proposed think tank with reviewing institutional governance at India's leading research institutions. Have the policy advisers work with institutional representatives to propose governance reforms capable of leading to cultural changes. Challenge institutional representatives to lead the cultural shift by rethinking their IP programs, how they measure success, and how they describe their achievements.

\subsection{Relating the Public Sector to the Private Sector}

\subsubsection{The U.S. Experience and the Bayh-Dole Act}

The mismatch between institutional culture and institutional goals is hardly unique unto India. A similar situation persisted in the United States throughout the 1970s. The U.S. remedy began with the 1980 Bayh-Dole Act, a legislated change to the IP laws that let public and private universities and research institutions retain IPRs on patentable innovations devised partly or wholly with government-funded research. The remedy progressed as those institutions internalized the new incentive structure and devised ways to integrate aspects of private sector thinking into their public sector or nonprofit sector mentalities. Many of the most successful integrators took a step that was controversial at the time, but that appears obvious in retrospect: they created independent companies and charged them with leveraging institutional patent portfolios to maximum effect — often by licensing, sometimes by selling patents, and at times by spinning off startup companies.

According to unofficial sources, there is significant interest in crafting Indian legislation analogous to Bayh-Dole. India is not the first country to see Bayh-Dole as critical to U.S. industrial successes since 1980. According to a 2002 report by the Organisation for Economic Co-operation and Development:

Emulating a policy change in the United States [Bayh-Dole], several OECD countries...introduced new legislation or implemented new policy measures in the late 1990s to clarify and make more coherent the policies toward ownership and exploitation of academic inventions and other creative works. The main focus of the legal and policy changes has been to grant PROs [public research organizations] title over the IP...The basis for this is that ownership by PROs...provides greater legal certainty, lowers transaction costs, and fosters more formal and efficient channels for technology transfer. ${ }^{92}$

In assessing these attempts to replicate U.S. success at university technology transfer across the developed world, however, Professors David Mowery and Bhaven Sampat contended that these emulation initiatives grew from a misunderstanding of the role that Bayh-Dole played within broader university culture and institutional structure. They concluded that "given the very different institutional landscape in the national higher education systems of much of Western

${ }^{92}$ OECD, Benchmarking Science-Industry Relationships (OECD, 2002). 
Europe and Japan, it seems likely that the 'emulation' of Bayh-Dole that has been discussed or implemented in many of these economies is far from sufficient to trigger significant growth in academic patenting and licensing or university-industry technology transfer." ${ }^{93}$

India's institutional landscape, and not just in its higher education system, likely differs from that of the United States to at least as large a degree as do those of the OECD countries that Professors Mowery and Sampat studied. The Government of India should thus spend at least as much time considering changes to institutional governance and culture as they do changes to legislation. Its policy advisers should, for example, contemplate creating fully competitive private sector concerns to manage the patent portfolios of India's research institutions. In thinking through the goals of promoting a successful Indian innovation system, both ideas warrant consideration. An analysis of the challenges currently facing India, however, indicates that India most needs a policy that achieves the same goals as Bayh-Dole, rather than a statute that attempts to achieve them in the same way.

The U.S. Congress was quite clear about the policies that it wanted the Bayh-Dole Act to further. Box 16 presents those policy goals as they are currently enshrined in U.S. law. The act's remaining provisions (as amended) define terms, add specificity, delineate exceptions, and note interactions with other bodies of law.

\section{Box 16 The Policy Objective that the U.S. Congress Sought with the Bayh-Dole Act ${ }^{94}$}

It is the policy and objective of the Congress to use the patent system to promote the utilization of inventions arising from federally supported research or development; to encourage maximum participation of small business firms in federally supported research and development efforts; to promote collaboration between commercial concerns and nonprofit organizations, including universities; to ensure that inventions made by nonprofit organizations and small business firms are used in a manner to promote free competition and enterprise without unduly encumbering future research and discovery; to promote the commercialization and public availability of inventions made in the United States by United States industry and labor; to ensure that the Government obtains sufficient rights in federally supported inventions to meet the needs of the Government and protect the public against nonuse or unreasonable use of inventions; and to minimize the costs of administering policies in this area.

India can and should share Bayh-Dole's policy objectives. Even a quick comparison of the U.S. situation circa 1980 and India's situation today, however, shows why a direct Bayh-Dole analog would not help India harness the power latent in its patent system. In the late 1970s the United States saw itself as leading the world in research but lagging in commercialization. Many observers noted that the incentive structure at prominent U.S. universities rewarded research, but not commercialization. Excellence in research led to promotion and professional advancement for individual professors and to prestige and government-funded grants for their institutions. Efforts toward commercialization generated none of these benefits - and at times even led to dismissal and disgrace, particularly when junior members of the faculty attempted them.

At that time, U.S. patent policy considered government research funds as the price that the public paid to obtain government research. U.S. patent law reflected that policy by prohibiting individual academics and academic institutions from patenting discoveries funded, even in part,

${ }^{93}$ David Mowery and Bhaven Sampat, "The Bayh-Dole Act of 1980 and University-Industry Technology Transfer: A Model for Other OECD Governments?" 30 The Journal of Technology Transfer 115 (2005).

9435 U.S.C. $§ 200$. 
by government grants. As a result no one in academia had much incentive to push discoveries out of their labs and into commercial development. Most academics viewed collaboration with industry as a diversion of time and a reduction in prestige for both individual faculty members and their institutions. Even worse, some of them misconstrued the patenting of academic innovation as an unfair enrichment of select corporations at the expense of the broad public.

This approach was clearly understimulating innovation. The legal assumption that the public was already paying for research in the form of grants was correct, but empirical evidence indicated that the U.S. public was paying too little to obtain useful, marketable commercialization of these innovations. (India faced a similar problem of understimulation between 1970 and 1995, when its patent system offered to pay innovators with exclusive rights that few of those innovators deemed large enough to warrant investment.) The Bayh-Dole Act increased the price to the public by allowing universities - public and private - to seek, obtain, and hold patents on research funded partly or wholly with government grant money. Patent holding, in turn, created significant opportunities for revenue generation, including patent sales, licensing fees, industrial collaboration, and enforcement litigation.

By most accounts the Bayh-Dole Act was enormously successful at achieving its goalsmotivating U.S. universities to actively engage in the technology transfer process. By letting universities retain patent rights, the legislation motivated them to devise new ways to do two things: encourage their faculty to think about the patentability of their innovations, and then to seek patents; and encourage industry to collaborate with academics on rapid commercialization.

These two changes helped motivate a third significant cultural change - namely, the rise of an entrepreneurial class on campus, whose professors and students went on to develop startup businesses. The many industrial parks that now appear near major U.S. universities-not to mention the numerous startups that powered the dot com bubble - are visible signs of these cultural changes. Both were quite rare before Bayh-Dole. A more direct and immediate consequence, however, was the rise of something else that had once been rare: the university patent licensing corporation.

Professors Mowery and Sampat, along with their colleagues Professors Richard Nelson and Arvids Ziedonis, prepared a book-length analysis of the role that Bayh-Dole has played in promoting technology transfer programs in the United States. ${ }^{95}$ They emphasized that many of the cultural predicates for successful technology transfer programs predated Bayh-Dole by more than a century. In fact, some universities established patenting programs and licensing corporations decades before Bayh-Dole - even though their activity was limited to nonsponsored research.

Their analysis combines empirical data from across the U.S. university system with anecdotes and case studies, including detailed studies at three major universities with active patenting programs: Stanford and the University of California, Berkeley (whose patenting programs predated Bayh-Dole) and Columbia (which developed its program in response to Bay-Dole). Box 17 presents their summary of the most important aspects of university patenting license

\footnotetext{
${ }^{95}$ See Mowery and others, supra n. 31.
} 
programs. Of perhaps even greater significance than their summary, however, is their overall conclusion:

We believe that much of the current discussion of the economic role of U.S. research universities and the contributions of U.S. universities to the economic boom of the 1990s exaggerates the role of Bayh-Dole. In fact, U.S. universities have been important sources of knowledge and other key inputs for industrial innovation throughout the twentieth century, and much of this economic contribution has relied on channels other than patenting and licensing... ${ }^{96}$ Our assessment of the Bayh-Dole Act emphasizes the role and responsibilities of universities, as well as those of public policymakers. U.S. universities must exercise considerable responsibility and political sensitivity in managing their intellectual property. ${ }^{97}$

\footnotetext{
Box 17 Advice on Developing Licensing Policies for Institutional Intellectual Property ${ }^{98}$

A critical first step in developing an institutional patenting and licensing policy is recognizing the tradeoffs among various legitimate objectives, including but not restricted to licensing revenues, maintenance or expansion of industrial research support, regional economic development, faculty retention, and technology commercialization.
}

Some policies seek to maximize licensing revenues despite the risk to relationships with corporate licensees who provide research support. Others eschew maximal revenues in favor of retaining faculty through revenue-sharing formulas or preferences for faculty-founded startups, or emphasizing regional economic development objectives.

Institutions must recognize that academic research flows to industrial application through a variety of channels, including the movement of faculty, students, and researchers between academia and industry, the publication of research articles, appearances by faculty and university researchers at conferences, and faculty consulting. All these channels are important and complementary.

Licensing revenues are a legitimate objective of licensing policy, but the limited profitability of technology licensing for most U.S. universities suggests that an exclusive emphasis on royalties at the expense of other goals is ill advised.

\section{$\underline{5.4 .2}$ India Today}

India's policymakers must be at least as attuned to the cultural and institutional barriers to a successful technology transfer program as they are to legal barriers. University licensing corporations, which inject private sector thinking into public and nonprofit institutions, can play an important role in helping those institutions negotiate deals that serve both public and private interests. The United States has hardly been alone in grasping the potential contribution that university patent licensing corporations can make both to their host institutions and to society at large. As Table 4 shows, Canada's University Technologies International (UTI) was the $45^{\text {th }}$ most active applicant for Indian patents between 1995 and 2005; its 149 applications place it just ahead of Dr. Reddy's. UTI's Website opens with a statement emphasizing the centrality of commercialization to its objectives:

\footnotetext{
${ }^{96} \mathrm{Id}$. at 179.

${ }^{97}$ Id. at 192.

${ }^{98} I d$. at $188-89$.
} 
UTI is dedicated to the pursuit of excellence in technology commercialization, creating business opportunities from scientific innovation. We are recognized internationally for our expertise and success in protecting, marketing and commercializing technology and innovation. Part of the University of Calgary, UTI was launched June 1, 1989, with a mandate to provide services on all matters related to technology transfer and commercialization. UTI serves a wide variety of research-based clients in post-secondary institutions, government research laboratories, industrial research and development installations, and private facilities. ${ }^{99}$

Again, this sort of self-image and understanding of mission contrasts starkly with the social objectives that CSIR, IIT Kharagpur, and other Indian research institutes and universities place at the fore of their IP objectives - and thus in the message that they convey to a public still uneducated in the motivational aspects of patent revenues.

Given that background and the history of success both in and beyond the United States, it is not surprising that India is interested in a Bayh-Dole analog. But the facts suggest that such legislation is unnecessary at this point, particularly if the analogy is construed narrowly. The reformed U.S. patent system worked not because it embodied inherently good ideas, but because it addressed specific problems inhibiting the development of U.S. technology industries. India should be asking itself questions similar to those that motivated the Bayh-Dole Act - not necessarily arriving at similar answers. And the central element of India's queries must be how the United States and other countries developed the mechanisms that allowed them to turn BayhDole from mere legislation into powerful institutions.

Perhaps the most critical relevant differences between the United States in 1980 (before BayhDole) and India today are that U.S. patent law prohibited patenting developments derived using government research funds, but U.S. norms for institutional governance at both public and private universities permitted numerous forms of contracting and collaborating with the private sector. Current Indian law permits public sector patenting, but the governing cultures and mechanisms of India's institutions complicate many of the steps needed if they are to excel at revenue generation, technology transfer, and full-blown collaboration with the private sector. India today is thus much closer to a functioning technology transfer system that was the United States in 1980 as a matter of statute - but may be further away as matters of institutional governance and institutional culture.

When it comes to public patenting, for example, the Ministry of Science and Technology and the Department of Ocean Development have adopted guidelines developed by CSIR and PFC for technology transfer and IPRs (Box 18). ${ }^{100}$ Like the Bayh-Dole Act, these guidelines explicitly encourage funded institutions to seek IPRs - and have allowed CSIR to amass its impressive patent portfolio. If India's lawmakers construe Bayh-Dole narrowly and craft legislation closely analogous to it, they will effectively be trying to solve the problem of insufficiently motivated institutional patentees (and potential patentees) by removing a nonexistent barrier.

\footnotetext{
${ }^{99}$ http://www.uti.ca/.

${ }^{100}$ See "Instructions for Technology Transfer and Intellectual Property Rights," Patent Facilitation Center.
} 


\section{Box 18 CSIR and PFC Guidelines for Institutional Patent Licensing ${ }^{10}$}

The current CSIR and PFC guidelines contain many important elements that future guidelines, regulations, or legislation should preserve. They:

- $\quad$ Encourage universities and research institutes to patent all patentable discoveries.

- Allow public institutions and private firms that develop patentable innovations jointly to own the patents jointly.

- Encourage public institutions to share patent revenues with individual inventors, but do not mandate a specific formula for that sharing.

- $\quad$ Require public institutions to set aside a portion of royalty revenues to maintain internal systems for updating innovation, filing new patent applications, litigating, licensing, and building IP awareness and competence.

- Require public institutions to provide detailed information about all patented innovations to the agency that funded the underlying research.

- Grant the Government of India a royalty free license.

Any future guidelines, regulations, or legislation should also consider another provision that neither these guidelines nor the Bayh-Dole Act incorporate:

- A portion of royalties that a public institution receives from patents derived through public research grants should flow back to a national public innovation fund to fund future research.

Though the CSIR and PFC guidelines are generally excellent, it is not clear how much money any institution or any innovator employed at an Indian research institution has earned subject to their terms. As a result their ability to motivate the sorts of behavior that they were designed to encourage remains limited. The underlying problem is that universities and institutes are not typical corporations, and professors and researchers are not typical employees. Even motivators that impel innovative research and commercialization in the private sector require at least some reassessment when the organizations in question lie in the public, academic, or nonprofit sectors.

Government-run institutes and universities receive both their funding and their obligations from the government. By all accounts, they lack the resources necessary to file patents, establish IP offices, train personnel in patenting, draft licensing programs, and negotiate partnerships with corporate collaborators. All these tasks require upfront resource commitments in exchange for promises of future revenues. In the absence of discretionary funds and authority, universities and institutes cannot undertake them. And without guaranteed retention of patent revenues in a way that does not imperil their other funding sources, they have no reason to want to undertake them.

These cultural and institutional characteristics, rather than any peculiarity of patent law, are the fundamental hurdles to Indian industry-academia collaboration, technology transfer programs, and ultimately the sorts of cultural environments that lead to industrial parks, incubators, startup clusters, and campus entrepreneurs. Furthermore, the absence of revenues flowing to the institutions means that they have nothing to share with individual innovators. These hurdles thus leave both institutional scientists and their host institutions with inadequate incentives to transfer technology from their laboratories to industry - and in turn, inadequate incentives to direct their research toward innovations likely to generate industrial growth, jobs, or consumer benefits.

\footnotetext{
${ }^{101}$ See id.
} 
Because a large part of this problem lies in institutional governance, changes to patent laws can have only a limited effect. Nevertheless, it is important to align institutional incentives with the goals of the patent system. Though legislation directly analogous to Bayh-Dole appears misplaced in this context, another way that India's situation today differs from the U.S. situation circa 1980 suggests that a related bit of legislation might nevertheless be warranted. In India individual ministries, departments, and agencies maintain significant autonomy. Thus, at any point in time, some or all ministries could decide to retain claims to all inventions to which they contributed funding - or to dedicate all such inventions to the public, rendering them unpatentable. Such decisions could have significant effects on India's overall innovation system. To the extent that legislation can remove discretionary rebalancing from individual ministries and embed it in a national policy preference, such legislation would serve a positive role.

The CSIR and PFC guidelines currently in force at some ministries provide an excellent starting point for such legislation (see Box 18). The proposed think tank should pay particularly close attention to the last point in Box 18-namely, diverting some revenues into a public research fund. Much as Bayh-Dole arose to counter inadequate motivation arising from a public price of grant money but no patent rights, it is possible that India's motivation arising from the public price of grant money plus full patent rights is too high.

In contemplating such legislation, the government must determine whether a reduced public price of research finding plus partial patent rights might be just as effective at motivating innovation. Should India choose to enact relevant legislation, it should ensure that it motivates both individual researchers and their host institutions to generate and transfer cutting-edge innovation into the Indian (and global) marketplace.

At least some of the proposals currently circulating try to do too much. They attempt to specify the nature of the relationships among the players, effectively substituting government fiat for private negotiations. Any such restrictions are bad ideas - in many ways worse than the absence of legislation. The framework for any such legislation should remain nonbinding. It should do what appears necessary to encourage participation, while leaving the specifics of each relationship as subjects for individual negotiations.

\section{$\underline{5.4 .3}$ Institutional Evolution}

The key to allowing India's front-line public institutions to evolve beyond their successful awareness campaign of the past decade to become equally successful at their current challenge of promoting patent understanding and technology transfer lies in a cultural transformation. Institutions need to look in the mirror to see what they possess that might be of value to the private sector. When they do, they will discover that the answer is, quite a lot.

India's research institutions employ many educated, talented individuals capable of deriving new results to fundamental technical problems, both large and small. India's institutions also own and manage laboratories that enable research, have reputations that can add prestige to many ventures, campuses that can incubate and house small and early-stage ventures, alumni networks and faculty contacts, and various other attributes that have helped make them successful. All these assets confer value on contractors and collaborators. 
At the same time, private parties - large and small, foreign and domestic - also possess valuable attributes. They can inject commercial inventiveness and the profit motive into institutions where a planned, statist mindset still dominates. They can justify absorbing risks on technology transfer ventures and commercialization drives that might not work. SMEs and individual innovators can inculcate a staid research institute with new ideas and insights unlikely to have arisen at academia's typical glacial pace. MNCs and large domestic corporations can share their innovations, insights, and IPRs with colleagues on campus. In short, there is ample room for synergy between India's premier public research institutions and the private sector. The challenge now is to develop a culture that nurtures those synergies.

Much as Bayh-Dole created a legal environment that permitted such a cultural shift in the United States, so too India must now ensure that neither statutory nor governance issues preclude the emergence of an entrepreneurial spirit on campus. Universities and research labs must be free to negotiate flexible deals with potential partners in the private sector; only such flexibility will allow them to determine what works well and what does not.

The NCL-GE deal described above is an excellent example of the sort of deal that could expand. Has NCL granted GE a right of first refusal on commercializing its discoveries? Has GE granted NCL the right to experiment with the technologies in GE's prodigious patent portfolio? Have they developed scholar exchanges, so that NCL's scientists can experience work at GE's worldclass facilities (including, but not restricted to, GE's research facility in Bangalore)? Do they have revenue-sharing agreements in place? What rewards flow to the individual NCL investigators who develop innovations that GE commercializes?

These are the sorts of questions that India's universities and research institutes must explore. The key is cultural. To the extent that statutes interfere with these analyses, corrective legislation is warranted. To the extent that governance issues preclude implementing the answers to these questions, the government must consider institutional governance reform. If India really wants to use its world-class research institutions to help promote commercial development, entrepreneurship, and job growth, it will have to inculcate the appropriate culture at these institutions. Governance reform may prove critical. These institutions need the flexibility to negotiate appropriate deals, see a direct benefit from successful deals, and allow rewards to flow directly to their most successful innovators.

Changes to the patent laws can provide only a partial solution. Legal reform is but a starting point for cultural change. Governance structures dictating an institution's ability to retain income, negotiate deals with the private sector, and establish industrial parks, incubators, patent licensing corporations, and startup clusters must provide the rest of the solution.

India must eliminate any institutional governance issues that preclude the formation of patent licensing corporations to manage public sector patents. Those corporations must operate under private sector incentives, with funds flowing back to the laboratories and individuals whose work contributes the most to revenues. As the U.S. experience demonstrates, a certain amount of detachment between the public and private sectors is necessary for a patent system to leverage public sector research to maximum commercial effect. And as the liberal market orientation of 
patent systems promises, leveraging that research to maximum commercial effect will also maximize social benefits.

The proposed IP policy think tank should launch inquiries into all these issues. In many ways the cultural attitudes of India's premier research institutions are the most important determinants of the shape that India's IP system will assume and the ways that IPRs, in turn, will help shape India's economic, industrial, and technological future. The challenge at this point is to take institutions that have been hugely successful at one task and retailor them to become equally successful at a different task. The policy analyses required are complex and the stakes enormous. The discussion above merely outlines the inquiries that the government's policy advisers must undertake.

Recommendation 16: Consider legislation requiring all government agencies issuing research grants to motivate universities, research institutes, and their individual researchers to seek and exploit patents, and to engage in technology transfer programs with industrial concerns. Such legislation should encourage institutional patenting, encourage royalty sharing with individual inventors but not mandate specific relationships between institutions and individuals, encouraging institutional and industrial collaborations, encourage the growth of internal IP offices, mandate information sharing and royalty-free government licenses, and reserve a specified portion of revenue flows to a new government innovation fund dedicated to promoting future research.

Recommendation 17: Examine the institutional governance issues surrounding the incorporation of profit-driven analyses into India's research institutions or the transfer of direct management of public sector patent portfolios to patent licensing corporations. Introduce a competitive tension whereby some elements of the labs push for publication and dedication of knowledge to the public domain to achieve specific social goals, and other elements-led by the new patent licensing corporations-motivate research on commercially promising technologies. Ensure that enough of the revenues from the new corporations flow back to the labs and individual inventors to motivate continued attention to technology transfer. Consider floating at least partial ownership of the patent licensing corporations on public markets to impose the sort of governance discipline impossible in a government-owned corporation.

\section{Traditional Knowledge}

\subsection{The Challenge}

The typically poor possessors of traditional knowledge present some of the greatest challenges to understanding how a patent system can motivate socially beneficial behavior in all strata of society. How can India bring the benefits of IPRs to its poor citizens living traditional lifestyles? Recall that IPRs promote growth by leveraging ideas and knowledge into securities, securities into capital, capital into investments, and investments into growth. India's traditional communities may possess considerable knowledge unknown to modern industry, much of which retains at least potential commercial value in the modern world. How can the Government of India help these communities and their members attain the sorts of growth that IPRs generate? 
Can India's policy advisers craft a new IPR - a new set of rights capable of applying the sorts of leverage to traditional knowledge that patents, copyrights, and other existing IPRs apply to contemporary science, technology, art, and expression?

Complicating the question even further is a point that goes beyond mere semantics. Any concept of "innovation" that included traditional knowledge would stretch the word's definition beyond any recognizable meaning. Perhaps as a result, historical patent law precepts have never addressed traditional knowledge in any meaningful way other than to regard it as part of the world of "prior art." Part of crafting a new IPR involves parsing an undifferentiated mass of "traditional" knowledge into individual knowledge "items" worthy of leveraging through an IPR.

Any attempt to craft an IPR for traditional knowledge will require revolutionary thinking and bold experimentation in both legislation and administration. It will also require a new sense of clarity and purpose among those dedicated to its realization. Advocates of traditional knowledge and its practitioners often embrace two distinct goals: protection and compensation. Unfortunately, these goals are in diametric opposition. Protection of traditional knowledge usually means retaining it as the sole property of its practitioners and their apprentices, ensuring that it continues to pass to future generations, denying MNCs the rights to obtain patents built on it, and generally removing it from the commercial domain. Compensation for traditional knowledge usually means promoting its commercial potential, pushing it into broad public awareness, encouraging the private sector to build on it, and permitting the patenting of improvements on it subject to some form of quasi-license that directs a fair share of commercial profits back to the communities who provided the foundational knowledge.

Protection of traditional knowledge, if successful, will preserve traditional lifestyles but do little to alleviate poverty or improve prospects for the integration of future generations of practitioners with the modern economy. Compensation schemes, on the other hand, risk sacrificing control of traditional knowledge in ways that could destabilize communities, but that could generate significant revenues for poverty abatement and educational improvement. In blunt terms, those seeking to protect traditional knowledge wish to preserve communities by reducing the integration prospects of their members. Those seeking compensation wish to empower individuals at the risk of community disintegration. Any country prepared to contemplate the revolutionary legislation and administration necessary to bring traditional knowledge into its IP system must choose - explicitly and unequivocally_-between these goals.

A single concrete example - albeit one akin to copyright concerns rather than patent issuesshould crystallize the potential chasm separating protection and compensation. ${ }^{102}$ A Morning Star Pole is traditional knowledge shared among members of the Galpu clan, a community in northeastern Australia. Members of the clan learn how to design these poles in initiation and revelation ceremonies. One clan member designed a specific pole, copyrighted its design, and sold the right to display it on a commemorative bank note to the Reserve Bank of Australia. The clan sued to enjoin the note, claiming that the design was clan property and that the individual

\footnotetext{
102 See Anil Gupta, "Rewarding Traditional Knowledge and Contemporary Grassroots Creativity: The Role of Intellectual Property Protection," Draft paper presented at a seminar at the Kennedy School, Harvard University, Boston, MA, May 2000, following the treatment of Michael Blakeney (Ed.), 1999, Intellectual Property Aspects of Ethnobiology, London: Sweet \& Maxwell.
} 
artist lacked the authority to permit its use in this culturally offensive matter. The trial judge sympathized with the clan, but nevertheless ruled against it because "Australia's copyright law does not provide adequate recognition of aboriginal community claims to regulate the reproduction and use of verbs which are essentially communal in origin." 103

Should IP law contain such provisions? To those striving to protect traditional knowledge, the answer is obvious: of course it should! This ruling was a calamity! The Galpu clan lost all control over its traditional knowledge, to the point of seeing it misused in a manner that the clan considered culturally offensive. To those striving to compensate holders of traditional knowledge, the matter is not as simple. One artist chose to share traditional knowledge with the world - and in return, received (presumably fair) compensation. The critical question is whether or not he owed part or all of that compensation to the clan. In other words, from a protection perspective, the question is not control, but rather possession of rights to a revenue stream.

While some might find this attitude cavalier, it is important to recall that IP law does not provide anyone with the ability to regulate the reproduction and use of its symbols. Crosses, stars of David, and national flags are subject to rampant culturally offensive treatment - often with the specific intent of offending those who hold them sacred. Nontraditional communities have only a limited arsenal with which to combat such offenses, and IP law is not part of it. The message here is instructive. Advocates for traditional knowledge and its possessors must recognize that the law will never afford possessors of traditional knowledge the rights that possessors of analogous nontraditional knowledge lack. In much the same way that nontraditional knowledge is only "protected" as long as it remains secret, so too the law can protect traditional knowledge only as long as it is secret. Once the world learns the secret-however it does so- the sole remaining questions concern compensation. Is any required? If so, how much, and to whom?

A pragmatic view thus suggests that true protection is unlikely to work. Commercially valuable secrets are notoriously difficult to preserve. Corporations that have done so successfully have developed complex, and often expensive, procedures. Nothing comparable is possible with traditional knowledge. As with any such secrets, the protection will evaporate as soon as someone capable of exploiting the commercial potential discovers them.

This situation is precisely the one that has prevailed for centuries - and the one against which traditional-knowledge advocates typically campaign. MNCs that learn traditional secrets patent them primarily because their status as prior art is undocumented. But were such documentation available, the traditional knowledge would no longer be secret-and someone would undoubtedly exploit it commercially, albeit without patent protection. Furthermore, the very basis of IPRs, and the characteristic unifying all branches of IP law, is the public's willingness to trade competitive advantage for increased knowledge. Because secrecy of any sort runs counter to that public-private bargain, society rarely if ever grants IPRs to those who keep their knowledge secret. At best, trade secret law respects their privacy and protects them against espionage and theft. As a result, if India wishes to lead the world in addressing the IP inherent in traditional knowledge, it must begin by adopting the goal of compensation explicitly and unequivocally.

\footnotetext{
${ }^{103}$ Yumbulul v. Reserve Bank of Australia (1991), 2 Intellectual Property Reports 481 at 490.
} 


\subsection{Toward an IPR for Traditional Knowledge}

Anyone contemplating the development of an IPR for traditional knowledge must bear in mind two thoughts: traditional knowledge is no more monolithic than is any other form of knowledge, and an IPR for it must make sense within the context of the overall analytic framework for assessing IP reform proposals.

On the first point, just as IP law provides the different sets of rights embodied in patent, copyright, and trademark laws to different types of innovators, so too will different forms of IPRs for traditional knowledge address the needs of those possessing traditional practical, decorative, and geographic knowledge. Because almost everything in this study has addressed India's nascent patent system, its discussion of IPRs for traditional knowledge will address the most closely analogous form of such knowledge - namely, functional traditional knowledge.

Professor Anil Gupta, Executive Vice Chairperson of India's National Innovation Fund (NIF), has articulated the challenge of protecting IPRs for functional traditional knowledge:

The key challenges before the [traditional knowledge] IP planners are: (a) How to provide incentives to local communities and individuals to share their knowledge innovation and practices without the fear of being exploited, (b) how to ensure that the intellectual property rights of the communities as well as individuals are protected through a low transaction cost system available globally in the form of registry like INSTAR [the International Network on Sustainable Technologies Applications and Registration], (c) how to ensure that patent offices in the developed countries do not issue patents on traditional knowledge and/or knowledge obtained either illegally or unethically or both from developing country sources...Protection of traditional knowledge may offer little benefit per se unless the protected traditional knowledge move[s] up the value chain and generates profits, which can then be shared with various stakeholders. The contribution of communities and individuals (not just the tribals, but also other local communities) needs to be understood not only in its functional attributes but also in analogic dimensions... We must recognise the need for developing new instruments, new ethics, and new frameworks for providing real life alternatives to knowledge rich and economically poor people. ${ }^{104}$

On the second point, IPRs for traditional knowledge must make sense within the context of the overall analytic framework for assessing IP reform proposals. India today-like the rest of the world - is part of system that lacks such IPRs. Introducing IPRs for traditional knowledge will both impose administrative costs and increase the restrictions on the use of such knowledge. Is it nevertheless a worthwhile undertaking?

The justification for introducing such a new and controversial category of IPRs should involve more than simply a desire to direct revenues toward poor, traditional communities. Were that the

\footnotetext{
${ }^{104}$ Anil K. Gupta, "Making IPR Regime Responsive to the Needs of Small, Scattered, and Disadvantaged Innovators and Traditional Knowledge Holders: Agenda for Policy and Institutional Change," Presented at the Workshop on Traditional Kowledge, 24 Jan. 2002, London, England.
} 
only benefit in their introduction, India (and the world) might be better served by maintaining the status quo on IPRs and sending increased aid into those communities, whether that aid derived from international donors or domestic taxes. A proper analysis of IPRs for traditional knowledge must therefore justify the system as generating internal benefits in excess of its costs.

To many people the primary benefit seems obvious: possessors of traditional knowledge hold a sort of moral right to their knowledge. Their knowledge, treatment, or craft, honed over generations of oral history and apprenticeship, seem inherent in their identities, and unauthorized use by anyone else would represent a moral wrong. Unfortunately, as visceral as this argument might appear to some, it has no place in either patent law or a liberal market economy. The concept of "moral rights" does exist in continental European copyright law (Box 19). Under French law, for example, an artist maintains an inherent inalienable connection to his or her work, even after deciding to place it in commerce and sell "all" alienable rights. Under this moral right, known as the droite de suite, a living artist continues to receive royalties from all subsequent sales, and maintains certain rights concerning the use of his or her work. Once the artist dies, these rights evaporate; they are no more heritable than alienable.

\section{Box 19 Is an IP System for Traditional Knowledge a Good Idea?}

European copyright law contains a notion of "moral rights" connecting creators to their work. Some people seem to believe that possessors or practitioners of traditional knowledge or crafts possess a similar moral connection. Such a belief about morality, however, cannot lead to a reasonable legal system of IPRs for functional traditional knowledge:

- Even in European copyright law, moral rights connect creators only to specific expressions, never to underlying ideas.

- Moral rights are anti-poor. They transfer revenues from the poorest members of a group to the richest members of that same group. In the case of functional traditional knowledge, moral rights would harm individual practitioners while strengthening the hand of communal or tribal leaders.

- Moral rights in traditional knowledge would give possessors of functional traditional knowledge rights that creators or innovators of analogous nontraditional knowledge lack.

The justification for an IP system for traditional knowledge must arise from the same economic analysis justifying all IP regimes. India should establish such a system only if the benefits to the Indian public of gaining restricted access to a larger knowledge pool exceed the costs of maintaining unfettered access to an ostensibly smaller pool.

The application of such moral rights to a patent context, or by extension to the patent-like system that IPRs for functional traditional knowledge would require, is problematic for several reasons. First, as noted, moral rights are a continental European tradition; much of Indian law derives from Anglo tradition, to which the concept is alien. ${ }^{105}$ Second, and again as noted, moral rights are strictly a copyright concept; they have no place in patent law. The very basis of a moral connection between artist and expression lies in the personal basis of that expression. Moral rights, like copyrights, do not protect an underlying idea. There is simply no comfortable way to transport the concept into patent law or patent-like protection of functional knowledge. Third,

\footnotetext{
${ }^{105}$ Nine U.S. states - including California and New York, the traditional centers of the U.S. arts community-have attempted to incorporate moral rights into their state laws, but they remain alien to federal law, where most copyright issues reside. Most commentators contend that these laws have failed to achieve their ultimate policy objectives of serving artists. See, for example, Landes and Posner, supra n. 9 at 270-75.
} 
economic analyses of moral rights demonstrate that they are decidedly anti-poor. ${ }^{106}$ An artist's inability to alienate all rights in a piece of work reduces the value that he or she can receive for its first sale in exchange for greater future revenues. This shift essentially deprives early-career artists of revenues and rewards late-career artists. Whether the shift is viewed as a rent transfer from today's young artists to today's successful artists or as a shift from today's young artists to that same artist tomorrow (assuming a successful career), the effect is the same: those most likely to need short-term revenues lose, while those least likely to need them gain.

An analogous situation would arise were the world to recognize moral rights in aspects of traditional knowledge. In the Australian case, for example, a moral right would have allowed the Galpu clan to block the bank note, but it also would have made it impossible for the individual artist to leverage his knowledge into a commercial opportunity. These rights would have given a noneconomic entity - the tribal leadership, however configured - a veto over the rights of its members to apply their knowledge and skills in economically productive ways, effectively sacrificing growth and individual advancement to the traditions of the clan. Such a tradeoff may have anthropological merit, but it is bad economics; it would represent the use of IP law to impede growth rather than promote it. By and large, the recognition of such moral rights runs directly counter to the needs of economic development. It is impossible to justify the creation of a new, controversial, administratively expensive, IP system for traditional knowledge simply because it "feels right."

\subsection{Efforts to Date}

The only legitimate justification for an IP system for traditional knowledge lies in the same analysis that underlies all proposed steps to extend the reach of an IP system: the benefits to the Indian public of gaining restricted access to a larger knowledge pool must exceed the costs of maintaining unfettered access to an ostensibly smaller pool. From the perspective of IPRs for functional traditional knowledge, this requirement again points back to the importance of adopting an unambiguous compensatory scheme. Neither India nor the world should reward the possessors of functional traditional knowledge merely for possessing it. Both India and the world should be eager, however, to reward these possessors for sharing their knowledge. In other words, the basis for the proposed IP system for traditional knowledge must parallel the basis of the patent system: Possessors of such knowledge must put it into full public view in exchange for temporary rights, revenues, or both. When that temporary period ends, the knowledge will become part of the global knowledge base, freely appropriable by anyone who grasps it — and no longer subject to anyone's IPRs.

By all indications, the Government of India believes that its villagers, craftsman, and others living traditional lifestyles possess ample functional traditional knowledge that both Indian society and the rest of the world consider not only worth preserving, but also of significant potential commercial value. If that assessment is accurate, the government is justified in investing the time and resources necessary to catalog India's functional traditional knowledge, and in developing a revolutionary new IPR aimed at compensating the possessors of functional traditional knowledge for sharing it with the world. The history of that investment, while

\footnotetext{
106 See id. at 276-80.
} 
interesting in its own right, also demonstrates the allure of crafting a new set of IPRs to protect traditional knowledge.

Work toward this catalog began at least as far back as 1988, with the founding of the Honey Bee Network, ${ }^{107}$ a group of nongovernmental volunteers committed to recognizing and rewarding the innovative ideas and traditional knowledge of India's grassroots individuals and communities. As the Honey Bee Network grew, its members discovered that they needed institutional support. In 1993, they founded another volunteer organization, the Society for Research and Initiatives for Sustainable Technologies and Institutions (SRISTI), to provide financial and institutional backing to the network. SRISTI began to receive research grants from international agencies, and to mobilize worldwide interest in and support for its projects. ${ }^{108}$

The shared major aim of the Honey Bee Network and SRISTI is to transform local innovations and traditional knowledge into viable products for diffusion through commercial and noncommercial channels and by building bridges between formal and informal science and technology. One of the steps toward that goal is the protection of all IPRs latent in traditional knowledge. In theory, then, these organizations fall within the camp of explicit IP compensators: they try to ensure that when a lucrative idea is latent in traditional knowledge, the possessors of that knowledge share in the revenue stream in exchange for disclosing it.

Both organizations have experienced many successes - though almost entirely outside the realm of commercial compensation. During its first 10 years Honey Bee Network volunteers cataloged more than 10,000 innovations and traditional knowledge practices from villages across India. ${ }^{109}$ The network grew in prestige and gained the confidence of many possessors of traditional knowledge willing to share it with the world. At the same time, the network learned an unsurprising lesson: without specific IPRs tailored to functional traditional knowledge, it was able to produce scant revenue to compensate the people whose knowledge comprised its formidable database. As volunteer organizations, the Honey Bee Network and SRISTI could work only within the confines of existing national IP regimes - systems never before applied to traditional knowledge and ill suited to its protection. Nevertheless, the groundwork that these organizations have laid has helped advance the debate on IPRs for traditional knowledge.

The Honey Bee Network's shortcomings in the commercial realm led the Gujarat government to establish the first institutional formalization of the network's activities, the Grassroots Innovation Augmentation Network (GIAN). GIAN set out to find ways to generate income for grassroots innovators. Other states soon followed Gujarat's lead; the current objective is to set up GIANs in every state. Again, though, the absence of IPRs for traditional knowledge doomed GIANs' attempts to turn such knowledge into revenue streams. GIANs have achieved many socially important goals, but they have not accumulated the revenues needed to compensate grassroots innovators for sharing their traditional knowledge with the world.

\footnotetext{
${ }^{107}$ www.sristi.org.

${ }^{108}$ See id.

${ }^{109}$ www.niscair.res.in.
} 
The Government of India began to build on the work that the Honey Bee Network, SRISTI, and GIANs had started when it set up the National Innovation Fund (NIF) in $2000 .{ }^{110}$ NIF is a formal effort to document and recognize grassroots innovations and traditional knowledge. Its home page, mission statement, and statements of goals tell an interesting story. Under the heading "Mandate," NIF provides the following quotation:

[T] he time has come to unleash the creative potential of our scientists and innovators at grassroots level. Only then can we make India truly self-reliant and a leader in sustainable technologies...propose a national foundation for helping innovators all over the country. This fund will build a national register of innovations, mobilize intellectual property protection, set up incubators for converting into viable business opportunities and help in dissemination across the country. ${ }^{111}$

NIF's mission statement translates this mandate into "to help India become an inventive and creative society and a global leader in sustainable technologies without social and economic handicaps affecting evolution and diffusion of green grassroots innovations." ${ }^{112}$ Its Website then lists five goals and six objectives, all focused on the primary social goals of linking India's informal to its formal sector-or more precisely, of formalizing the knowledge latent in "green grassroots innovation." The only mention of anything capable of generating revenues lies in a single phrase, repeated in both the goals and objectives, of promoting "wider social awareness and possible commercial and non-commercial applications of innovations." ${ }^{113}$ Not surprisingly, discussions of its achievements — which are numerous and significant along several social dimensions - make little mention of revenue generation.

The Government of India has also undertaken a more concrete and ambitious project, the Traditional Knowledge Digital Library (TKDL). ${ }^{114}$ The motivation for this project lay in a patent battle waged when the USPTO granted a patent to the University of Mississippi for the healing properties of turmeric, and a similar battle at the European Patent Office over a patent to the U.S. Department of Agriculture protecting the fungicidal properties of neem. Indian practitioners of traditional knowledge had long known of both herbal remedies. The Indian government contributed input to the U.S. and European reexamination processes, and the patent offices canceled both patents. The government then decided to build a computerized database of indigenous knowledge related to medicinal plants to prevent any future attempts at misappropriation through the various national patent systems. According to Secretary Dua, the current catalog reportedly stands at 130,000 items; projections suggest that it will reach 170,000 in the near future.

The government plans to make the entire TKDL available online to patent offices around the world to use as parts of their prior art searches. But the TKDL is a purely defensive measure. Its purpose is to eliminate patenting of traditional knowledge; as currently envisioned, it will neither

\footnotetext{
${ }^{110}$ www.nifindia.org.

111 www.nifindia.org.

$112 \mathrm{http}: / /$ nifindia.or/mission htm.

$113 \mathrm{http}: / /$ nifindia.or/mission_htm.

${ }^{114}$ www.niscair.res.in.
} 
curtail commercial exploitation nor guarantee that the revenues from such exploitation flow to traditional communities.

In many ways this defensive focus mirrors the focus on the social rather than the commercial aspects of IP - though this focus is more likely to be complete in the traditional knowledge context than in the context of the actual patent system. The government may conclude that the likely costs of devising and administering the system - costs that may include strained international relationships - outweigh the benefits of developing an IPR for traditional knowledge. If, to the contrary, the government determines that the benefits are likely to outweigh the costs, it will have to begin by appreciating that crafting an appropriate compensation scheme for traditional knowledge IPRs - a complex undertaking that warrants significant analysis and experimentation. Such a task is tailor-made for the proposed IP policy think tank.

\subsection{Possible System Structures for Traditional Knowledge IPRs}

An appropriate analysis must begin by recognizing that in addition to merely cataloging traditional knowledge, compensation requires that each item specify a source-typically a guild, community, or region rather than an individual. The administrator in charge of the catalog will have to publish reasonable and nondiscriminatory license terms for each item. Conservators will have to collect license fees and use them for specific, defined benefits accruing to the attributed holders of the rights - likely regional development, infrastructure, or education. Enforcers will have to seek stiff penalties from those who infringe on the traditional knowledge. Government negotiators will have to seek international accommodations from both developed countries likely to resist the introduction of traditional knowledge into the IP system and developing countries likely to insist that their citizens, rather than (or in addition to) India's, deserve compensation for the knowledge at issue. Finally, the Government of India, possessors of traditional knowledge, and conservators administering the funds must all recognize that only some of the cataloged knowledge will generate revenue. Much of it, like most patents, will simply bring knowledge to public view without creating either clear commercial opportunities or revenues to the source of that knowledge.

The challenge remains daunting. All the unspecified issues rest on the same sorts of definitional issues that plague other forms of IP, along with some new, sui generis questions: What sorts of ideas qualify as traditional knowledge? What is the definition of a single item? How long should traditional knowledge rights last after publication? How is attribution determined? What principles should guide licensing terms? Who are the conservators? What are their charges? What are the penalties for noncompliance or infringement? What negotiating terms are most likely to maximize widespread adoption of traditional knowledge rights while minimizing conflicts among national traditional knowledge systems? The launch of an IP system for functional traditional knowledge will require an assessment parallel to every basic assessment underlying patent law, as well as determinations of source and stewardship of each protected item (Box 20). 


\section{Box 20 Possible Approaches to Designing an IP System for Traditional Knowledge}

Possibility 1: A direct national traditional knowledge IP system analogous to the patent system. This "equitable" proposal places possessors of traditional and nontraditional knowledge on footing as equal as possible. In addition to calling for a reassessment of all fundamental issues of patent law, however, this proposal raises many new challenges:

- Establishing rules for publishing traditional knowledge to share knowledge with the world.

- Circumscribing classes of ideas that qualify as traditional knowledge.

- Defining an "item" of traditional knowledge.

- Determining the appropriate length for such IPRs, beyond which the published knowledge enters the public domain.

- Identifying a source for each item of traditional knowledge.

- Setting and publishing reasonable and nondiscriminatory licensing terms, including both prices and rights.

- Designating conservators and specifying appropriate outlays for moneys collected.

- Designating enforcers and defining penalties for noncompliance or infringement.

- Drafting international cooperation treaties in the likely event of noncomplying MNCs.

Possibility 2: An international direct traditional knowledge IP system analogous to the patent system. This proposal eases many coordination problems, but risks holding the entire venture hostage to international intransigence.

Possibility 3: A blanket license for a traditional knowledge IPR:

- Reduces the complexity of system administration.

- Eliminates much of the direct incentive for innovation, but may leave enough motivation to spur volunteer and nongovernmental organization (NGO) efforts on collection and cataloging.

- Does not really address challenges inherent in international coordination, enforcement, and distribution.

Possibility 4: Establish a voluntary fund and encourage MNCs to contribute an amount related to the value that they extract from the Traditional Knowledge Digital Library (TKDL):

- Raises problems of free riding and the general limitations of applying moral suasion to business decisions.

- Easier to establish and begin quickly.

- Could lead to larger short-term pools of disbursable money than any of the other alternatives.

- Likely to present the fewest problems of international coordination and participation.

Each of these possibilities, along with various hybrid strategies, presents potential costs and benefits. The Government of India should seek input from trusted advisers on the best ways to leverage its imminent TKDL into an IP system capable of leveraging traditional knowledge into aid for traditional communities.

Though it is possible to suggest answers to all these questions, experimentation and empirical evidence will play central roles in the development of meaningful rights for traditional knowledge. India - as the putative pioneer in this area-must recognize that whatever statutory choices it makes must be subject to constant review and revision.

The triple challenges of complexity, controversy, and transaction costs inherent in crafting IPRs for traditional knowledge have led some commentators - including NIF's Professor Gupta— to advocate international rather than national action. While there may be much wisdom in such prudence, it also risks holding the entire venture hostage to a recalcitrant international community. Though international rights might be preferable to national ones, India must decide what serves its national interests. If unilateral movement will help the practitioners and possessors of traditional knowledge in India, India should move unilaterally. A key part of this 
equation is an appreciation that a successful program launched in India will impel action elsewhere; a failed launch will set things backward.

The government's policy advisers in the proposed think tank should consider these issues before India launches any IP system for traditional knowledge. The best approach may be to proceed on several parallel tracks. The technical questions outlined above are merely the tip of a very large iceberg. A full-blown IP system for functional traditional knowledge must revisit every issue in patent law and devise an analogous provision tailored to such knowledge. Some issues that seemed straightforward in the patent context—such as source or ownership — may become difficult. Some that seemed difficult in the patent world - such as the role of compulsory licenses - may become straightforward. Either way, revisiting them all will take time, and likely delay the launch of a functioning system for at least several years.

The government also may want to consider a less complex mechanism, in the form of blanket licenses. Many MNCs, particularly those in the electronics and computing industries, offer licensees a relatively small number of options: they may choose to license, say, one, two, three, or all of the MNC's patents. The latter approach achieves a number of objectives. From the perspective of the MNC, it significantly reduces the complexity of managing its portfolio. From the perspective of the licensees, it incorporates a recognition that many new business ventures cannot know ahead of time precisely which technologies they will need - and thus, which licenses. As a result it tends to lead to license fees somewhat higher than they might incur were they to take only the items they wanted, but it also reduces their work in determining precisely what they need. In other words, it reduces transaction costs on all sides, provides the patentee with slightly higher revenues, and provides the licensee with vastly increased potential.

Such blanket licenses have eased cross-licensing and R\&D efforts in many industries. They have also proved their usefulness to IPRs other than patents. ASCAP and BMI, holders of the largest collections of U.S. music copyrights, have long sold blanket licenses to television networks to allow them to choose from a broad array of popular songs as background for their programs. The licensors contend that this approach is the only one practical, and that the transaction costs inherent in managing individual licenses on a song-by-song basis would lead to prices so high that no one would ever take a license. In 1979, and in apparent tension with long-established principles of U.S. antitrust law, the U.S. Supreme Court accepted this argument and agreed that blanket licenses were a practical necessity for the functioning of a modern music copyright system. ${ }^{115}$ The Government of India may discover that the same is true for a traditional knowledge compensation system.

The Government of India should consider implementing a variant of this blanket license plan concurrent with its launch of the TKDL. Though it will be difficult to direct funds to traditional communities in proportion to the value that they confer, it will nevertheless be possible to collect significant development revenues for the benefit of these communities.

This approach thus lacks much of the specific motivation that the patent system confers on individual innovators, but may retain the motivation needed to engage both development professionals and volunteers like the Honey Bee Network. In the case of functional traditional

${ }^{115}$ See Broadcast Music, Inc. v. Columbia Broadcasting System, Inc., 441 U.S. 1 (1979). 
knowledge, it is these interlocutors, rather than the possessors themselves, who are most likely to share the information with the world. As a result, if a blanket license system generates enough development assistance revenue to keep them motivated, it will achieve at least one of its most important objectives. At the same time, the launch of a TKDL blanket license will serve at least two additional goals. One, it will still be the first formal attempt to secure IPRs for the informal sector's traditional knowledge - and as such, will provide a focal point for continuing debates over an expanded international program. Two, it will provide valuable feedback about the workings of such a system, informing the drive toward a more detailed item-by-item approach.

Still, the idea of a blanket license is not without its potential downsides. One-relevant only if Government of India intends the blanket license to be a step toward a more complex individualized system - is that a blanket license TKDL may complicate the drive toward an itemized approach by creating transitional complexities. A second potential downside is that a blanket license does not obviate the need for a full inquiry into the best ways to adjust patent law concepts to new terrain - it simply reduces the complexity of the task somewhat. India cannot launch even a blanket license requirement without addressing the meaning of novelty and nonobviousness or, perhaps more important, without determining penalties for noncompliance.

These problems suggest that a fourth track may also warrant consideration: establishing a voluntary fund into which MNCs can contribute an amount related to the value that they extract from the TKDL. The shortcomings of such a fund are obvious: voluntary compensation invites free riding. At the same time, it has its upsides. A combination of moral suasion and a promise to assist rather than impede knowledge transfer may prove more successful than a new, controversial, complex, potentially unenforceable law. As a practical matter, voluntary contributions may generate a larger compensation pool faster than would be possible within any sort of compulsory framework. It may also make it easier for the fund conservator to allocate funds appropriately than would be possible under a blanket license; contributing companies and organizations can explain where in the TKDL they found value, then work with the relevant community directly, and with the Government of India's blessings rather than its opposition. A voluntary approach may also ease international participation and acceptance of the TKDL as the basis for channeling funds to traditional communities, in India and around the world.

The government should charge the proposed IP policy think tank with assessing the costs and benefits associated with individualized IPRs for traditional knowledge (national or international), a blanket TKDL license, and a voluntary fund. Each structure poses its own complexities and potential pitfalls, but each promises to address the challenge of compensating the possessors of traditional knowledge for revealing their knowledge to the world. Adoption of any one of these approaches, concurrent with or shortly after the launch of the TKDL, will establish India's leadership on this issue, and reinforce its image as a country taking bold, novel approaches to developing its human capital, innovation system, and burgeoning role as a leading player in the global knowledge economy. 
Recommendation 18: In line with current plans, launch the TKDL as soon as it is complete and suitable for international consumption. Continue negotiations to increase international respect for IPRs for traditional knowledge. Create a standing expert committee to assess and where necessary revise the necessary definitions and procedures as national inputs, international comments, and empirical experiences arise.

Recommendation 19: Charge the IP policy think tank with considering a new category of IPRs to motivate the appropriate sharing of traditional knowledge, a blanket license to cover all items in the TKDL, and a voluntary fund to cover the transfer of technology from the TKDL into the global knowledge base and the commercial realm. As part of this inquiry, and as necessary for each of the options, prepare definitions of traditional knowledge and its "items" and sources. Draft guidelines for determining attribution of traditional knowledge, clearly defining it, and delineating its boundaries. Devise a suitable length for the life of traditional knowledge IPRs. Determine reasonable and nondiscriminatory licensing terms. Set penalties for noncomplianceand stiff penalties for ongoing, willful noncompliance. Identify suitable conservators or administrators and detail the rules that they must follow in administering traditional knowledge IP licenses on behalf of attributed rights holders and, if applicable, the rules that they must follow in administering the blanket license fund.

\section{Summary of Recommendations}

This study has discussed several concrete areas that India needs to address in the short to medium term, leading to 19 specific recommendations. Work toward many of these recommendations is already under way. Some, such as Patent Office modernization, may soon be complete. Others, notably the development of a functioning IP system for traditional knowledge, will require several rounds of proposal, notification, and comment - a process likely to take several years. The basis for many of these recommendations lies in the study's first one: establishing an independent think tank oriented around IP policy to advise the Government of India and inform its ultimate decisions.

This study followed a logical organization: Policy precedes legislation. Legislation precedes regulation. Regulations form the basis of training. Trained personnel permit the system to work as designed. Incentives encourage participation in a working system. Newly designed rights augment established ones. As a result the study makes no attempt to prioritize its recommendations. Work on many of them can proceed in parallel — though because training curriculums must correspond to regulations, the promulgation of regulations must precede the development of viable training programs.

An alternative arrangement of the study's recommendations may help highlight the areas in greatest need of immediate action. The study identifies eight areas where the Government of India has already conducted the analysis needed to know what to do. All that remains is an allocation of the necessary resources and a commitment to action: 
- Establish an IP policy think tank as soon as possible. Staff it with Indian and foreign IP scholars charged with assessing the likely impact of contemplated IP policies on India's public.

- Complete the statutory framework for India's new patent laws as soon as possible.

- Finish modernizing the Patent Office as soon as possible. Enable automated applications and online searching. Launch a prior art database and interconnect these databases and search engines with as many foreign patent offices as possible, as quickly as possible.

- Create a standing expert committee on patent guidelines to consider frequent revisions, amendments, and additions, as part of the new think tank.

- Identify the extent to which the enforcement of court-ordered IP remedies may fall short of general enforcement standards. Provide suitable training for customs and police personnel engaged in enforcing orders related to IPRs.

- Implement the government's current plan to upgrade IPTI into a full-blown staff training college as soon as possible. Design the curriculum for staff-namely, examiners and enforcers - but encourage private practitioners to enroll as well.

- Adopt the current government proposal to launch a management-oriented education and research facility as soon as possible. Focus its curriculum on issues related to patent exploitation - licensing, negotiating, and litigating to convert patents into revenue streams.

- Launch the TKDL as soon as it is complete and suitable for international consumption. Continue negotiations to generate international respect for traditional knowledge IPRs.

The study's other recommendations require more thought before the best course of action becomes clear. The discussions presented in this study outline many questions and delineate many tradeoffs, but their resolution must lie with a trusted cadre of IP advisers who combine an understanding of IP theory with a deep, intimate awareness of India's sociopolitical environment. As the study mentions in several places, the government would be served well by setting up a permanent think tank committed to assessing and advising on these issues - and on others that will arise as India's IP system matures. Once such an institution exists, the government should charge it with:

- Assessing the relative merits of a patent registration system and a patent examination system.

- Determining the class of patents most likely to serve India's needs, and drafting detailed substantive and procedural guidelines for the Patent Office oriented toward that class.

- Developing a "workbook," or catalog of illustrations, drawn from a variety of disciplines, taken from previous foreign experience, to accompany the guidelines.

- Exploring the interrelationships among registration systems, examination systems, and specialized tribunals, and crafting recommendations to ensure that India chooses a judicial configuration for patent litigation consistent with its administrative decisions concerning the evaluation of patent applications.

- Investigating the best ways to promote juridical consistency in patent laws, including the practicality and desirability of creating specialized patent tribunals, appellate courts, or both. 
- Considering the ramifications of both two-tier filing fee structures and maintenance fees designed to limit the ability of underused patents to impede progress.

- Examining the institutional governance issues surrounding the incorporation of profit-driven analyses into India's research institutions or the transfer of direct management of public sector patent portfolios to patent licensing corporations.

- Promoting patenting and patent exploitation among individual inventors and SMEs, and considering government-sponsored or -subsidized loan programs and patent prosecution clinics to facilitate foreign applications.

- Reviewing institutional governance at India's leading research institutions.

- Drafting legislation requiring all government agencies issuing research grants to motivate universities, research institutes, and their individual researchers to seek and exploit patents, and to engage in technology transfer programs with industrial concerns.

- Studying several variants of a new category of IPRs that would motivate the appropriate sharing of traditional knowledge.

\section{Conclusion}

This study has outlined the next steps in a journey on which India embarked a bit more than a decade ago. Almost immediately upon WTO accession, and impelled at least in part by the rules of TRIPS, India started transforming its thinking away from its previous opposition to patenting as a giveaway to wealthy foreign corporations toward a more liberal recognition that IPRs can promote innovation and development.

India's new statutory framework appears to have achieved TRIPS compliance - at least on all major points. Its provisions for challenging patents and for forcing licenses promise to eliminate the most egregious anecdotes that fueled the previous antipathy to patenting. Its remaining policy and legislative debates will round out the compromises needed to promote domestic innovation in drug-related industries without impeding the government's commitment to public health.

The recommendations outlined in this study will take the process the rest of the way. Clear guidelines, better training, a single appellate path, and professional enforcement will promote coherence and consistency throughout the patent system. Improved public awareness of revenuegenerating mechanisms and subsidies on filing fees will enhance incentives for individual and SME participation in the patent system. Formalization of guidelines for patents derived through government research funds - if coupled with necessary changes in institutional governance-will enhance the prospects for technology transfer from laboratories to commercial markets. Traditional knowledge compensation schemes will extend the benefits of IPRs to the poorest members of society-those for whom participation in the existing patenting system is both impractical and inappropriate. And perhaps most important, a new think tank, focused on IP policy, will provide the Government of India with independent guidance and analysis as it tries to understand the best ways to leverage IPRs to meet the challenges facing India's development.

This inquiry into India's IP system was prepared as part of the World Bank's broader study of India's innovation system. The purpose of the broader study is to derive concrete action items 
that can turn India into a full, creative member of the information economy within the next few years - and eventually, into an important leader in the economy of the information age. The study is also concerned with India's poor: those at greatest risk of being left behind as their better-educated countrymen prosper.

The author's charter was to study India's IP system and assess its greatest needs. Because India's copyright and trademark systems are well developed - and functioning well — while its patent system is undergoing major changes, the study has focused almost entirely on patenting. The only issues that it addresses in any detail outside the scope of patent law are the development of patent-like IPRs for functional traditional knowledge and the needs of a software industry governed by a combination of patent, copyright, and trade secret law.

On the patent side, the basic contours of India's regime are relatively new. Many of the recent changes are controversial, and many proposals relevant to implementation and augmentation remain. The study discusses many of the pending controversies and proposals - all with an eye on how they motivate innovation and contribute to India's overall innovation system. For the most part, these issues fall into four broad categories: resolving the remaining statutory ambiguities of particular relevance to high-tech industries, developing administrative and judicial mechanisms that reduce subjectivity and increase consistency and reliability across the entire patent system, rethinking the incentives that India offers to its innovators and the behavioral responses those incentives are likely to motivate, and considering the development of a new IP regime tailored to traditional knowledge. The study's first recommendation-that the government establish a think tank to advise it on IP issues-plays an indispensable role in developing the intellectual infrastructure needed to evaluate all these issues. Appropriate policies should combine a concern with international norms with the specifics of India's economic and social needs. A trusted body of independent policy advisers should be able to help the Government of India reach suitably balanced policies.

India's movement over the past decade indicates a commitment to building an effective patent system. Its statutory law reflects a coherent policy decision to use patents to promote innovation, motivate commercialization, harmonize with the developed world, embrace treaty obligations, and address local concerns. Its public education campaigns have raised awareness of patent issues throughout the technical and legal communities, as well as among the general public. The study's overall assessment is that the past decade — culminating in the significant 2005 amendments to the Patent Act of 1970 - has constructed a solid foundation for a vibrant, fully functioning patent system for India, but that significant work remains to build such a system atop that foundation.

The government must recall, however, that IPRs are a small but critical component of a national innovation system, and that a national innovation system in turn is only part of the national economy. Laws on FDI, taxation, and securities may work with good IP laws to promote growth through innovation, they may work to counter the positive effects of sound IP policies, or they may work with poor IP policies to cripple growth. Professionalism, integrity, and commitment to the rule of law are critical for long-term economic success in the information age; they are neither more nor less important in IP settings than they are elsewhere. 
In the final analysis, IP law will contribute to India's ongoing reformation of its economy from its past of overregulated statism preoccupied with self-sufficiency to its future as an integrated part of the global liberal free market. The effects of this transition will ripple first through India's businesses, then through its institutions concerned with employment and education, and ultimately into every corner of Indian society. IPRs are a part of this transformation - but only a part. Reforms to the IP system must make sense within the broader context of economic reform. As in the patent system, India has come a long way in the past 15 years-but it still has far to go.

India has covered a huge distance in developing an IP system capable of enhancing national innovation in a very short period. The work done has been remarkable, and overwhelmingly positive. The critical goal at this point must be to ensure that implementation turns policy preferences into reality. The suggestions in this study — many of which are already under waywill maximize the country's prospects for success.

As the world enters a global information age, innovation systems will play an increasingly important role in dividing winners from losers. India's innovation system is poised to reap significant returns not only for India's innovators, but also for their neighbors-who will benefit from the positive externalities of increased innovation. This study's recommendations, if followed, will help India achieve both a fully functioning patent system and a mechanism for ensuring that poor Indians living traditional lifestyles receive their share of the societal gains that a working innovation system can confer. 



\section{Policy Research Working Paper Series}

Title

WPS4280 Governance Matters VI: Aggregate and Individual Governance: Indicators, 1996-2006

WPS4281 Credit Growth In Emerging Europe: A Cause For Stability Concerns?

WPS4282 Are Cash Transfers Made to Women Spent Like Other Sources of Income

WPS4283 Innovation Shortfalls

WPS4284 Customer Market Power and the Provision of Trade Credit: Evidence from Eastern Europe and Central Asia

WPS4285 Poverty Analysis Using An International Cross-Country Demand System

WPS4286 Institutional Effects as Determinants of Learning Outcomes: Exploring State Variations in Mexico

WPS4287 A Cross-Country Analysis of Public Debt Management Strategies

WPS4288 Actual Crop Water Use in Project Countries A Synthesis at the Regional Level

WPS4289 Sensitivity of Cropping Patterns in Africa to Transient Climate Change

WPS4290 The Impacts of Climate Change on Regional Water Resources and Agriculture in Africa

WPS4291 An Empirical Economic AssessmentOf Impacts Of Climate Change On Agriculture In Zambia

WPS4292 Assessment of the Economic Impacts of Climate Change on Agriculture in Zimbabwe:

A Ricardian Approach

WPS4293 Assessing the Economic Impacts of Climate Change on Agriculture in Egypt: A Ricardian Approach

WPS4294 Scarperation: An Empirical Inquiry into The Role of Scarcity in Fostering Cooperation Between International River Riparian

WPS4295 Economic Benefit of Tuberculosis Control
Author

Daniel Kaufmann

Aart Kraay

Massimo Mastruzzi

Sophie Sirtaine

Ilias Skamnelos

Norbert Schady

José Rosero

William Maloney

Andrés Rodríguez-Clare

Neeltje Van Horen

J. A. L. Cranfield

Paul V. Preckel

Thomas W. Hertel

Jesús Álvarez

Vicente García Moreno

Harry Anthony Patrinos

Martin Meleckyy

Robina Wahaj

Florent Maraux

Giovanni Munoz

Alexander Lotsch

Kenneth Strzepek

Alyssa McCluskey

Suman Jain

Reneth Mano

Charles Nhemachena

Helmy M. Eid

Samia M. El-Marsafawy

Samiha A. Ouda

Shlomi Dinar

Ariel Dinar

Pradeep Kurukulasuriya

Ramanan Laxminarayan

Eili Klein

Christopher Dye

Katherine Floyd

Sarah Darley

Olusoji Adeyi
July 2007

July 2007

\section{Date}

July 2007

. Bonfield

31248

July 2007

July 2007

July 2007

July 2007

July 2007

July 2007

July 2007

July 2007

July 2007

July 2007

Kokila

33716

P. Kokila

33716

July 2007

July 2007

P. Kokila 33716

August 2007

M. Elias

82175

S. Sirtaine

I. Hafiz

37851

V. Cornago

M. Gamboa 34847

P. Flewitt

S. Baksh 31085 82602

P. Kokila 33716

P. Kokila

P. Kokila 33716

P. Kokila 33716

as

M. Rosenquist 
Policy Research Working Paper Series

Title

WPS4296 When Do Creditor Rights Work?

WPS4297 Big Dragon, Little Dragons:

China's Challenge to the Machinery Exports of Southeast Asia

WPS4298 Yield Impact of Irrigation Management Transfer: A Success Story from the Philippines

WPS4299 Balancing Expenditures on Mitigation of and Adaptation to Climate Change An Exploration of Issues Relevant to Developing Countries

WPS4300 Country Stakes in Climate Change Negotiations: Two Dimensions of Vulnerability
Author

Mehnaz Safavian

Siddharth Sharma

Sjamsu Rahardja

Sushenjit Bandyopa
Priya Shyamsundar

Mei Xie

Franck Lecocq

Zmarak Shalizi

Piet Buys

Uwe Deichmann

Craig Meisner

Thao Ton That

David Wheeler
Date

August 2007

August 2007

August 2007

\section{Contact for paper}

S. Narsiah 88768

K. Shaw 81307

A. Sears 82819

August 2007

P. Kokila 33716

August 2007

Y. Edwards 36308 